Prepared for the U.S. Department of Energy under Contract DE-AC05-76RL01830

\title{
Evaluation of Non-Nuclear Techniques for Well Logging: Technology Evaluation
}
LJ Bond
RV Harris
KM Denslow
TL Moran
JW Griffin
DM Sheen
GE Dale
T Schenkel

November 2010

Pacific Northwest

NATIONAL LABORATORY

Proudly Operated by Battelle Since 1965 


\title{
DISCLAIMER
}

This report was prepared as an account of work sponsored by an agency of the United States Government. Neither the United States Government nor any agency thereof, nor Battelle Memorial Institute, nor any of their employees, makes any warranty, express or implied, or assumes any legal liability or responsibility for the accuracy, completeness, or usefulness of any information, apparatus, product, or process disclosed, or represents that its use would not infringe privately owned rights. Reference herein to any specific commercial product, process, or service by trade name, trademark, manufacturer, or otherwise does not necessarily constitute or imply its endorsement, recommendation, or favoring by the United States Government or any agency thereof, or Battelle Memorial Institute. The views and opinions of authors expressed herein do not necessarily state or reflect those of the United States Government or any agency thereof.

\author{
PACIFIC NORTHWEST NATIONAL LABORATORY \\ operated by \\ BATTELLE \\ for the \\ UNITED STATES DEPARTMENT OF ENERGY \\ under Contract DE-AC05-76RL01830
}

Printed in the United States of America

Available to DOE and DOE contractors from the

Office of Scientific and Technical Information,

P.O. Box 62, Oak Ridge, TN 37831-0062;

ph: (865) 576-8401

fax: $(865) 576-5728$

email: reports@adonis.osti.gov

\footnotetext{
Available to the public from the National Technical Information Service,

U.S. Department of Commerce, 5285 Port Royal Rd., Springfield, VA 22161

ph: (800) 553-6847

fax: (703) 605-6900

email: orders@ntis.fedworld.gov

online ordering: http://www.ntis.gov/ordering.htm
}

This document was printed on recycled paper.

(9/2003) 


\section{Evaluation of Non-Nuclear Techniques for Well Logging: Technology Evaluation}

$\begin{array}{ll}\text { LJ Bond } & \text { RV Harris } \\ \text { KM Denslow } & \text { TL Moran } \\ \text { JW Griffin } & \text { DM Sheen } \\ \text { GE Dale }^{(a)} & \text { T Schenkel }^{(b)}\end{array}$

November 2010

Prepared for

the U.S. Department of Energy

under Contract DE-AC05-76RL01830

Pacific Northwest National Laboratory Richland, Washington 99352

(a) Los Alamos National Laboratory Los Alamos, New Mexico 87545

(b) Lawrence Berkeley National Laboratory Berkeley, California 94720 



\section{Abstract}

Sealed, chemical isotope radiation sources have a diverse range of industrial applications. There is concern that such sources currently used in the gas/oil well logging industry (e.g., americium-beryllium [AmBe], ${ }^{252} \mathrm{Cf},{ }^{60} \mathrm{Co}$, and ${ }^{137} \mathrm{Cs}$ ) can potentially be diverted and used in dirty bombs. Recent actions by the U.S. Department of Energy (DOE) have reduced the availability of these sources in the United States. Alternatives, both radiological and non-radiological methods, are actively being sought within the oilfield services community. The use of isotopic sources can potentially be further reduced, and source use reduction made more acceptable to the user community, if suitable non-nuclear or non-isotope-based well logging techniques can be developed. Data acquired with these non-nuclear techniques must be demonstrated to correlate with that acquired using isotope sources and historic records. To enable isotopic source reduction there is a need to assess technologies to determine (i) if it is technically feasible to replace isotopic sources with alternate sensing technologies and (ii) to provide independent technical data to guide DOE (and the Nuclear Regulatory Commission [NRC]) on issues relating to replacement and/or reduction of radioactive sources used in well logging.

This report presents an initial review of the state-of-the-art nuclear and non-nuclear well logging methods and seeks to understand the technical and economic issues if AmBe, and potentially other isotope sources, are reduced or even eliminated in the oil-field services industry. Prior to considering alternative logging technologies, there is a definite need to open up discussions with industry regarding the feasibility and acceptability of source replacement. Industry views appear to range from those who see AmBe as vital and irreplaceable to those who believe that, with research and investment, it may be possible - to transition to electronic neutron sources and employ combinations of non-nuclear technologies to acquire the desired petro-physical parameters. In one sense, the simple answer to the question as to whether petro-physical parameters can be sensed with technologies other than AmBe is probably "Yes". The challenges come when attention turns to record interpretation. The many decades of existing records form a very valuable proprietary resource, and the interpretation of subtle features contained in these records are of significant value to the oil-gas exploration community to correctly characterize a well. The demonstration of equivalence and correspondence/correlation between established and any new sensing modality, and correlations with historic records is critical to ensuring accurate data interpretation. Establishing the technical basis for such a demonstration represents a significant effort.

The focus of this study is the understanding of the technical obstacles that hinder the replacement of and the disadvantages from the loss of extensive interpretation experience based on data accumulated with AmBe. Enhanced acoustic and electromagnetic sensing methods in combination with non-isotopebased well logging techniques have the potential to complement and/or replace existing isotope based techniques, providing for the opportunity to reduce oil industry dependence on isotopic sources such as AmBe.

This report provides initial insights to establish the information resources needed to provide independent technical data to guide DOE (and NRC) on issues relating to replacement and/or reduction of radioactive sources used in well logging. 



\section{Summary}

There is a diverse range of industrial applications for sealed radiation sources. There is concern that such sources (including americium-beryllium currently used for well logging by the oil and gas industry) can potentially be diverted and used in dirty bombs. Recent actions by the U.S. Department of Energy (DOE) have reduced the availability of such sources in the United States. Alternatives, both radiological and non-radiological, are actively being sought within the oil-field services community. The use of isotopic sources could be further reduced, and source use reduction made more acceptable to the user community, if suitable non-nuclear or non-isotope-based techniques can be developed and demonstrated.

This study is focused on the need to assess petrochemical well-logging technologies to determine if it is technically feasible to replace logging techniques requiring isotopic sources (such as $\mathrm{AmBe},{ }^{252} \mathrm{Cf}$,

${ }^{137} \mathrm{Cs}$, ${ }^{60} \mathrm{Co}$ ) with alternative non-nuclear sensing methods. It also will provide the independent technical data needed to guide DOE (and the U.S. Nuclear Regulatory Commission [NRC]) on issues relating to replacement and/or reduction in radioactive sources used in well logging.

The initial phase of this study has:

1) Provided a preliminary assessment of the neutron-based measurement methods (using AmBe sources).

2) Defined the parameters for a rock reference library needed for sensor evaluation and comparison.

3) Identified both acoustic/ultrasonic and electromagnetic techniques (including nuclear magnetic resonance [NMR]) as having the potential to determine formation parameters of composition and porosity, that are currently measured using nuclear methods.

4) Established the experimental approach and some of the key issues to be addressed.

In looking at alternatives to the current AmBe sources, three approaches are being considered:

a) Reduction in the activity of the AmBe source required (through approaches that included the deployment of enhanced sensors)

b) The use of electronic deuterium-tritium (D-T) neutron generators (although these provide neutrons with different spectra and data inter-comparison requires attention)

c) The use of enhanced and novel acoustic and electromagnetic sensing tools, including NMR, used either in combination with reduced activity AmBe sources and/or D-T generator derived data.

These activities, under the Radiological Source Replacement Program, are positioning Pacific Northwest National Laboratory (PNNL) and partnering laboratories to be able to provide independent technical assessment and technical advice to DOE and the NRC. This support includes guidance regarding the issues encountered in reducing use of isotopic sources by the oil and gas well-logging industry and implementing alternative well-logging technologies. 
The National Academies Report (NRC 2008, pg. 9) on radiation source use and replacement identifies the pertinent issues relating to well logging and other uses of isotopes. That report acknowledges that the radioactive sources, in particular AmBe, are at some risk of loss and diversion to be used in dirty bombs, and indicates that the use of alternatives should be investigated. This project is investigating various technologies in order to determine the barriers to source replacement and to determine whether it is technically feasible to replace isotopic sources with alternate technologies. The study is seeking to identify the critical technological issues and determine what can be done to work with the industry to reduce the need for radioisotope sources. In reviewing this body of knowledge and the industry activities, the project is seeking to collect and organize independent technical data needed to guide DOE (and NRC) on issues relating to replacement and/or reduction of radioactive sources used in well logging.

Geophysical well logging is an industry with a history that dates back to the 1920s. It now employs a variety of measurement techniques that fall under several broad categories, including mechanical, electrical, acoustic/sonic, and nuclear - all employing specialized sensors or detection devices, the latter of which may employ sealed radioactive sources. The fundamental physics for the various sensing technologies employed in well logging has been investigated by a multitude of researchers and is reported in numerous books and papers. A fundamental challenge is that natural rock systems exhibit a diverse array of subtle features. Data interpretation involves models that relate the measured parameters given by well logs, in some cases supplemented by core samples, to the desired petro-physical formation parameters. The data inversion problems involved are often ill-posed and result in non-unique solutions. Non-uniqueness also stems from inference of petro physical properties, such as porosity, from a response that can have multiple sources - such as detection of hydrogen to infer porosity. Multiple data types derived from different sensors are combined in a semi-quantitative fashion with historic records to constrain the inversion, and give estimates for the desired parameters. Well logging, and the subsequent data analysis and integration, is remarkably successful in providing the oil and gas industries with petrophysical properties for sub-surface formations. The data interpretation which is performed remains a mix of art and science. Interpretation of values in the log data involves numerous corrections and qualitative insights. The merging of insights gained from the independent sensor data streams is performed by experienced log analysts who use historical records to guide decision making.

In looking at current practice it is seen that well logging occurs in two basic forms: (i) logging while drilling (LWD) and (ii) wire-line logging. The LWD is applied to new wells - while drilling - and wireline can be applied to both new wells and cased production wells. The technologies used in the two forms of logging are in many cases similar, but cost and other considerations drive decisions regarding who provides the oil field services. Neutron sources are used to determine several formation parameters. Well logging relies on a large body of neutron (e.g., porosity) log data that has been accumulated using AmBe sources.

The cost and limited availability of isotopic sources is causing oil-field service companies to look for alternative technologies. The industry leaders (e.g., Schlumberger and Halliburton) do now have and employ some form of D-T accelerator-based nuclear porosity tool for LWD. In addition, new and improved sonic tools have also been developed and deployed by major companies including Schlumberger. There remain major challenges with both LWD and wire-line technology deployment, not the least due to the hostile high temperature and high pressure environment. For LWD measurements the difficulties are further compounded by shock, vibration, and noise from drilling. LWD tools face challenges due to on-board data storage limitations, power supply constraints and the limited ability to 
transmit data to the surface via the low-bandwidth channels of mud and/or drill string. The drilling mud, being either oil or water based, impacts some of the measurements, as do the casing and the grouting for production wells. From a security perspective, the use and deployment of D-T neutron generators is not totally issue free, as it is a defense dual-use technology.

In the development of structural models (inversion of the well logging data) there are complementary data that can be used to enhance evaluations. There would appear to be opportunities for extracting more perto-physical parameters through combinations of seismology and down-hole acoustic measurements which measure and acquire similar formation parameters, but are operated in very different frequency bands due to significant differences in the sound-medium interactions (considered in terms of scale of wavelength and measurement). There is also increased interested in some more innovative approaches, including seismic while drilling (SWD) that uses the drill-generated noise as a source that produces signatures recorded at the surface. The implications for potential to reduce isotope use are still being developed.

SWD specifically encompasses the seismic techniques operated while the drill string is lowered in the borehole, during effective drilling, during maneuvers or while connecting drill pipes. A related concept introduced by Schlumberger is vertical seismic profile while drilling. VSP-WD is recording the seismic signal generated by a surface seismic source on seismic sensors integrated inside the down-hole borehole assembly (BHA). There are also more novel measurement schemes which are receiving attention in welllogging applications. These include both NMR and utilization of electro-kinetic effects to induce sound wave material interactions (piezo-seismic interactions).

In addition to technical issues, there are various economic and political issues, including the proprietary nature of well log information. These issues are particularly acute for smaller logging service companies. Smaller independent well logging companies find a substantial market in re-logging old wells. These companies are more likely to require comparisons of old AmBe data to new AmBe data. Major oil-field service companies win most contracts for LWD, and thus are better poised to deploy new technologies, at least for new well applications. These issues need attention, but detailed analysis of them is beyond the scope of this report.

To speed adoption of new sensors, there is a need for rock reference samples that can function as standards (calibrated rock-fluid samples) to be used in studies to demonstrate sensor equivalence.

Discussions have been initiated with industry regarding the feasibility of source replacement. Views range from those who see AmBe as vital and irreplaceable to those who view, that with research and investment, chemical source replacement may be possible. In a strict technical sense, the simple answer to the question as to whether petro-physical parameters can be sensed with technologies other than AmBe is probably "Yes".

The challenges come when attention turns to record interpretation and product development in the forms and methods of data interpretation. The many decades of existing records form a very valuable proprietary resource. Methods of interpretations derived from these records are of significant value to the oil-gas exploration community.

The demonstration of equivalences and/or correlations between established and new sensing modalities, and the ability to make correlations with historic records are critical to ensuring accurate data 
interpretation. Such an equivalence demonstration represents a significant technical effort. Electronic (accelerator) neutron sources and ${ }^{252} \mathrm{Cf}$ show promise for replacement of AmBe sources.

The goal of this study is to gain an understanding of the technical obstacles to AmBe source replacement and to assess the disadvantages (e.g., the loss of extensive interpretation experience) associated with the use of newer non-nuclear technologies (e.g., NMR).

The aim of this study is to understand the technical obstacles that hinder the replacement of AmBe sources and to identify disadvantages due to loss of extensive interpretation experience based on data accumulated with AmBe. Enhanced acoustic and electromagnetic sensing methods, in combination with non-isotope-based well logging techniques, have the potential to complement and/or replace existing isotope based techniques, providing for the opportunity to reduce AmBe use. To enable inter-technology comparisons there is a need for a library of well-calibrated rock samples with fluid filled porosities. Demonstrations of sensor equivalence (e.g., AmBe vs. electronic neutron sources and those using nonnuclear modalities) must ultimately incorporate realistic downhole pressure and temperature variations. However, room temperature measurements offer the potential to acquire proof-of-concept data that demonstrates feasibility.

\section{Path forward:}

The goal for this study is to move beyond insights provided in the current report to establish the information resources needed to provide independent technical data to guide DOE (and NRC) on issues relating to the potential for replacement and/or reduction in radioactive sources used in well logging.

To address the issues that hinder elimination of the use of AmBe in well logging:

1) Develop a better understanding of the equivalence in formation measurements using chemical radiation sources (gamma density, neutron activation, neutron inelastic scattering, etc.) and other nonnuclear sensing technologies (electromagnetic propagation, NMR, etc.):

a. How are indirect physical parameter data used to infer formation parameters (e.g., how is formation porosity derived from neutron scattering measurements)? How is formation porosity derived from non-nuclear NMR measurements?

b. Develop a better understanding of the relative sensitivity (and accuracy) and measurement regions of logging methods (there are differences in the physics) including the depth of investigation and achieved spatial resolutions. Complete the technology comparison matrix. How does the performance (sensitivity, range, robustness) of non-isotopic nuclear methods compare with isotopic nuclear methods? For example, is there an advantage in using the higher energy neutrons provided by the D-T source $(14.1 \mathrm{MeV})$ over the low energy neutrons provided by a chemical source (2-6 MeV)? Does the D-T source afford greater range and/or accuracy? Does the relative similarity of the neutron spectra form the tritium-tritium reaction and from AmBe sources offer opportunities for cross-calibration?

2) Establish a well characterized library of rock reference samples, which are needed to support an investigation the equivalence of nuclear well logging sensor response and those from other methods (in terms of ability to sense petro-physical parameters). 
3) Investigate the potential for new sensing ideas which can better quantify petro-physical parameters for example, acoustic/ultrasonic diffuse field, which is not currently implemented for well logging.

4) Engage and encourage discussion within the industry. Seek to focus attention on articulation of issues relating to barriers to eliminating AmBe sources in well logging. Determine which issues are based on technical challenges and which are based on capability perceptions.

Other technical hurdles are those issues where the replacement techniques require more sophisticated packaging and can be more operationally complex. AmBe sources are simple passive sources, robust, able to operate over a large range of well bore conditions (i.e., temperature, well completions, etc). 



\section{Acknowledgments}

This project was supported by the U.S. Department of Energy, Office of Nonproliferation Research and Engineering (NA-22) under contract DE-AC05-76RL01830. The authors acknowledge the excellent support of Terra Tech, Inc. regarding identification and preparation of the sandstone sample set. We also acknowledge the valuable contribution of Ms. Azaree Lintereur, a National Science Foundation Fellow assigned to Pacific Northwest National Laboratory during the summer/fall of FY2009, who acquired all of the nuclear data used in this study. 



\section{Acronyms and Abbreviations}

\begin{tabular}{|c|c|}
\hline AmBe & americium-beryllium \\
\hline API & American Petroleum Institute \\
\hline ARC5 & Array Compensated Resistivity ${ }^{\mathrm{TM}}$ tool (Schlumberger) \\
\hline BHA & borehole assembly \\
\hline BHGM & borehole gravity meter \\
\hline BHTV & borehole televiewer \\
\hline CAD & circumferential acoustic log \\
\hline CALLISTO & Calibration (at Leicester) and In-Situ Tool Optimization \\
\hline CDR & Compensated Dual Resistivity ${ }^{\mathrm{TM}}$ tool (Schlumberger) \\
\hline CNL & compensated neutron log \\
\hline $\mathrm{C} / \mathrm{O}$ & carbon/oxygen log \\
\hline D-D & deuterium-deuterium \\
\hline DOE & U.S. Department of Energy \\
\hline $\mathrm{DPT}$ & Deep Propagation Tool ${ }^{\mathrm{TM}}$ (Schlumberger) \\
\hline $\mathrm{D}-\mathrm{T}$ & deuterium-tritium \\
\hline ECS & elemental capture spectroscopy \\
\hline EPT & (Schlumberger) Electromagnetic Propagation Tool \\
\hline HPGe & high-purity germanium \\
\hline LASL/SWAL & long-space and shear-wave acoustic logs \\
\hline LWD & logging-while-drilling \\
\hline MERT & multiple-electrode resistivity tool \\
\hline $\mathrm{mm}$ & millimeter \\
\hline MRI & magnetic resonance imaging \\
\hline MRIL & (Halliburton) Magnetic Resonance Imaging Logging \\
\hline MWD & measurement-while-drilling \\
\hline NA-22 & DOE Office of Nonproliferation Research and Engineering \\
\hline NDE & non-destructive evaluation \\
\hline NML & nuclear magnetism log \\
\hline NMR & nuclear magnetic resonance \\
\hline NRC & U.S. Nuclear Regulatory Commission \\
\hline PNNL & Pacific Northwest National Laboratory \\
\hline PNP & pulsed-neutron porosity log \\
\hline p.u. & porosity units \\
\hline RF & radio frequency \\
\hline RMS & root-mean-square \\
\hline SP & spontaneous potential \\
\hline
\end{tabular}


SWD

$\mathrm{T}-\mathrm{T}$

ULSEL

VSP

WD

WLL seismic while drilling

tritium-tritium

ultra-long spaced electric log

vertical seismic profiling

while drilling

(University of Houston) Well Logging Laboratory 


\section{Contents}

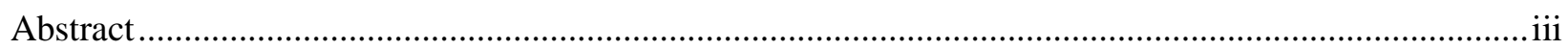

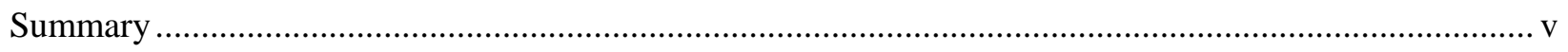

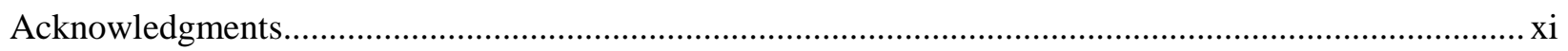

Acronyms and Abbreviations ......................................................................................................ii

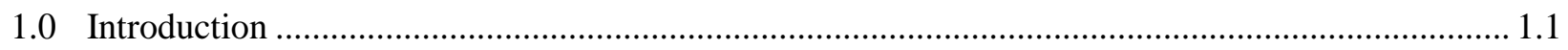

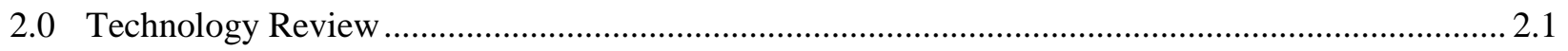

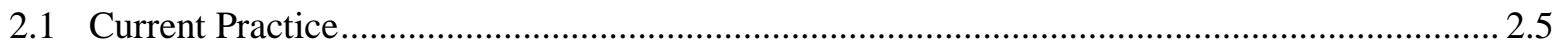

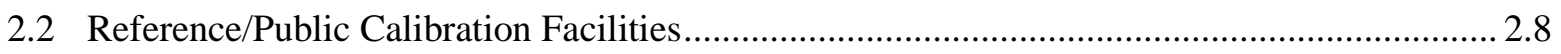

2.3 Nuclear Measurements in Well Logging.......................................................................... 2.10

2.3.1 Summary of Measurement Methods …................................................................... 2.10

2.4 Brief Description of Nuclear Well Logging Methods......................................................... 2.11

2.4.1 Natural Gamma (Gamma Emission from Atomic Nuclei)......................................... 2.11

2.4.2 Gamma-gamma Density (Compton Scattering of Gamma Radiation by Electrons) ….................................................................................................... 2.12

2.4.3 Neutron Scattering (Elastic and Inelastic).......................................................... 2.14

2.4.4 Elemental Composition (Neutron Activation Analysis)........................................... 2.18

2.4.5 Summary Comments ............................................................................................ 2.20

2.5 Electrical and Electromagnetic Measurements in Well Logging .......................................... 2.20

2.5.1 Summary of Measurement Methods ….................................................................. 2.21

2.5.2 Electromagnetic Propagation Methods ................................................................... 2.22

2.5.3 Interpretation of Electromagnetic Propagation Logs .............................................. 2.25

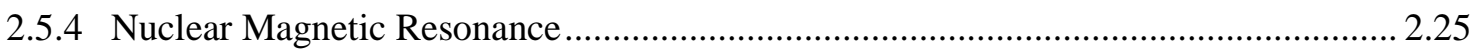

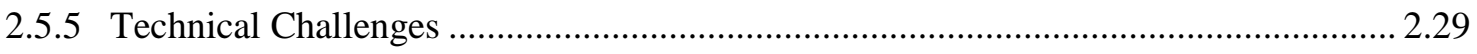

2.5.6 UH WLL - Well-Logging Software Tools .......................................................... 2.29

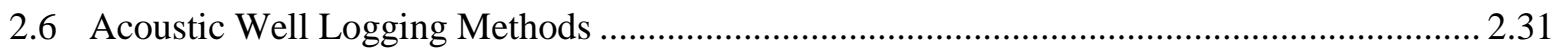

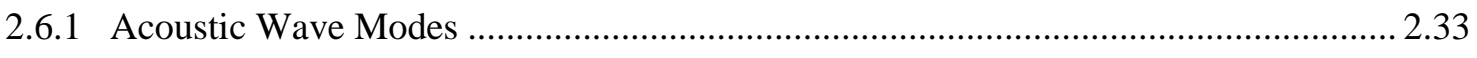

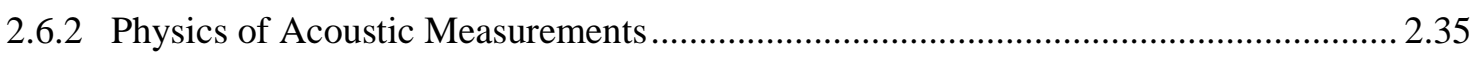

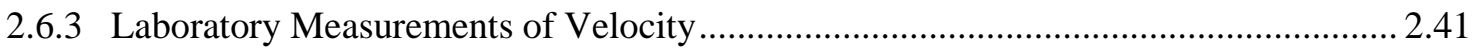

2.6.4 Acoustic Well Logging Tools ............................................................................... 2.42

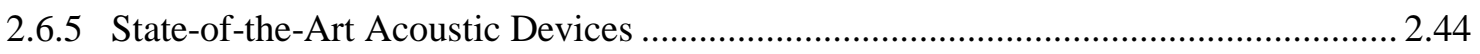

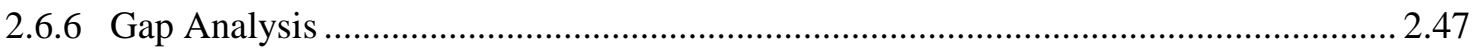

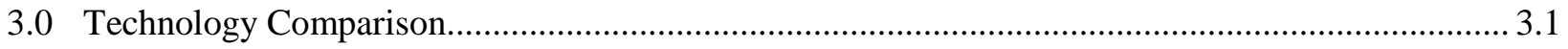

3.1 Technology Performance Comparison .............................................................................. 3.8

3.1.1 Comparing the Correctness of Neutron and Other Logging Tools .............................. 3.11

3.1.2 Volumetric Variations and Their Relation to Measurement ....................................... 3.21

3.1.3 Variability of Some Important Parameters................................................................ 3.23

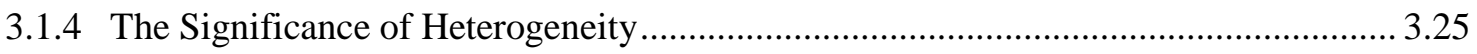




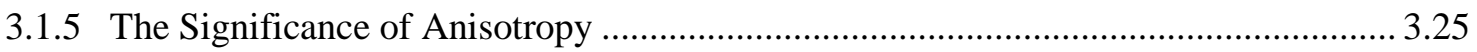

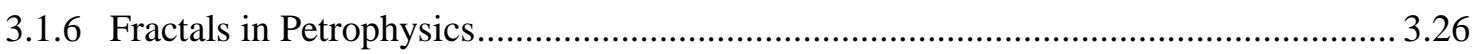

3.2 Differences between Chemical (Isotopic) and Electronic (Accelerator) Neutron Sources ..... 3.26

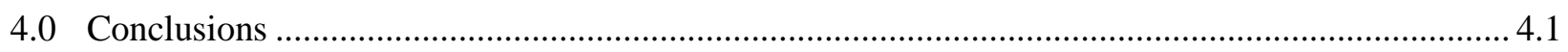

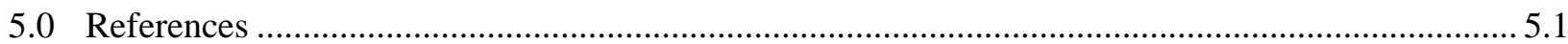




\section{Figures}

2.1 Schematic Showing the Process of Well Log Modeling and Field Data Interpretation................... 2.6

2.2 Spectrum of Electromagnetic Borehole Measurement Techniques ............................................. 2.7

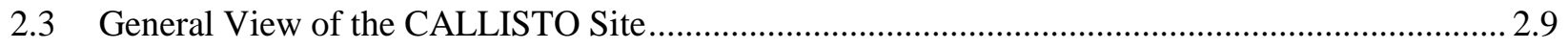

2.4 Well Logging Laboratory - University of Houston .................................................................... 2.9

2.5 Detectors for Gamma Rays: Geiger-Muller Tube................................................................. 2.11

2.6 Formation Gamma-Gamma Density Device Applied to Side of Borehole.................................. 2.12

2.7 Generic Dual-Detector Neutron Tool................................................................................... 2.15

2.8 Energy-dependent Neutron Capture Cross Section for ${ }^{3} \mathrm{He},{ }^{10} \mathrm{~B}$, and ${ }^{6} \mathrm{Li}$............................... 2.16

2.9 Fast Neutron Inelastic Scattering Reactions with Carbon and Oxygen ....................................... 2.17

2.10 Inelastic Gamma Spectra Recorded with a Second-Generation C/O Instrument in an Oil

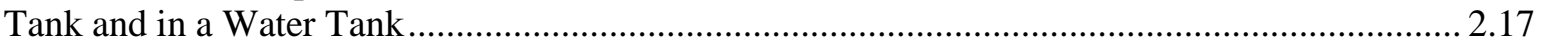

2.11 Measured Gamma Ray Spectrum from an Elemental Capture Spectroscopy Sonde in a Sandstone Formation................................................................................................................ 2.19

2.12 Dielectric Constant for Distilled Water and Oil Over the Frequency Range $50 \mathrm{MHz}$ to

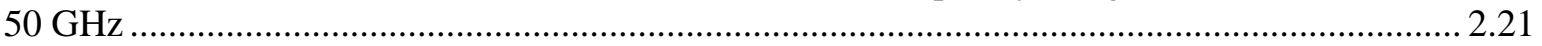

2.13 Use of Single Transmit Antenna and Multiple Receive Antennas to Eliminate Tool Effects

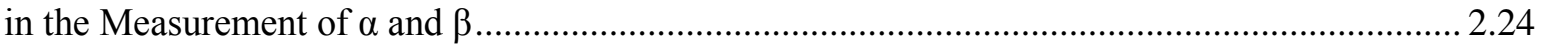

2.14 Transmit-Receive Antenna Arrays Used in Electromagnetic Propagation Tools ......................... 2.25

2.15 Precession of a Proton in a Superimposed DC Magnetic Field ................................................. 2.26

2.16 Inducing Proton Flips with an Applied Radio Frequency Electromagnetic Field......................... 2.27

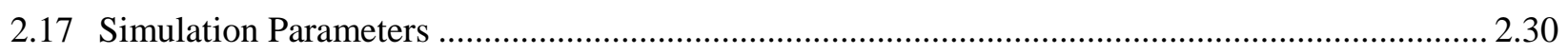

2.18 AIT Induction Tool Simulation Results ................................................................................ 2.31

2.19 Illustration of the Particle Motion Versus the Direction of Wave Propagation for P-waves

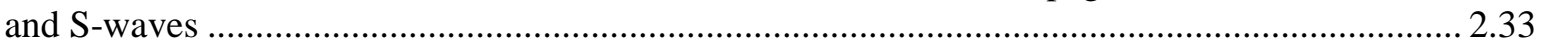

2.20 Compression-to-Shear Velocity Ratios $\mathrm{V}_{\mathrm{p}} / \mathrm{V}_{\mathrm{s}}$ versus Compressional Wave Velocity Plot for Different Rock Types ................................................................................................................ 2.41

2.21 Schematic of a Full-Waveform Acoustic Sonde with Two Transmitters and Two Receivers....... 2.44

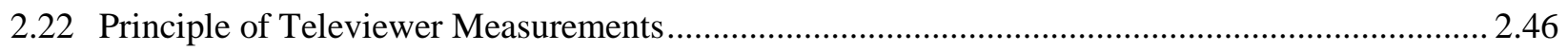

2.23 Oriented, $360^{\circ}$ Image of the Borehole Wall and Calculation of Strike and Dip of Planar

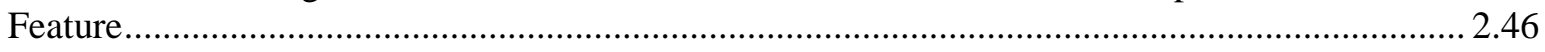

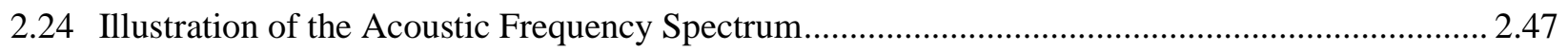

3.1 Well Logging: Sensor Measurement Techniques …................................................................... 3.2

3.2 Logging Tool Types and Formation Properties Sensed .............................................................. 3.9

3.3 Depth of Investigation of Some Logging Tools.................................................................... 3.10

3.4 Schlumberger Data, Comparison of Accelerator Porosity Tool’s Near-to-Far Porosity Sandstone Corrected Trace and a Trace from a Separate Run of the CNL Neutron Porosity........ 3.18

3.5 Histogram of Difference Between Two Porosity Traces in Schlumberger Example..................... 3.19

3.6 Tucker Log: Main Run and Repeat Run .............................................................................. 3.20 
3.7 Histogram of Difference Between Tucker Main Log and Repeat Section.

3.8 Vertical Resolution, Maximum Penetration, and Finest Azimuthal Resolution of the Tools Characterized in Table 3.10, Scaled to a 20-cm Borehole

3.9 Histogram of the Difference Between Measured Core Porosity and Calculated Log Value of Porosity

\section{Tables}

2.1 Significant Advances in Logging Technology Development .................................................... 2.2

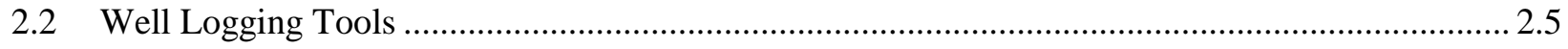

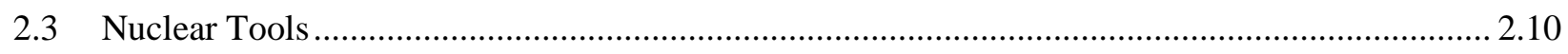

2.4 Neutron Sources for Downhole Well Logging...................................................................... 2.14

2.5 Electromagnetic Well-Logging Tools..................................................................................... 2.20

2.6 Electrical and Electromagnetic Well Logging Tools ............................................................. 2.22

2.7 Electromagnetic Propagation Constant Inside Various Types of Media in Terms of Material

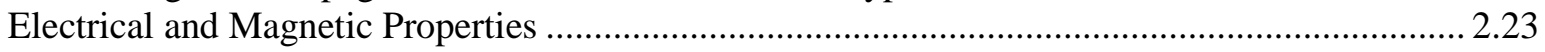

2.8 Electrical Permittivity and Propagation Delays for a Variety of Formation Constituents ............. 2.24

2.9 Acoustic-Wave Propagation and Summary of Well-Logging Applications ................................ 2.34

3.1 Summary of Nuclear Measurement Techniques for Geophysical Formation ................................. 3.3

3.2 Relationship Between Composition of a Rock and Well Logging Parameters................................ 3.6

3.3 Relationships Between Rock Texture and Well Logging Parameters............................................ 3.6

3.4 Relationships Between Sedimentary Features and Well Logging Parameters............................... 3.7

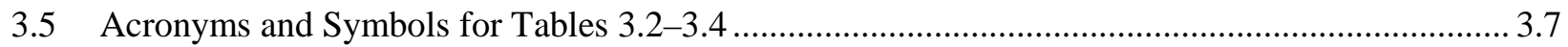

3.6 Basic Well Logs and Their Correlations and Related Attributes ................................................ 3.8

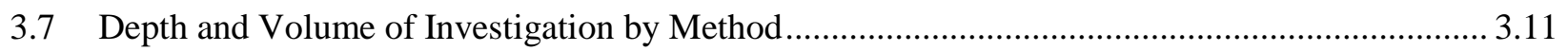

3.8 Well Logging Methods and the Parameters They Measure …...................................................... 3.13

3.9 Methods from Asquith and Krygowski (2004), and Other Sources............................................ 3.13

3.10 Depth and Resolution of Investigation by Method ................................................................. 3.23 


\subsection{Introduction}

There is a concern that sealed radiation sources, including those using americium-beryllium (AmBe), which is currently used in well logging by the oil and gas industry, can be diverted and incorporated in dirty bombs. Various agencies have taken an interest in the industrial applications of sealed sources, and potential alternative non-nuclear technologies. For example, a study performed for the U.S. Environmental Protection Agency (Trinity 2002) provided an overview of technologies, as well as stakeholder attitudes and implementation considerations, for non-destructive evaluation (NDE), industrial gauging, and well logging. However, while serving as a useful starting point for this present investigation, the study lacked depth, particularly with regard to investigation of fundamental sensing technologies, alternate technologies, and the issues encountered. The risk of radiological source diversion was highlighted in a National Academies report that provides motivation for the current study (NRC 2008, pg. 9). The report provides a listing of types and numbers of sources currently used in the United States. It also discusses some of the technical obstacles faced when proposing replacements for AmBe and other radioactive sources used in well logging. It further highlights some of the issues that need to be addressed, including differences in sensor response, use of hybrid tools employing nuclear and nonnuclear sensors, issues relating to determination of petro-physical parameters, and correlations between data using new approaches with that provided in historic records. In assessing technologies, it is necessary to ensure that any replacement methods provide the required data, and meet or exceed performance of current devices. Most importantly, data derived from new sensing methods must correlate well with that acquired using traditional tools.

When reviewing use and life cycle for sources it is seen that, in addition to risks associated with deliberate diversion, isotopic sources can also be lost (e.g., Patlovich et al. 2005). For example, in Texas between 1956 and 2001, a total of 426 sources were reported as lost down hole. Recent actions by the U.S. Department of Energy (DOE), restricting isotope supply, have served to reduce the availability of isotopic sources in the United States and has heightened interest in alternative technologies.

Strong opinions are held by some within the user community regarding the importance and need for isotopic sources in well logging (Rosemann 2009). Although isotopic sources are still viewed as a tool of choice for formation characterization, the challenges faced in obtaining and deploying sources are motivating the search for alternatives. There is current interest within the community to reduce (and potentially eliminate) the use of radioactive sources (Adolph et al. 2005). The petrochemical industry is looking at some new and improved tools for use in both logging-while-drilling (LWD) and for traditional wire-line logging. Alternative non-isotopic nuclear/radiological and non-nuclear/isotopic technologies are both being actively investigated. However, any alternative technology needs to:

- meet or exceed current characterization capabilities achievable with AmBe or other isotopic sources;

- provide data with excellent correlation to historic data sets (obtained with AmBe or other neutron sources); and

- meet, and preferably exceed, current field deployment requirements, including ease of use, required data acquisition rates, reliability, and robustness.

This project seeks to provide the basis for an independent assessment of well-logging technologies and assess the feasibility of potentially reducing isotope use in the well-logging community. It is focused 
on AmBe sources used in the petrochemical well logging. Is not focused on other isotopes, nor on other well-logging applications - water well, environmental, soil science, civil engineering, etc. The insights gained will be used to provide guidance to NA-22 with regard to the technical feasibility and performance of potential AmBe replacement technologies. This activity is part of the Radiological Source Replacement Program and it is intended to lead to reducing the use of isotopic sources in the oil-services community, both in the United States and especially in foreign oil-rich regions, where there is less control of access to well-logging isotope sources. This report presents findings from an initial evaluation of the current state-of-the-art for well-logging technologies, and alternate methods of petro-physical property determination.

Section 2 of this report presents a review of current well-logging science and technology. Section 3 presents an initial technology performance comparison. The conclusions are reported in Section 4. Section 5 contains a list of the references. 


\subsection{Technology Review}

Nuclear well logging using radioactive sources for rock characterization is a vital part of the activities within the geophysical exploration community, in particular in connection with oil exploration and production. The well-logging literature is extensive and reported in numerous books, journal and conference papers, and company publications.

An introduction to well logging in nontechnical language is provided by Johnson and Pile (2006). A more comprehensive, but a little dated, coverage is provided by Desbrandes in a translation of a text in French by Desbrandes and Brace (1985). A comprehensive description of the latest logging technology, which includes both standard and more challenging conditions, is provided in the book by Hearst et al. (2000). The text explains the physical principles behind logging methods and enables the reader to understand much of the technology. Another useful text is that of Schlumberger (1989). This document, written for the log analyst, is a comprehensive review of the technologies used in well logging, the various forms of logs and the challenges faced in the determination of petro-physical parameters from indirect physical data. A further text is that by Ellis and Singer (2007), which again provides an overview of well logging including an insightful discussion of the empiricism that is a cornerstone of well-log interpretation. The texts listed above are usefully complemented by those by Darling (2005) and by Asquith and Krygowski (2004), which address formation, evaluation and basic well log analysis. Final significant resources are the log interpretation charts produced and made available by Schlumberger (2009). These charts serve to introduce the complexity of interpretation, including the need for various corrections necessary for anything more than a most basic reporting of properties derived from log data.

Beyond the book literature, it is found that journal and proprietary documents on aspects of well logging science and technology is truly vast. The interpretation of logging data is a mix of art and science, with a significant component being based on historic correlations. Interpretation of the petrophysical correlations between sensed data and formation parameters requires the use of correction factors (Schlumberger 2009). These corrections are widely applied, particularly in the more complex morphologies, where fusing of multiple sensing modalities is required. Sophisticated interpretations are becoming more common as oil and gas are now increasingly found in difficult, complex geologies. Large oil fields in relatively simple dome configurations, such as those in Saudi Arabia, have not been found for many years. This makes accurate interpretation of logging data more critical as companies explore hostile environments such as the North Slope in Alaska and in various shallow and deep off-shore locations. Geophysical characterization of these sites incurs higher costs with the reward of smaller, economically marginal oil fields.

This section is intended to introduce the reader to the technology reported in the literature and provide pointers to some of the key reviews that the project team has found to be particularly useful. A state-ofthe art assessment, including a review of the technology in 1975, together with recommendations to improve well-logging capabilities, was provided by Baker et al. (1975). This was followed by a review by Timur and Toksoz (1985), which considered the full suite of logging technologies. Snyder and Fleming (1985) provide an overview of 25 years of technology development that preceded the paper's publication. It particularly emphasizes nuclear and resistivity measurements, major developments with acoustic logging, and the impact of digital computers. 
The well logging industry has seen many major advances over the intervening decades since the first logs were acquired in the 1920s. Some of the significant advances in logging technology development are summarized in Table 2.1.

Table 2.1. Significant Advances in Logging Technology Development (Prensky 2002)

\begin{tabular}{ll}
\hline Decade & \multicolumn{1}{c}{ Device } \\
\hline 1950 s & Acoustic log \\
& Nuclear magnetism log (NML) \\
& Borehole gravity meter (BHGM) \\
& Dielectric tool \\
1960s & Borehole gravity meter (BHGM) \\
& Borehole televiewer (BHTV) \\
& Ultra-long spaced electric log (ULSEL) \\
& Compensated neutron log (CNL) \\
& Carbon/oxygen log (C/O) \\
$1970 s$ & Dielectric tool \\
& Natural gamma-ray spectral log \\
1980s & Long-space and shear-wave acoustic logs (LSAL/SWAL) \\
& Circumferential acoustic log (CAD) \\
& High-resolution induced polarization log \\
& Pulsed-neutron porosity log (PNP) \\
Rotary sidewall tool & Multiple-electrode resistivity tool (MERT) \\
$1990 s$ & Logging-while-drilling (LWD) devices \\
2000s & $\begin{array}{l}\text { Electromagnetic and acoustic array designs } \\
\text { Second-generation pulse-echo nuclear magnetic resonance (NMR) devices } \\
\text { Electromagnetic multi-electrode lateral device, through-casing resistivity } \\
\text { tools, a high-resolution azimuthal laterolog service, and a multicomponent } \\
\text { induction instrument } \\
\text { Through-tubing pulsed-neutron devices } \\
\text { Permanent reservoir monitoring sensors }\end{array}$ \\
\hline
\end{tabular}

Electrical and electromagnetic borehole measurements were reviewed in detail by Spies (1996). A survey of then recent developments and emerging technologies in well logging and rock characterization was reported by Prensky (1994). The same author provided a discussion of advances in borehole imaging, including both wire-line and LWD applications (Prensky 1999). An assessment of the technology, driven by the need to address the requirement of deepwater development and associated costs, was reported in 2002 (Prensky 2002). The paper discusses new classes of down-hole wire-line sensors, permanently placed sensors, and LWD sensors that have been developed since 1994. The DOE Geophysical Monitoring Working Group (Snieder et al. 2007) provides a complementary review of the wider topic of non-invasive geophysical monitoring techniques, and includes discussion of measurement of formation mechanical properties and fluid transport.

Logging using radiation of nuclear origin started in 1940, with early tools recording natural background radiation emitted from formations that were crossed by boreholes. Passive tools were developed to measure gamma rays and interest eventually progressed to active nuclear interrogation. 
Active Gamma-ray logging was introduced in 1962. Technology developed further with deployment of neutron logging tools in the late 1960s. The original neutron logs were later augmented by pulsed (electronic source) neutron logs and neutron-induced gamma spectroscopy. These technologies are routinely deployed, and in some cases use AmBe sources. Reviews of advances in nuclear oil-well logging have been periodically published (e.g., Mills et al. 1991; Gilchrist Jr. 2009).

In addition to nuclear based technologies, a variety of non-nuclear measurements are routinely made. One such family of technologies is based on sonic or acoustic measurements. Sonic logging was originally demonstrated in 1946, working largely with technology developed during World War II. Over the next three decades, sonic logging moved into several measurement fields including:

- Porosity measurement

- Cement bond evaluation

- Fracture detection

- Lithology determination

- Mechanical rock property measurement

- Borehole and casing inspection

- Seismic calibration

- Abnormal formation pressure detection

- Gas-bearing formation identification

In recent years, nuclear logging has tended to supplant acoustic measurements for some of these characterization functions. However, sonic techniques are still used in validation and/or verification measurements to corroborate data observed with other types of sensor.

In acoustic logging, a transmitter located in the borehole emits a pulse of mechanical (acoustic or elastic wave) energy that is recorded by one or more receivers located in the borehole some distance away from the transmitter. This technology changed after 1970 when it became possible to digitally record “full waveform” acoustic logs (Paillet and Cheng 1991). In full-waveform acoustic logging, the complete acoustic wave at each receiver is recorded digitally. The character of the detected acoustic signal is affected by, among other things, the mechanical properties of the rock and any fluid which it contains. The deployment of acoustic methods (as with the other sensing modalities) is a multidisciplinary activity that encompasses a range of fields including basic theory, instrumentation, and data interpretation (Tang and Cheng 2004). This technology has many applications, including:

- The in-situ determination of compressional and shear-wave velocities, which are useful in the interpretation of hole-to surface measurements, hole-to-hole seismic tomography, and surface seismic data;

- The compressional and shear velocities, which can be combined with data from a density-logging tool to calculate formation elastic parameters such as Poisson's ratio, Young's modulus, bulk modulus and shear modulus - important parameters in many geotechnical engineering problems and in mine development;

- The determination of porosity in porous rocks from the compressional-wave velocity; 
- The measurement of permeability in porous rocks (Stoneley wave amplitude and velocity);

- The detection of fractures and the measurement of fracture permeability (Stoneley wave amplitude);

- Hole-to-hole lithology correlation using logs of compressional and shear-wave velocity;

- Determining the presence of cement grout behind steel casing and assessment of the degree of bonding between casing and formation in "the cement bond log" (using the compressional wave amplitude).

Various recent acoustic developments have occurred and they have been included in advanced well logging tools such as the Schlumberger Sonic Scanner acoustic scanning platform (Schlumberger 2005a).

There is also an extensive family of electromagnetic tools and borehole electrical and electromagnetic methods that cover 17 decades of the electromagnetic frequency spectrum - from direct current to $\mathrm{GHz}$ (e.g., Spies 1996). One of the most important advances has been the advent of NMR logging. There is now extensive interest in investigating the potential use of NMR (Zhang et al. 2000) with complementary acoustic and electromagnetic sensors (Prensky 1994). Newer electro-seismic methods utilize electrokinetic phenomena to characterized formation porosity and pore fluids (Zhu et al. 1999; Mikhailov et al. 2000; Thompson et al. 2006).

The current range of well-logging tools was summarized in the National Academy study (NRC 2008) as shown in Table 2.2. These comprise two general families: logging while drilling - LWD (those measurements where the sensors are deployed as special sections in the drill string) and wire line logging - which can be used for a new well or one in production. Tools are designed to operate in wells that are "cased" (i.e., a pipe/liner is in place - commonly with grout between the liner and rock formation) or "uncased," where the hole is open to the formation morphology. The fluids present may be a water- or oil-based drilling mud, or the widely varying oil/water/gas/sand mixture found in a production well. There will be a zone around the borehole which will include modified properties (i.e., the "invasion" zone), that exhibits cracking and permits permeation of drilling mud into the formation. As tools operate at depth they encounter harsh conditions of elevated temperatures and pressures and in LWD operation they will experience significant mechanical vibrations and shocks. 
Table 2.2. Well Logging Tools (NRC 2008)

\begin{tabular}{|c|c|c|c|}
\hline Tool & $\begin{array}{l}\text { Typical Method } \\
\text { of Logging }\end{array}$ & Source of Signal & $\begin{array}{c}\text { Geologic Parameter } \\
\text { Sought }\end{array}$ \\
\hline \multicolumn{4}{|l|}{ Non-nuclear Tools } \\
\hline Resistivity & LWD or wireline & Electrodes & Formation water saturation \\
\hline Spontaneous potential & Wireline & Electrodes & $\begin{array}{l}\text { Formation composition and } \\
\text { water content }\end{array}$ \\
\hline Induction & LWD or wireline & Coils & $\begin{array}{l}\text { Formation composition and } \\
\text { water content }\end{array}$ \\
\hline RF dielectric & Wireline & RF antenna & $\begin{array}{l}\text { Formation composition and } \\
\text { water content }\end{array}$ \\
\hline Formation pressure & Wireline & Pressure in formation & Fluid content \\
\hline Acoustic & Wireline & Sonic transceiver & Fluid content and porosity \\
\hline Nuclear magnetic resonance & Wireline & Media in magnetic field & Fluid content and porosity \\
\hline \multicolumn{4}{|l|}{ Nuclear Tools } \\
\hline Natural gamma & Wireline & $\begin{array}{l}{ }^{40} \mathrm{~K} \text {, Th, and } \mathrm{U} \text { in } \\
\text { formation }\end{array}$ & Formation composition \\
\hline Gamma-gamma density & LWD or wireline & ${ }^{137} \mathrm{Cs}$ & $\begin{array}{l}\text { Formation density and shale } \\
\text { content }\end{array}$ \\
\hline Neutron cross section & LWD or wireline & D-T accelerator & Rock density and porosity \\
\hline Elemental composition & LWD or wireline & AmBe or D-T accelerator & Formation composition \\
\hline Neutron moderation & LWD or wireline & AmBe or D-T accelerator & Hydrogen content \\
\hline $\mathrm{C} / \mathrm{O}$ ratio & Wireline & D-T accelerator & $\begin{array}{l}\text { Hydrocarbon and water } \\
\text { content }\end{array}$ \\
\hline
\end{tabular}

NOTE: AmBe is americium-241 and beryllium; C/O ratio is carbon-to-oxygen ratio; D-T is deuterium-tritium; LWD is logging-while drilling; Th is thorium; $\mathrm{U}$ is uranium.

\subsection{Current Practice}

The primary interest of oil and gas companies is:

1) to determine the location and quantity of hydrocarbon materials present in a formation;

2) to determine if water is present; and

3) based on an understanding of rock permeability and fluid transport parameters, estimate how easily (and efficiently in terms of a recovery fraction) the well will produce oil from the formation.

Achievement of full-formation characterization from well logging data is a complex and, to a significant extent, an empirical process. This process integrates data from a suite of physical sensors and compares it to output from semi-empirical inversion models. The process is iterative and is depicted in simple schematic form as Figure 2.1. The process can be more complex as well-log analysts and geologists often analyze multiple datasets using neural nets? 


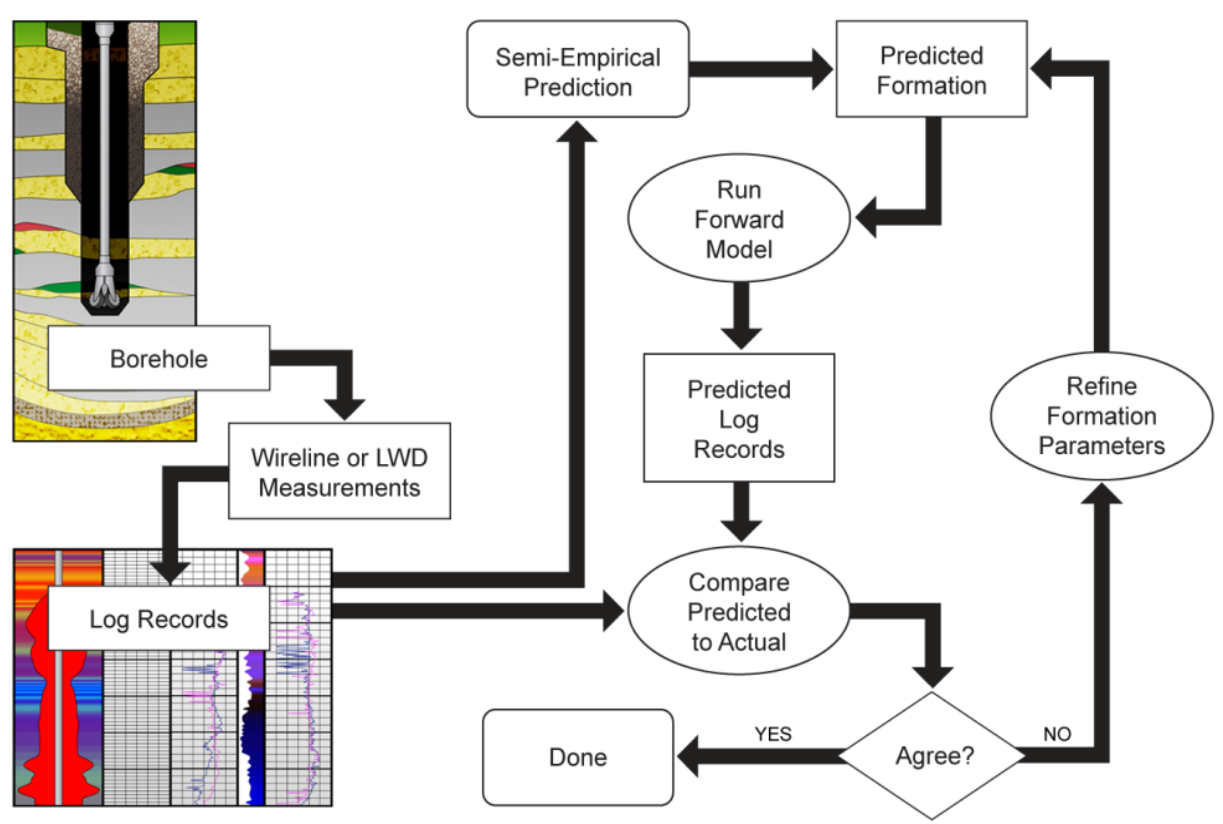

Figure 2.1. Schematic Showing the Process of Well Log Modeling and Field Data Interpretation

Traditionally, a suite of tools are lowered into the borehole at scheduled times during drilling or after drilling is completed. This is termed "wireline" logging. In recent years, there has been increasing use of novel sensor suites integrated into the drill string in an operation termed logging-while-drilling or LWD. The LWD environment is particularly harsh, and data need to be acquired at the speed at which drilling is performed. The rotating drill string introduces significant acoustic noise into the measurement process, and the mud in the well can contain significant debris. There is an industry move from wireline logging (post drilling) to LWD, but both are of significant commercial importance (Adolph et al. 2005).

The tools used incorporate both neutron and gamma radiation sources and sensors, and these are used to give data to estimate formation density, detect fluid-filled porosity, and identify the presence of hydrocarbons. Resistivity or conductivity measurements are used to help distinguish between oil and water $\left(\rho_{\text {oil }}>\rho_{\text {water }}\right)$. The electromagnetic tools use frequencies that range from $\mathrm{Hz}$ to GHz. The water content and rock porosity are related to the measured dielectric constants. This array of tools and their position in the electromagnetic frequency spectrum is shown in Figure 2.2.

In current practice, it is estimated that resistivity probably accounts for $60-70 \%$ of all well logs and gamma/neutron logs account for another 20-30\%. Sonic techniques tend to be used in a confirmatory mode, with velocity related to porosity. Passive gamma is used for shale-sandstone boundary determination. Mechanical and acoustic devices are used to measure bore diameter (caliper), shape, and rugosity (defined as the quality of roughness or irregularity of a solid surface such as the borehole wall). Gyroscopes and magnetometers supplement data from other sensors. Some compositional data are obtained with NMR systems. The nuclear tools (gamma and neutron) are the tools of first choice in many parts of the industry. 


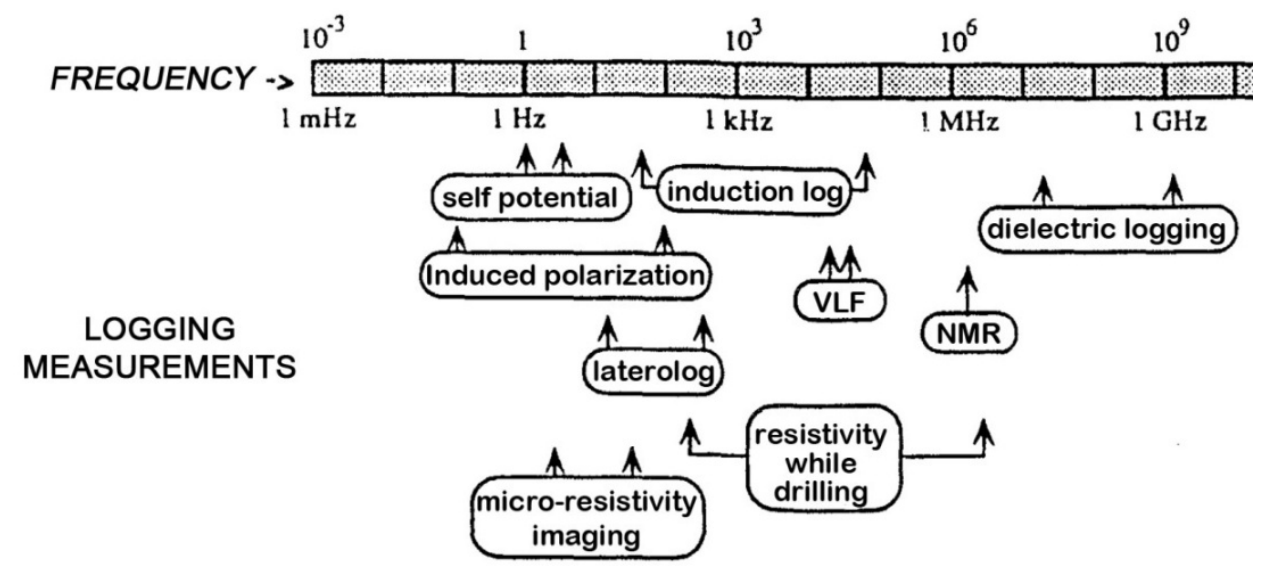

Figure 2.2. Spectrum of Electromagnetic Borehole Measurement Techniques (after Spies 1996)

Other than for the simplest formations and rock-fluid systems, there are almost no simple one-to-one correlations between sensed parameters and petro-physical rock-fluid properties. Interpretation is a mix of art and science, typically depending on the 20-30+ years of experience for many of the best log analysts. The data obtained with AmBe sources provide comparison with historic data, helping to increase confidence in interpretation. In many cases more than one sensed parameter is used to identify a formation characteristic, and numerous semi-empirical correlations are employed to provide petrophysical parameters (Asquith and Krygowski 2004) in log interpretation charts (Schlumberger 2009). There are also fundamental mathematical challenges posed by the fact that the sensor data set represents average values acquired throughout the depth of penetration of the sensor. Hence, the data set is generally sparse relative to formation structure (resulting in under-sampling) and sets a limit on the quality of data inversions. Correlations with confirmed historic features in records are an invaluable resource for complex formation interpretation and, as new tools are introduced, it is necessary to provide a bridge to historic data.

In addition to the temperature and pressure seen at depth, particularly for LWD, there are mud issues: mud properties influence most sensor measurements and there is also a radial modified zone in the borehole due to mud-invasion. This in turn favors tools that can sense more deeply into the undisturbed formation volume. The current well drilling muds are in two general families: oil-based (nonconductive) and water-based muds. These can be encountered in both lined and unlined boreholes. In the LWD configuration, many sensors will only probe $75 \mathrm{~cm}(\sim 2 \mathrm{ft})$ into the formation whereas for wireline sensing some sensors probe as far as $7 \mathrm{~m}(\sim 20 \mathrm{ft})$. The current sonic tools have challenges in that they may only probe a few $\mathrm{cm}(5-12 \mathrm{~cm}$ or $2-5 \mathrm{in}$.), although recently significantly larger penetrations of 2-3 m or more (tens of feet) have been reported (Arroyo Franco et al. 2006).

Geophysical well-logging tools to acquire all the various borehole physical properties measurements are designed to determine hydrocarbon quantities in underground formations. Modern tools are capable of providing information in the form of one-dimensional (1-D), 2-D, and 3-D morphology maps. Raw data are combined in a comprehensive interpretation process - generally using mathematical inversion codes - to obtain values of geological parameters (e.g., see Paillet and Cheng 1991, and cited references). This process is at the heart of geophysical-petro-physical parameter determination. The ability to provide the mapping (or correlation) between measured data and formation parameters is at the core of 
geophysical exploration and oil-field characterization. Challenges remain in many aspects of data interpretation. An example relating to scale is seen in simply correlating acoustically determined parameters (e.g., velocity, density, and porosity) from higher-resolution sonic-ultrasonic probes with that from lower-resolution (lower frequency) probes ortheoretical predictions (Bayuk et al. 2008).

Estimating the uncertainty in petro-physical and geophysical parameters derived from well-logging data is difficult, and some say often near impossible. Recent studies are still debating the dependence between the uncertainty of nuclear and acoustic tool response and the estimated uncertainty in the interpreted geological parameters (e.g., porosity, water saturation, etc.) (Woznicka et al. 2005).

\subsection{Reference/Public Calibration Facilities}

To evaluate and standardize performance, calibration facilities have been developed to meet the needs of particular measurement modalities. A review of logging calibration technologies and the thenavailable facilities was published by Arnold and Butler (1988). Some new approaches to calibration were discussed in a subsequent paper (Butler et al. 1990). This work was part of the background investigating the need for a new European nuclear well-log calibration facility that opened in 1999. There are at present reported to be only two publicly accessible test facilities. One is named CALLISTO - Calibration (at Leicester) and In-Situ Tool Optimization - and the other is at the University of Houston, in their Well Logging Laboratory (UH WLL). Availability of facilities for direct comparison of different measurement modalities appears to be extremely limited and published open literature data for inter-comparisons are particularly sparse.

The CALLISTO facility in the United Kingdom is a European facility, originally proposed in the early 1980s. Since its opening in 1999, it has finally evolved to be a new world standard facility for the calibration of nuclear well logs, supported through a consortium and the University of Leicester (Samworth and Lovell 2001). The size of the facility is illustrated with a general view of the site shown in Figure 2.3. Rock blocks are installed in four tubes, and part of the available rock collection comprises some 108 machined slabs that in total weigh more than 160 tons. Some samples are maintained in a saturated condition. Data at this facility are taken using various logging tools.

The UH WLL was established in 1979 in the Department of Electrical Engineering to investigate the electromagnetic properties of reservoir rocks over a wide range of frequencies. In addition, theoretical and experimental studies have been carried out to obtain a better understanding of electric tool response in complex borehole environments (e.g., dipping formations, thin invaded beds, and anisotropic formations). All of these studies have the primary objective of improving interpretation of logs obtained with existing tools. Information is also being generated on the design of possible new tools, the limitations of existing tools, and logging response in complex borehole environments. The research program is supported by a consortium of oil exploration and well service companies. The main UH WLL facility is shown in Figure 2.4. The UH WLL operates the API Nuclear Logging Calibration Facility and has constructed, under a joint API-industry funding arrangement, a set of potassium-uranium-thorium standard pits

[http://welllogging.egr.uh.edu]. The advertised program of the WLL is focused on computer modeling of electromagnetic tools rather than intercomparisons with nuclear techniques. 


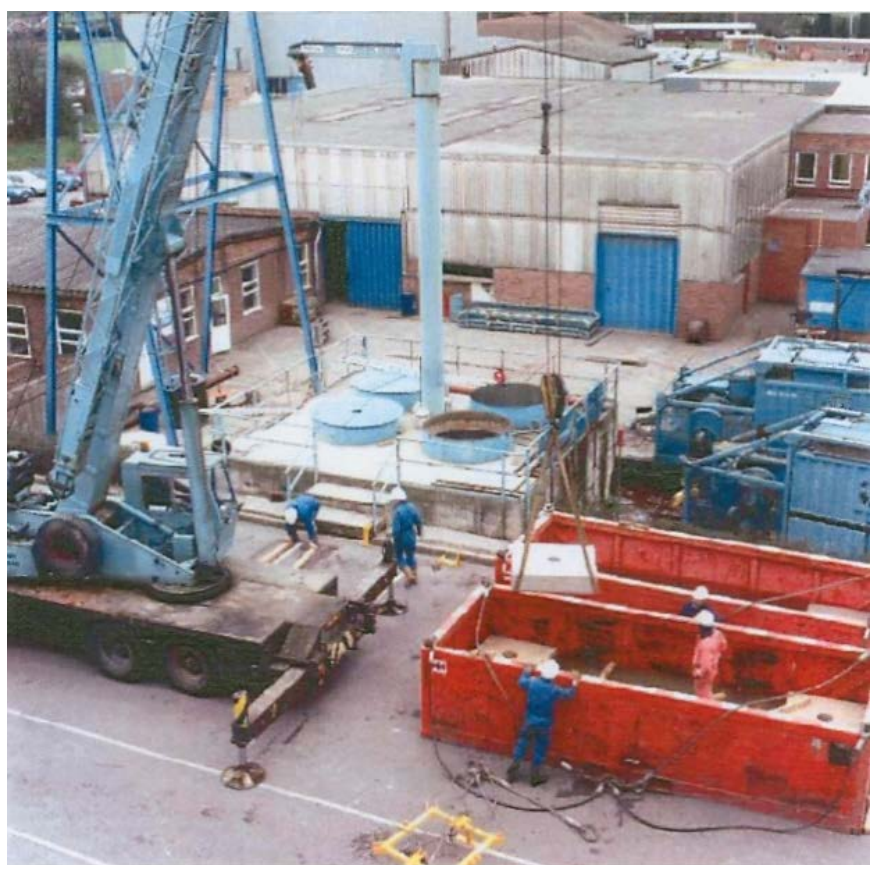

Figure 2.3. General View of the CALLISTO Site (Samworth and Lovell 2001). CSPG@ 2001; reprinted by permission of the CSPG whose permission is required for further use.

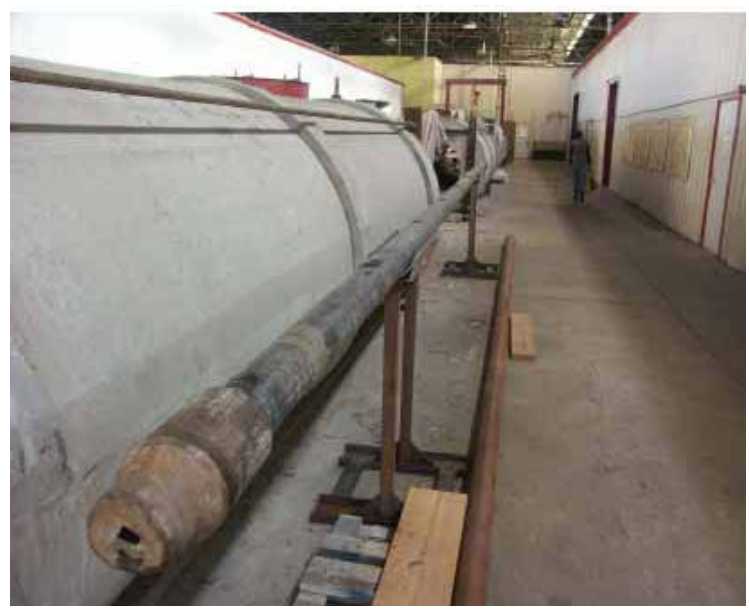

Figure 2.4. Well Logging Laboratory - University of Houston

Within the United States, limited facilities have been established to meet specific calibration needs, such as those at the DOE Hanford Site (Last and Horton 2000) and Grand Junction Colorado (Stromswold 1995), which include concrete cylinders containing various sources/isotopes (Stromswold 2005). 


\subsection{Nuclear Measurements in Well Logging}

Nuclear well-logging methods are sensitive to atomic nuclei. In this respect, they are welldifferentiated from electrical or electromagnetic methods which are sensitive to outer-shell or conduction band electrons. The nuclear methods can be classed as passive (e.g., gamma ray spectroscopy) or active (requiring a probing particle [neutron] or probing high-energy photon [gamma ray] to interrogate the measurement region). The first passive nuclear well-logging method was demonstrated in the late 1930s when a simple Geiger-Muller tube sensor was used down-hole to differentiate between shale-bearing and clean formations (i.e., no shale) by measuring gross gamma counts. Today, both gamma and neutron radiations are used to probe formations for elemental species, formation density, and the presence of water-filled or oil-filled porosity.

\subsubsection{Summary of Measurement Methods}

Nuclear tools currently used in the well logging industry are summarized in Table 2.3 (NRC 2008).

Table 2.3. Nuclear Tools

\begin{tabular}{|c|c|c|c|c|}
\hline $\begin{array}{l}\text { Common } \\
\text { Name }\end{array}$ & Sensed Variable & Source of Signal & $\begin{array}{c}\text { Chemical/Nuclear } \\
\text { Sensitivity }\end{array}$ & $\begin{array}{c}\text { Geologic } \\
\text { Parameter Sought }\end{array}$ \\
\hline Natural gamma & $\begin{array}{l}\text { Count rate and energy } \\
\text { distribution of } \\
\text { formation-emitted } \\
\text { gamma radiation }\end{array}$ & $\begin{array}{l}\text { Nuclear transitions in } \\
\text { elemental species }\end{array}$ & $\begin{array}{l}\text { Uranium, thorium and } \\
\text { their decay daughters } \\
\text { (in shale) and }{ }^{40} \mathrm{~K}\end{array}$ & $\begin{array}{l}\text { Formation } \\
\text { composition }\end{array}$ \\
\hline $\begin{array}{l}\text { Gamma-gamma } \\
\text { density }\end{array}$ & $\begin{array}{l}\text { Count rate and energy } \\
\text { distribution of } \\
\text { formation-scattered } \\
\text { gamma radiation }\end{array}$ & $\begin{array}{l}\text { Compton scattering of } \\
{ }^{137} \text { Cs gamma radiation } \\
\text { by elemental electrons }\end{array}$ & $\begin{array}{l}\text { Compton scattering } \\
\text { cross section is } \\
\text { weighted toward high } \\
\mathrm{Z} \text { elements (higher } \\
\text { electron densities) }\end{array}$ & $\begin{array}{l}\text { Formation density } \\
\text { and shale content }\end{array}$ \\
\hline $\begin{array}{l}\text { Neutron cross } \\
\text { section }\end{array}$ & $\begin{array}{l}\text { Count rate of } \\
\text { thermalized neutrons } \\
\text { scattered back to tool }\end{array}$ & $\begin{array}{l}\text { Elastic and inelastic } \\
\text { scattering of neutrons } \\
\text { by target nucleus }\end{array}$ & Many elements & $\begin{array}{l}\text { Rock density and } \\
\text { porosity }\end{array}$ \\
\hline $\begin{array}{l}\text { Elemental } \\
\text { composition }\end{array}$ & $\begin{array}{l}\text { Energy spectrum of } \\
\text { gamma radiation } \\
\text { emitted by neutron- } \\
\text { activated species in } \\
\text { formation }\end{array}$ & $\begin{array}{l}\text { Capture of thermal } \\
\text { neutrons by target } \\
\text { nucleus and emission } \\
\text { of characteristic } \\
\text { gammas. Also termed } \\
\text { "neutron activation } \\
\text { analysis." }\end{array}$ & $\begin{array}{l}\text { Many elements. } \\
\text { Sensitivity depends on } \\
\text { thermal neutron } \\
\text { capture cross section } \\
\text { of target }\end{array}$ & $\begin{array}{l}\text { Formation } \\
\text { composition }\end{array}$ \\
\hline $\begin{array}{l}\text { Neutron } \\
\text { moderation }\end{array}$ & $\begin{array}{l}\text { Time-resolved count } \\
\text { rate of thermalized } \\
\text { neutrons scattered } \\
\text { back to tool. }\end{array}$ & $\begin{array}{l}\text { Slowing down of fast } \\
\text { neutrons due to elastic } \\
\text { and inelastic collisions } \\
\text { with formation nuclei }\end{array}$ & $\begin{array}{l}\text { Low mass atomic } \\
\text { nuclei (e.g., } \mathrm{H} \text { and } \mathrm{C} \text { ) } \\
\text { most rapidly decrease } \\
\text { neutron energy }\end{array}$ & Hydrogen content \\
\hline $\begin{array}{l}\text { Carbon/oxygen } \\
\text { ratio }\end{array}$ & $\begin{array}{l}\text { Detection of element- } \\
\text { specific gamma } \\
\text { radiation due to } \\
\text { inelastic neutron } \\
\text { scattering }\end{array}$ & $\begin{array}{l}\text { Inelastic scattering of } \\
\text { fast neutrons by target } \\
\text { nuclei }\end{array}$ & $\begin{array}{l}\text { Requires knowledge } \\
\text { of gamma spectrum } \\
\text { for elements of interest }\end{array}$ & $\begin{array}{l}\text { Hydrocarbon and } \\
\text { water content }\end{array}$ \\
\hline
\end{tabular}




\subsection{Brief Description of Nuclear Well Logging Methods}

There are several modes in which nuclear well logging methods are implemented. Each of the common methods is introduced.

\subsubsection{Natural Gamma (Gamma Emission from Atomic Nuclei)}

There are three natural gamma-emitting isotopes of interest in downhole gamma logging: ${ }^{40} \mathrm{~K}$ (potassium) - $1.46 \mathrm{Mev},{ }^{214} \mathrm{Bi}$ (bismuth) - $1.76 \mathrm{Mev}$ (from the uranium decay series), and ${ }^{208} \mathrm{Tl}$ (thallium) $2.62 \mathrm{Mev}$ (from the thorium decay series). Emissions from the uranium and thorium decay series arise from decayed plant material (shale layers) since the high solubilities of uranium and thorium permit substantial transport-to and uptake-in plants. Uranium- and thorium-bearing minerals are rare. Potassium is a significant component $(>1 \%)$ of the earth's crust.

Shale is considered to be a fine-grained rock composed of silt and clay materials. The silt is predominantly quartz but may contain feldspars and organic matter. The principal use of the gamma ray $\log$ is to distinguish between shales and non-shales. Gamma emissions from clay minerals are primarily due to potassium and thorium. Relative clay gamma emission intensities from potassium, thorium, and uranium permit identification of the clay type which can be a useful diagnostic.

Gross gamma counts (i.e., containing no gamma energy information) can be measured with a simple Geiger-Muller tube (Knoll 2000). Gamma spectroscopy is performed using an alkali halide scintillator (e.g., thallium-doped NaI) and photomultiplier tube. The Geiger-Muller GM tube is illustrated in Figure 2.5.

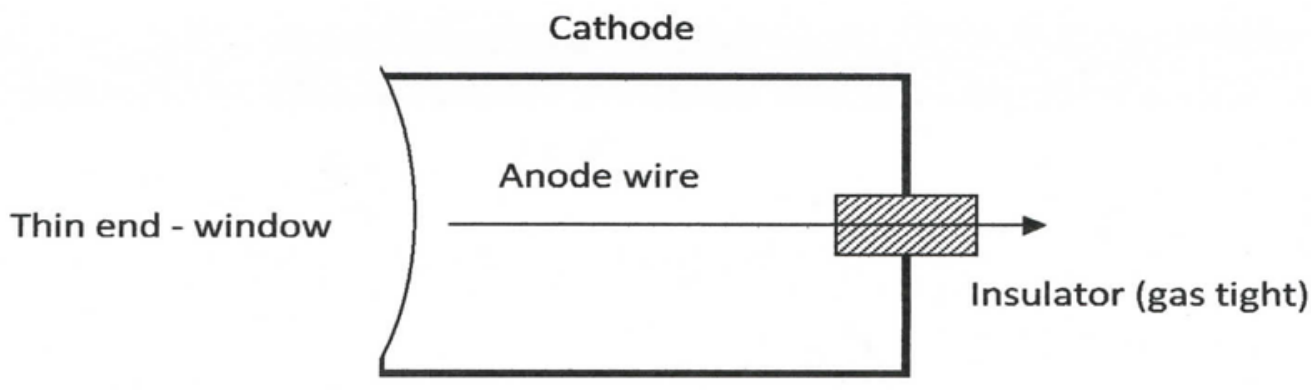

Figure 2.5. Detectors for Gamma Rays: Geiger-Muller Tube

Since the gamma spectroscopy probe experiences severe downhole temperature and pressure fluctuations, it is necessary to affix a self-calibration isotope (usually a small source of ${ }^{137} \mathrm{Cs}, \mathrm{E}_{\gamma}=$ $662 \mathrm{keV}$ emitted from ${ }^{137 \mathrm{~m}} \mathrm{Ba}$ ) to enable pulse-height compensation for temperature effects in the scintillator and photomultiplier. High-purity germanium (HPGe) detectors would provide much improved energy resolution in downhole gamma spectroscopy probes but their requirement for cooling to liquid nitrogen temperatures $(77 \mathrm{~K})$ prevents their use. 


\section{Topics for Consideration:}

Due to the rapid extraction rate of wireline gamma spectroscopy tools and the small detector area, only high-activity sources can be detected with a NaI gamma probe. This operating mode suggests the following questions:

1) Could additional formation information be obtained if longer counting times were permitted (e.g., by slowing the tool extraction or by deploying a stationary, disposable sensor on the borehole wall)?

2) Could improvements in $\mathrm{NaI}$ detector geometry (e.g., a larger crystal or multiple crystals) or photomultiplier performance (e.g., lowering dark counts by cooling the photocathode) permit increased sensitivity for other radioisotopes that might reveal information about the formation?

3) In addition to thorium, uranium, and potassium, what other isotopes or decay series could provide useful information to the petrochemical engineer and reduce the potential for environmental impact?

\subsubsection{Gamma-gamma Density (Compton Scattering of Gamma Radiation by Electrons)}

The gamma-gamma density tool utilizes a gamma-emitting radioactive isotope (usually ${ }^{60} \mathrm{Co}$ or ${ }^{137} \mathrm{Cs}$ ) to introduce probe radiation into the formation. The fate of these gammas is largely a function of formation elemental composition and lithology. The energy distribution and count rate of gamma radiation scattered back to the logging tool provides formation information. A typical 2-detector gamma-gamma probe appears in Figure 2.6. Two detectors are required to compensate for mudcake adhering to the borehole wall (density $=\rho_{\mathrm{mc}}$ and thickness $=\mathrm{t}_{\mathrm{mc}}$ ) and permit determination of the formation density, $\rho_{\mathrm{b}}$.

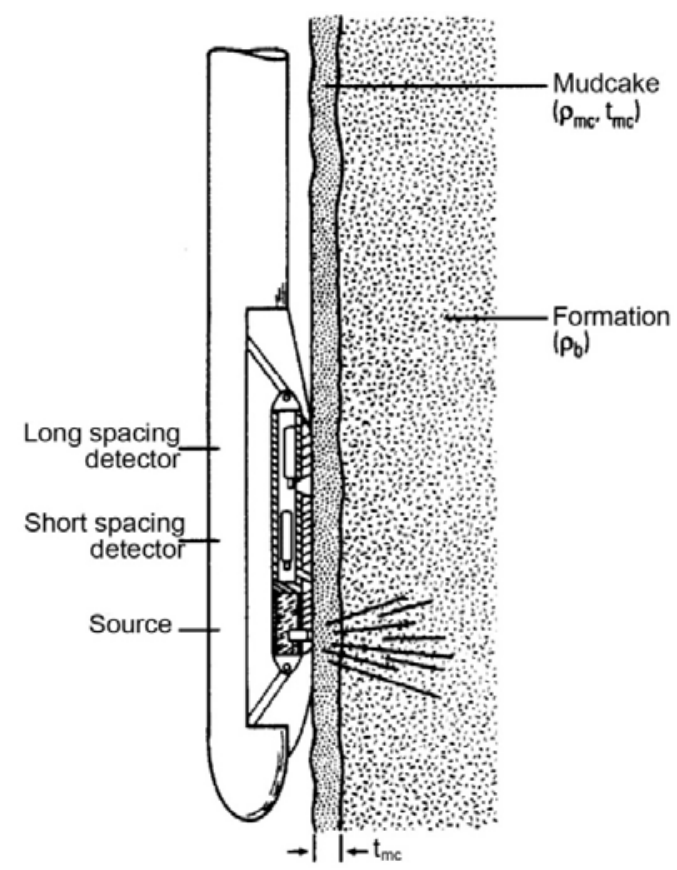

Figure 2.6. Formation Gamma-Gamma Density Device Applied to Side of Borehole (Ellis and Singer 2007) 
Gamma rays emitted into the formation can experience several types of interactions (Kaplan 1962):

1) Compton scattering by the elemental electrons (favored for high gamma photon energies, $>1 \mathrm{Mev}$ ). Compton scattering occurs when a gamma photon interacts with an elemental electron in the formation. The electron is removed from the atom and the scattered gamma photon departs in a different direction with lower energy. The process may be regarded as the scattering of a photon by a free electron initially at rest, and because each electron in the atom scatters independently, the Compton scattering coefficient per atom is proportional to the atomic number Z. Single- and multiple-Compton scattering can result in gamma photons being scattered back to the detector in the logging tool.

If the dominant radiation interaction is Compton scattering, gamma-ray transmission/reflection can be used to estimate bulk density. The bulk density measurement is motivated by its direct relationship to formation porosity. A scattering measurement can be strictly related to the bulk density, $\rho_{\mathrm{b}}$, only if $\mathrm{Z} / \mathrm{A}$ is constant. For most geologically common elements, $\mathrm{Z} / \mathrm{A}$ is about 0.5 , but there are several significant departures (e.g., hydrogen has a ratio of nearly 1). It is convenient to define an electron density index, $\rho_{\mathrm{e}}=2 \rho_{\mathrm{b}}(\mathrm{Z} / \mathrm{A})$. The bulk density and $\rho_{\mathrm{e}}$ for the three major minerals (limestone, dolomite, and quartz) are practically identical except that in water there is an $11 \%$ discrepancy between the two due to the extreme Z/A value for hydrogen (Schweitzer and Ellis 1988).

2) Photoelectric absorption (favored for low gamma photon energies, $<500 \mathrm{keV}$ ). In photoelectric absorption the incident photon is absorbed and an inner shell electron is ejected. This electron has a very short range; hence, the probing gamma photon is effectively lost to absorption.

3) Electron-positron pair production (only possible for $E_{\gamma}>1.02 \mathrm{MeV}$ ). The range of the electron and positron in the formation will be very small. However, their recombination results in emission of two gamma rays of energy $0.51 \mathrm{MeV}$.

4) Gamma resonance fluorescence. This low cross-section process occurs when the source gamma energy matches the energy of a nuclear transition in the target nucleus. The incident gamma is absorbed causing an excited, unstable nuclear state. When the nucleus returns to its ground state, another gamma photon (of different energy) is re-emitted by the target nucleus. Observation of this effect requires very high incident gamma fluxes and a carefully designed measurement geometry.

\section{Topics for Consideration:}

If the Compton scattering measurements could be performed using electrically generated x-rays, the need for a chemical radioisotope source would be eliminated. This suggests the following questions:

1) In the mid 1980s, x-ray generators were investigated for downhole well logging. What prevented their development and deployment?

2) Can x-rays be electrically generated downhole of sufficient energy to favor Compton scattering (and detection at the tool location) over photoelectric absorption?

3) Could x-ray fluorescence be utilized to identify and quantify elemental species in a geologic formation? 


\subsubsection{Neutron Scattering (Elastic and Inelastic)}

Neutron transport in a formation depends on two processes: (1) neutron energy loss as the neutron energy decays to thermal energies and (2) thermal neutron diffusion (up to the point of neutron capture). The epithermal neutron flux from a point source can be characterized by an exponential dependence on the distance from the source with a length parameter given by the slowing-down length $\mathrm{L}_{\mathrm{s}}$. The thermal neutron flux can be described by including a diffusion length, $L_{d}$ (Schweitzer and Ellis 1988).

All downhole neutron-scattering measurements require a source of neutrons in the logging tool. There are two source options, chemical or electronic. Their properties are summarized in Table 2.4 (NRC 2008). Note that the chemical sources provide essentially constant neutron emission rates. The electronic or pulsed deuterium-deuterium (D-D) and deuterium-tritium (D-T) sources provide short (10's to 100's of $\mu \mathrm{sec})$, controlled pulses of neutrons that permit time-resolved studies of induced gamma or scattered neutron radiations. Miniature D-T neutron generators have been in development since 1955 (by Schlumberger). These sources incorporate approximately 1.5 Curies of tritium (a beta emitter) in the generator head so they present a manageable radiation hazard to service personnel. Standard operating conditions are: (1) high voltage $=100 \mathrm{KV}$, (2) beam current $=100 \mu \mathrm{A}$, and (3) pulse frequency $=1 \mathrm{kHz}$ giving a neutron flux of $2 \times 10^{8}$ neutrons per second over $4 \pi$ solid angle. The output is adjustable over one order of magnitude. The system can be operated in the DC mode or in a pulsed mode with a pulse frequency of $15 \mathrm{kHz}$ or less. The pulse width is variable with a minimum of $10 \mu \mathrm{sec}$. When operated in the pulsed mode, the duty factor is restricted to $50 \%$ or less.

Table 2.4. Neutron Sources for Downhole Well Logging

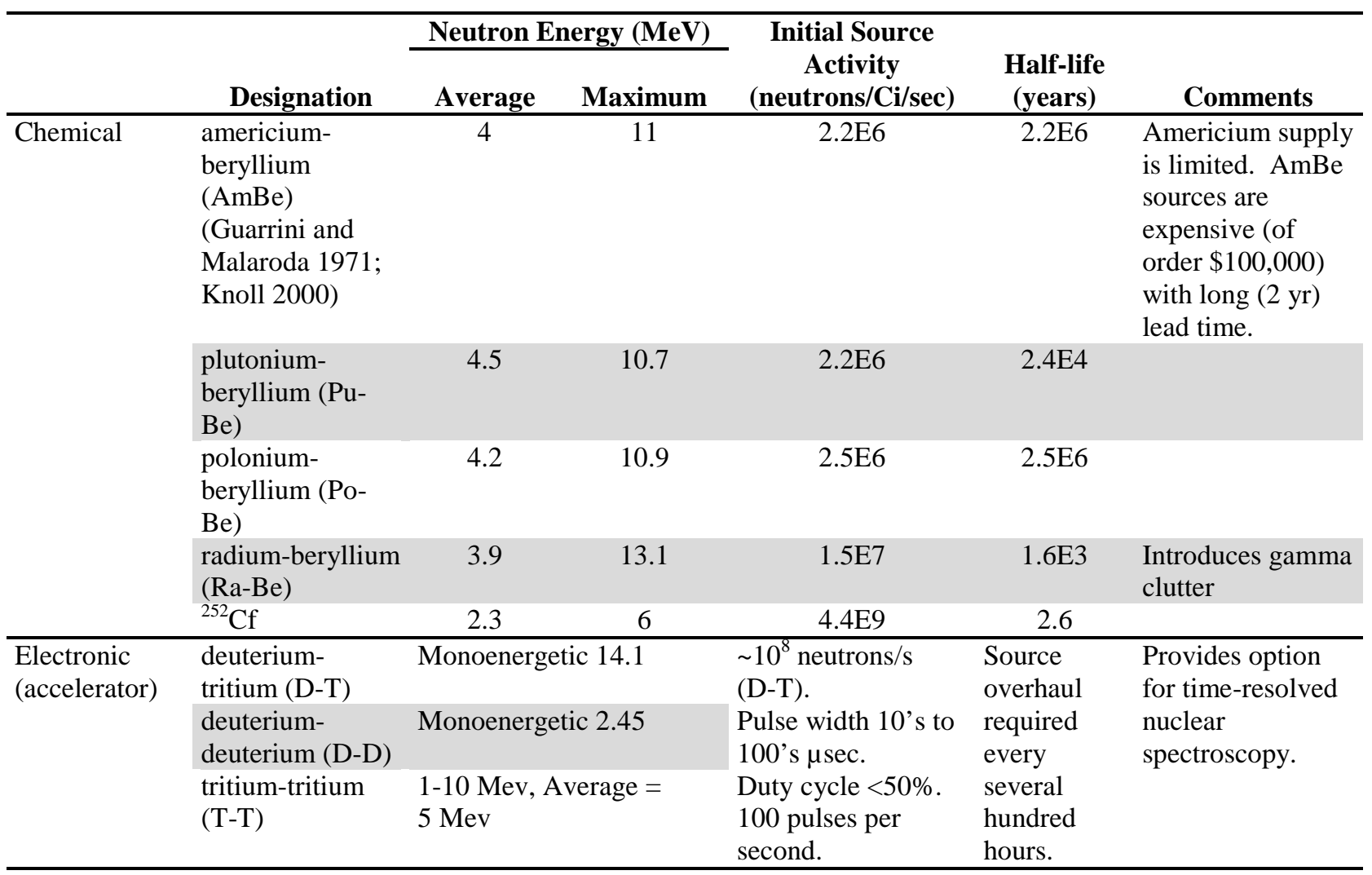


The neutron generator can be built with a deuterium-only (or a tritium only) fill producing $2.5 \mathrm{MeV}$ neutrons from the D-D reaction (or 0 to $10 \mathrm{MeV}$ neutrons from the T-T reaction), but neutron flux for both the D-D and the T-T reactions is 100 times lower than the flux from the equivalent D-T generator (Csikai 1987; Pfutzner et al. 1994). Having the ability to simultaneously or sequentially generate 2.4 MeV neutrons from D-D generators and 14.1 MeV neutrons from D-T generators allows a tool to perform measurements that are impossible or inconvenient with conventional tools. Such a scheme would permit measurement of neutron porosities using thermal and epithermal neutron measurements to take advantage of the different moderation times and penetration depths of the neutrons (Stoller 2009).

Neutrons can be used to interrogate atomic nuclei in the formation. Two scattering interactions are of interest (radiative capture of neutrons is discussed under the topic "Carbon/Oxygen Ratio"):

1. Elastic scattering - A neutron collides with an atomic nucleus in the formation. Depending on the mass difference between the neutron and the target nucleus, the neutron can experience a wide range of changes in energy and direction. Multiple elastic scattering collisions serve to slow the neutron down and can ultimately direct it back to a detector in the logging tool. Elastic scattering is favored for neutron energies less than $1 \mathrm{MeV}$.

2. Inelastic scattering - At neutron energies higher than $1 \mathrm{MeV}$, the scattering interaction can leave the target nucleus in an excited state. When this state decays, a gamma ray is emitted from the target nucleus. The emitted "characteristic gamma” can be captured in a scintillation detector, an energy assigned, and the emitting element identified using archived nuclear data. Elements that can be detected using inelastic scattering include carbon, oxygen, silicon, calcium, iron, and sulfur. A schematic of a generic neutron logging tool appears in Figure 2.7.

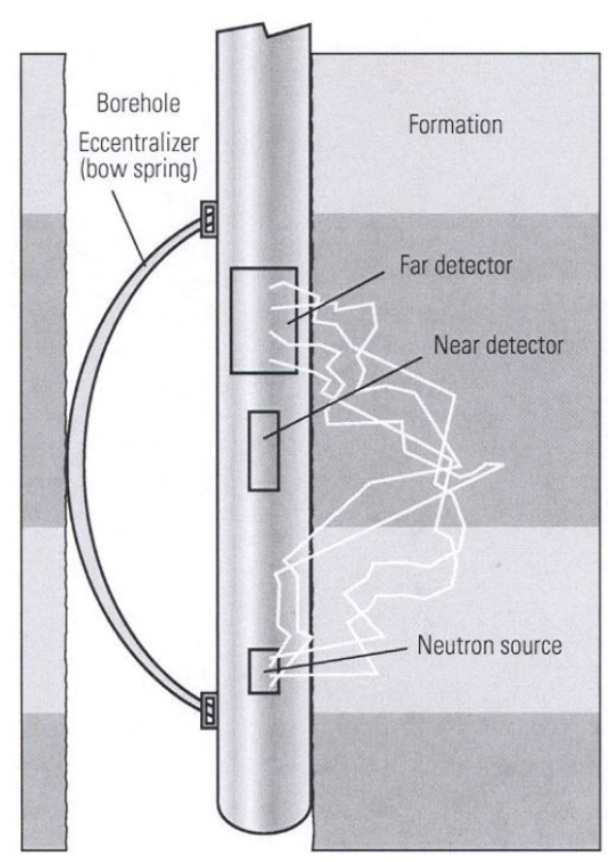

Figure 2.7. Generic Dual-Detector Neutron Tool (Ellis et al. 2003). Reprinted with permission from Society of Petrophysicists and Well Log Analysts. 
The dual neutron detectors (dubbed "near" and "far") permit compensation for borehole effects such as neutron absorption by chlorine (due to borehole salinity). The two detectors may also be designed for detection of thermal (slow) or epithermal (fast) neutrons. Neutron tools designed for LWD may have only one neutron detector because they effectively fill the bore space (displacing salt water).

An important consideration in any measurement scheme utilizing neutrons is the detector. The most widely used neutron detector is the ${ }^{3} \mathrm{He}$ tube. This detector operates via the ${ }^{3} \mathrm{He}(\mathrm{n}, \mathrm{p}) \mathrm{T}$ reaction which is favored for very low (thermal) neutron energies. The neutron capture cross section as a function of energy for ${ }^{3} \mathrm{He}$ appears in Figure 2.8 (after Knoll 2000).

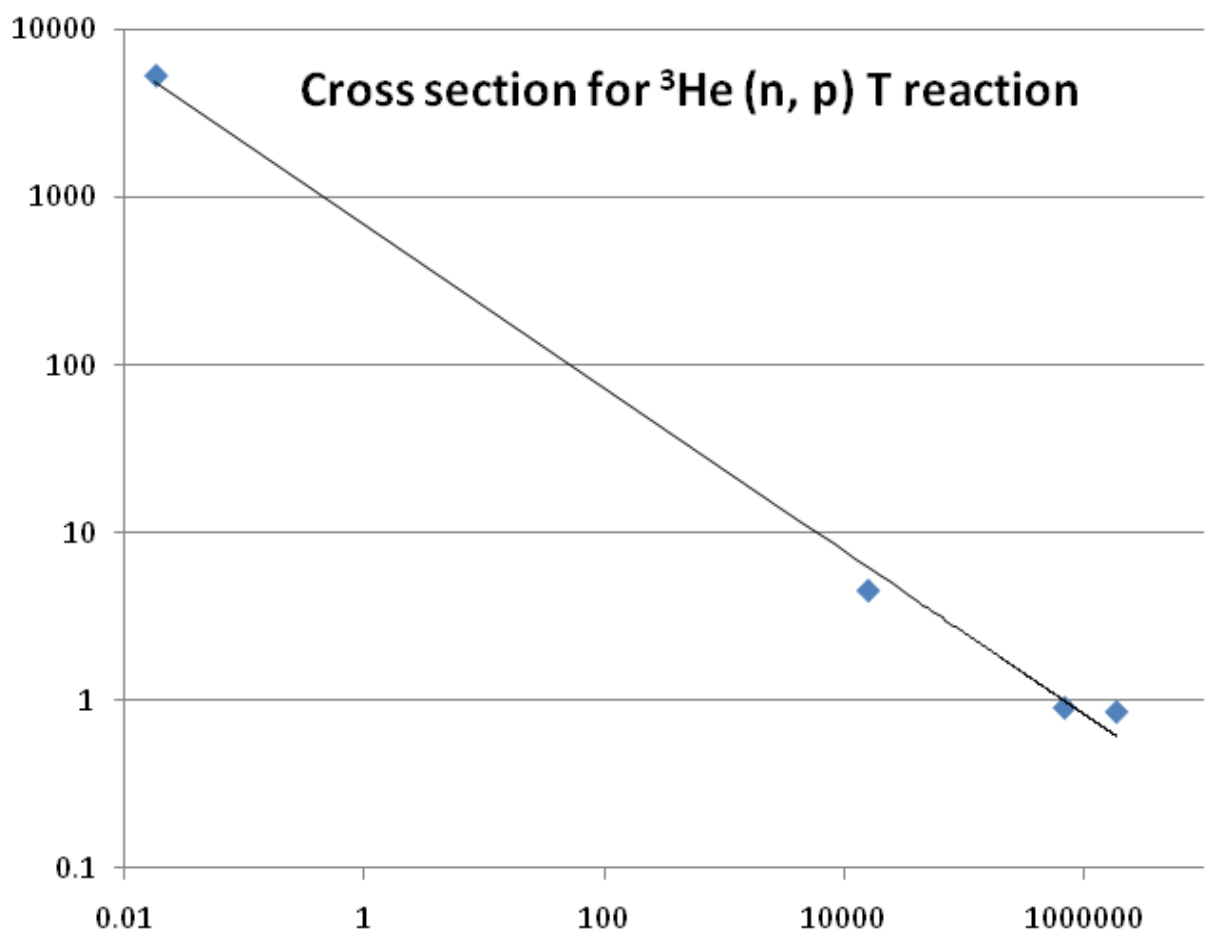

Figure 2.8. Energy-dependent Neutron Capture Cross Section for ${ }^{3} \mathrm{He},{ }^{10} \mathrm{~B}$, and ${ }^{6} \mathrm{Li}$ (Knoll 2000)

This graph indicates that for ${ }^{3} \mathrm{He}$, the probability of capturing a thermal neutron $(\mathrm{E}=0.025 \mathrm{eV})$ is roughly 5000 times greater than for a fast neutron at $\mathrm{E}=1 \mathrm{MeV}$. Hence, the detector response is severely skewed toward detection of neutrons that have been slowed down by elastic or inelastic collisions in the formation. ${ }^{3} \mathrm{He}$ detector sensitivity can be modified to favor higher energy "epithermal” neutrons (E > $1 \mathrm{eV})$ by: 1) wrapping the detector in a layer of cadmium metal $\left({ }^{109} \mathrm{Cd}\right.$ has a very high thermal neutron capture cross section of about 2500 barns) or; 2) wrapping the ${ }^{3}$ He detector in a blanket of hydrogen-rich moderator material (e.g., polyethylene or some other hydrogen-rich polymer).

\section{Carbon/Oxygen Ratio}

A specific application of neutron inelastic scattering is the determination of formation carbon/oxygen ratio. High-energy nuclear reactions with oxygen and carbon are depicted in Figure 2.9. 


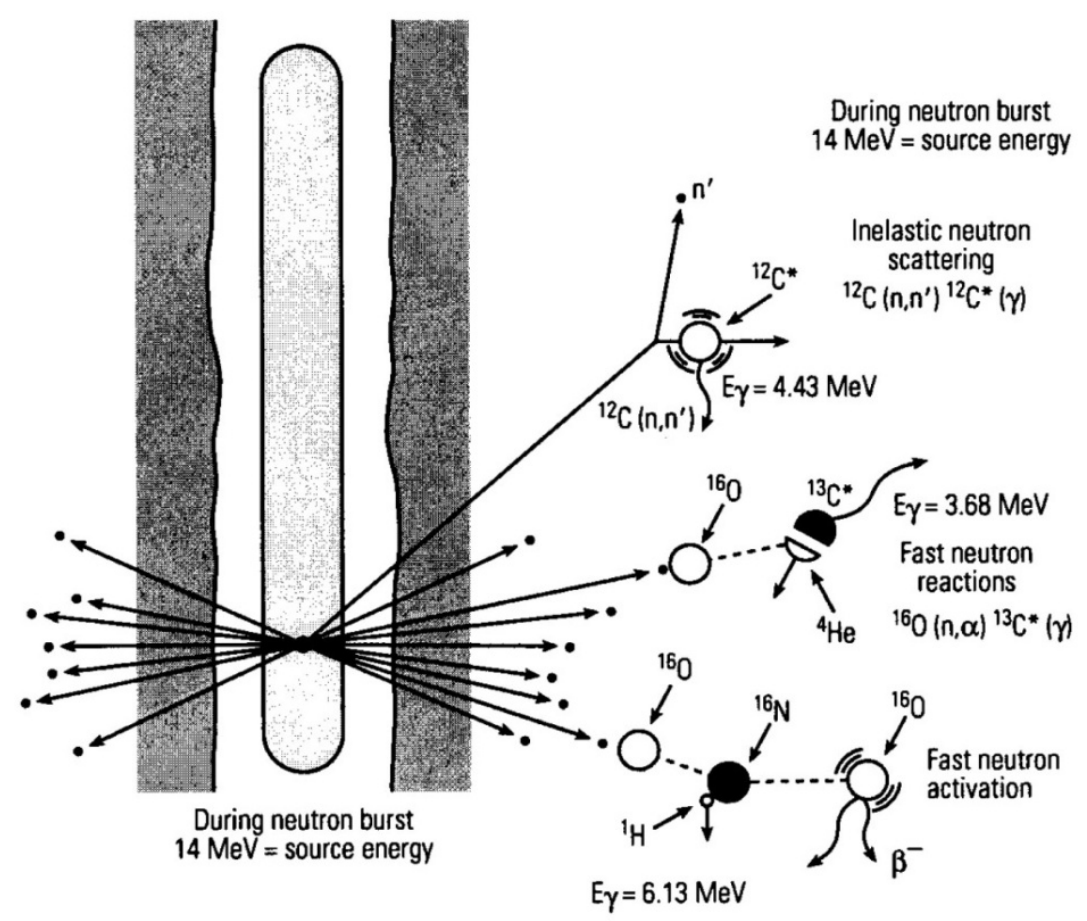

Figure 2.9. Fast Neutron Inelastic Scattering Reactions with Carbon and Oxygen (Ellis and Singer 2007)

Inelastic scattering reactions with these two elements result in the gamma-ray energy spectra in Figure 2.10. Areas under the respective peaks can be ratioed to give an estimate of the ratio of carbon to oxygen concentrations (to distinguish between water and oil).

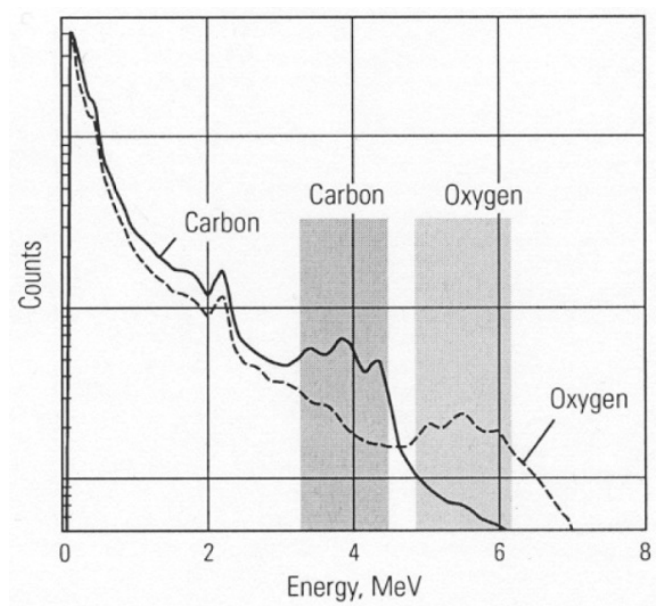

Figure 2.10. Inelastic Gamma Spectra Recorded with a Second-Generation C/O Instrument in an Oil Tank (solid) and in a Water Tank (dashed). Windows used to extract a statistically improved value of C/O are indicated (Ellis and Singer 2007, Fig. 15.9). Reproduced with kind permission from Springer Science and Business Media. 


\section{Porosity}

Conventional commercial neutron porosity logging tools consist of a pair of thermal or epithermal neutron detectors and a source of relatively low-energy neutrons. Porosity can be estimated from the slowing down length, $\mathrm{L}_{\mathrm{s}}$, and the formation thermal neutron absorption cross section, $\sigma_{\mathrm{a}}$. $\mathrm{L}_{\mathrm{s}}$ is roughly the root-mean-square (RMS) distance that a neutron travels from the source until its energy reaches the appropriate epithermal regime. The neutron slowing-down process can be considered a "random walk" or diffusion process. The number of steps in the walk is given by the average number of collisions needed to reduce the energy of the neutron to epithermal energy, and the length of each step is the neutron mean free path. The RMS distance of the random walk is proportional to the square root of the number of collisions. Due to the presence of hydrogen, the number of collisions necessary to reduce neutrons from a nominal energy of $4.2 \mathrm{MeV}$ to $0.1 \mathrm{eV}$ in water is approximately 16 ; in a non-porous limestone, it takes about 132 collisions.

Although the neutron slowing-down length is a convenient parameter for neutron transport, it is not an intuitive parameter. Computer codes have been developed to compute its value from the formation constituents. For some applications, it can be computed from the formation bulk density and the hydrogen weight fraction. This latter parameter is of considerable use in interpreting shale-bearing sands or in comparing neutron "porosity" results with those of core analysis, usually quoted in weight fractions (Ellis 1990).

\subsubsection{Elemental Composition (Neutron Activation Analysis)}

Elemental composition of a geologic formation can be determined using neutron activation analysis. This method relies on measurement of the energy spectrum of formation-emitted gammas arising from neutron capture. Neutron capture (with subsequent gamma emission) is favored for thermal neutron energies. This means that, following high-energy $(>1 \mathrm{MeV})$ neutron emission from the source, the neutron must experience numerous elastic or inelastic scattering events to slow down to thermal energies $(\mathrm{E} \approx 0.025 \mathrm{eV})$. An example of neutron-activation gamma spectra for formation elements of interest appears in Figure 2.11.

The slowing-down or "moderation" process is highly variable, occurring most rapidly in the presence of abundant hydrogen and/or carbon nuclei. If pulsed neutron sources are used (in contrast to chemical sources), there is an opportunity to acquire "neutron slowing-down time" or "neutron moderation time” measurements. The degradation rate of neutron energy through elastic/inelastic collisions and the ultimate capture of the thermalized neutrons is a function of formation constituents. The time delay between neutron pulse and detection of the gamma ray can therefore provide information on the fluid filling the porosity (water or oil). 


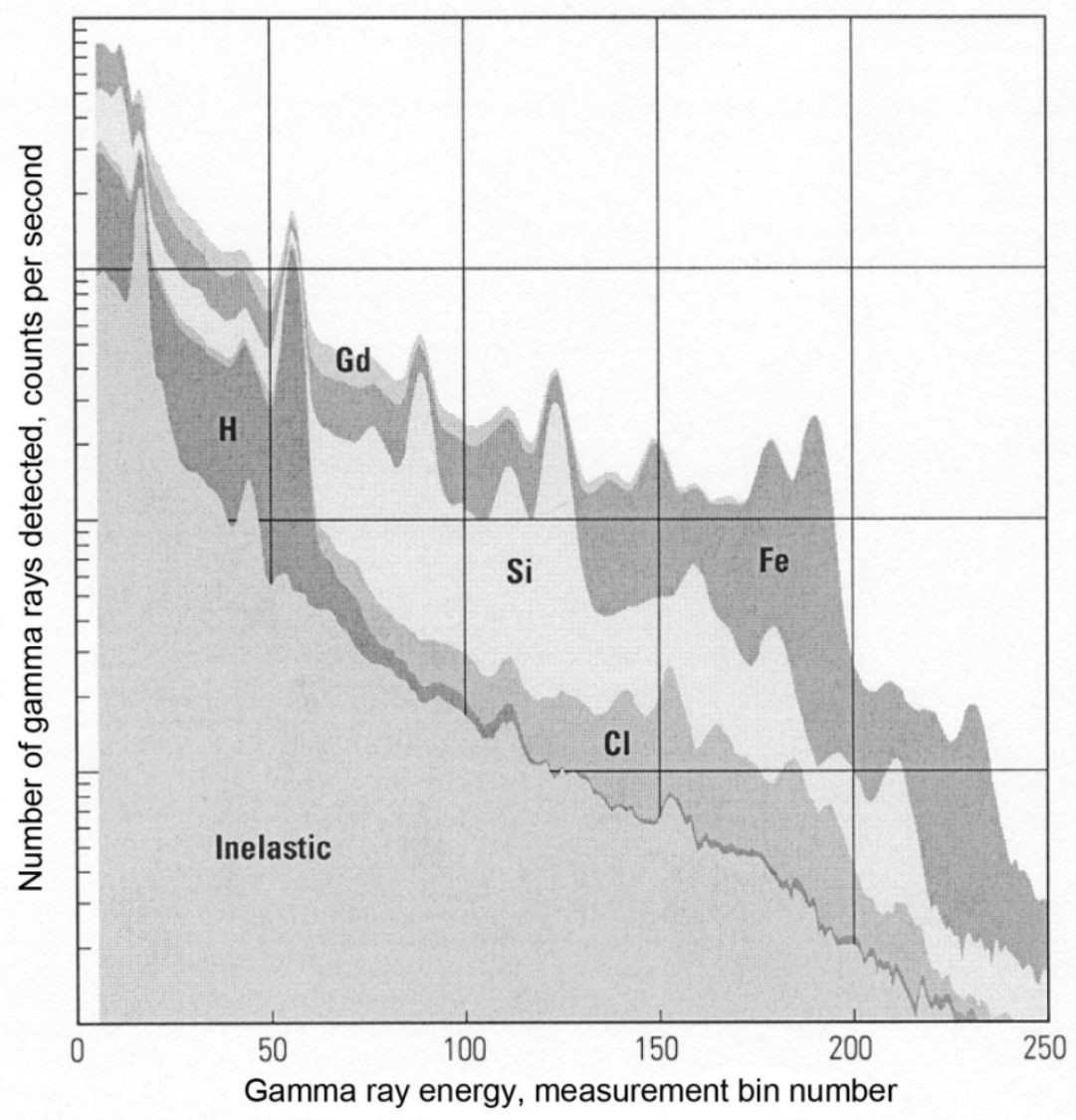

Figure 2.11. Measured Gamma Ray Spectrum from an Elemental Capture Spectroscopy (ECS) Sonde in a Sandstone Formation. The composite spectrum appears in the top trace. The spectral contributions of a number of elements are indicated in the lower traces (Ellis and Singer 2007, Fig. 15.18). Reproduced with kind permission from Springer Science and Business Media.

In practice, separation of neutron capture and inelastic neutron scattering methods is artificial. If a pulsed neutron source is used, gamma spectra can be recovered for both interactions simultaneously. Neutron capture permits detection of chlorine (i.e., salt water-filled porosity), hydrogen, silicon, calcium, iron, and sulfur. Inelastic scattering adds carbon and oxygen to the list. In combination, the following constituents can also be quantified (Desbrandes and Brace 1985):

1. $\mathrm{C} / \mathrm{O}$ gives the saturation

2. $\mathrm{Cl} / \mathrm{H}$ gives the salinity of the fluids

3. $\mathrm{H} /(\mathrm{Si}+\mathrm{Ca})$ is linked to porosity

4. $\mathrm{Fe} /(\mathrm{Si}+\mathrm{Ca})$ is an indicator of clay

5. $\mathrm{Si} /(\mathrm{Si}+\mathrm{Ca})$ gives the lithology

Note that the neutron scattering/capture tool can only be operated stationary in the borehole ( $~ 8 \mathrm{~min}$ per measurement) or at a very slow retrieval speed (less than 100 meters/hour). Due to the sharper 
gamma energy peaks, elemental detection by neutron capture is generally preferred over use of inelastic scattering data whenever possible.

The state of the art in neutron probes is represented by the Schlumberger EcoScope ${ }^{\mathrm{TM}}$ (Schlumberger 2007). This tool can log formation data while drilling (LWD). The EcoScope ${ }^{\mathrm{TM}}$ provides a complete suite of both drilling and formation evaluation measurements without the use of chemical neutron sources. The tool has a pulsed neutron generator that allows neutrons to be generated only when the tool is powered. EcoScope ${ }^{\mathrm{TM}}$ provides measurements such as elemental capture spectroscopy, formation capture cross section, and neutron-gamma density (Mirto et al. 2006) that enable determination of porosity.

\subsubsection{Summary Comments}

The use of fast and slow (thermalized) neutrons to probe a geologic formation is a very powerful method. There are large volumes of historic data that form the basis for well log interpretation, including the development of empirical and semi-empirical correction factors. There is detailed discussion of neutron log interpretation in numerous technical publications and texts and in the Schlumberger Log Interpretation Charts (Schlumberger 1989).

There is a move towards use of non-isotopic radiation sources. Use of a pulsed electronic neutron source (such as that incorporated in the Schlumberger Ecoscope ${ }^{\mathrm{TM}}$ tool) minimizes the environmental and personal hazards. Deployment of these devices appears to be limited by cost, reliability (two duplicate sources are required at the logging site in the event one fails), and maintenance requirements (sources must be overhauled after several hundred hours of service). There are also issues related to establishing correlations with previously recorded data, particularly when used to re-survey an operating well. In these cases direct comparisons between new and old data records is considered particularly important.

\subsection{Electrical and Electromagnetic Measurements in Well Logging}

Electrical and electromagnetic well-logging methods are sensitive to free and bound electrons and ions in the formation constituents (i.e., the atoms and molecules comprising the formation and fluids). Current electromagnetic well-logging techniques are summarized in Table 2.5 (Spies 1996).

Table 2.5. Electromagnetic Well-Logging Tools

\begin{tabular}{lcc}
\hline \multicolumn{1}{c}{ Tool Names } & Trade Names & Frequency of Operation \\
\hline Conduction resistivity & & $35 \mathrm{~Hz}-1.5 \mathrm{kHz}$ \\
Induction resistivity & CDR, ARC5 & $20 \mathrm{kHz}-100 \mathrm{kHz}$ \\
Propagation resistivity & DPT & $2 \mathrm{MHz}$ \\
Propagation dielectric resistivity & EPT & $25 \mathrm{MHz}$ \\
Propagation dielectric & $1.1 \mathrm{GHz}$ \\
\hline CDR = Compensated Dual Resistivity ${ }^{\mathrm{TM}}$ tool (Schlumberger) & \\
ARC5 = Array Compensated Resistivity ${ }^{\mathrm{TM}}$ tool (Schlumberger) & \\
DPT = Deep Propagation Tool ${ }^{\mathrm{TM}}$ (Schlumberger) $^{\mathrm{T}}$ & \\
EPT = Electromagnetic Propagation Tool & \\
\hline
\end{tabular}


Brief discussions of these methods (resistivity, spontaneous potential, and low-frequency magnetic induction) appear in a prior project report (Griffin et al. 2009) focused on the use of electromagnetic propagation methods.

This section describes the use of electromagnetic propagation measurements. The prime challenge for electrical methods is to sense formation parameters beyond the borehole that are not influenced by or can be compensated for the drilling mud, bore diameter, borehole rugosity, or drill string. Neither electrical nor electromagnetic logging methods are useful for cased wells.

Electromagnetic propagation measurements are most useful for distinguishing fresh water from oil, using the large difference in dielectric constant (i.e., the real part of the complex dielectric permittivity $\left(\varepsilon^{\prime}\right)$ ). This contrast is illustrated in Figure 2.12 where $\varepsilon^{\prime}$ is plotted for both distilled water and crude oil over the frequency range $50 \mathrm{MHz}-50 \mathrm{GHz}$.

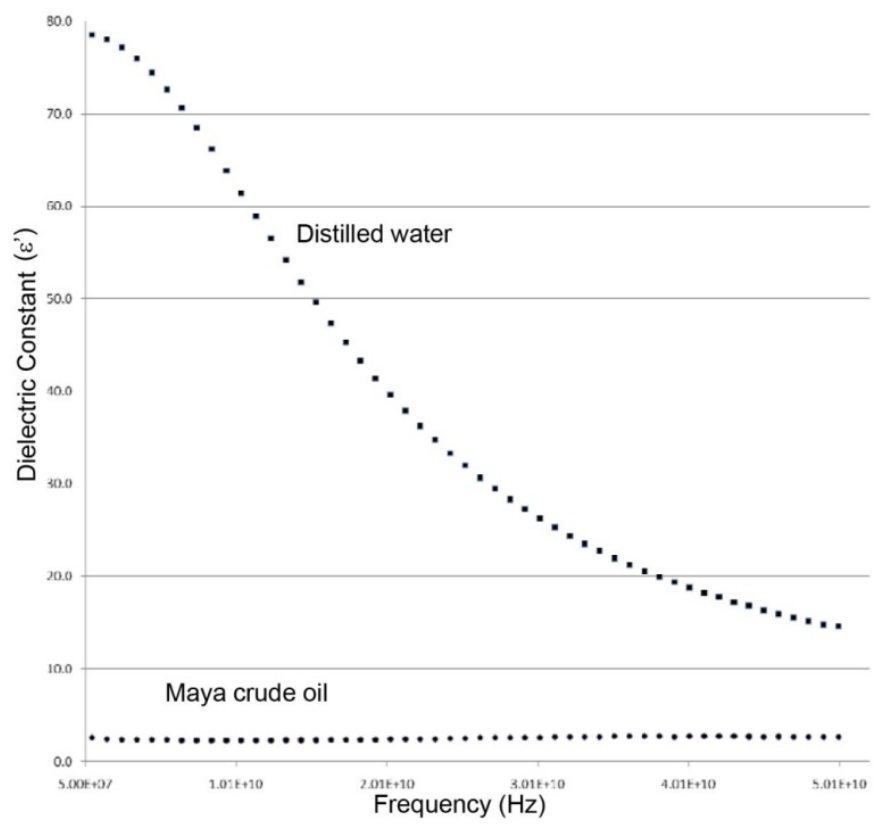

Figure 2.12. Dielectric Constant for Distilled Water and Oil Over the Frequency Range $50 \mathrm{MHz}$ to $50 \mathrm{GHz}$

\subsubsection{Summary of Measurement Methods}

Electrical and electromagnetic well logging tools are summarized in Table 2.6 (NRC 2008). Resistivity, spontaneous potential, and AC induction methods were described in a prior report (Griffin et al. 2009). These techniques are very mature and commonly used in the well-logging industry today. 
Table 2.6. Electrical and Electromagnetic Well Logging Tools

\begin{tabular}{|c|c|c|c|c|}
\hline $\begin{array}{c}\text { Common } \\
\text { Name }\end{array}$ & Sensed Variable & Source of Signal & Chemical Sensitivity & $\begin{array}{c}\text { Geologic } \\
\text { Parameter } \\
\text { Sought } \\
\end{array}$ \\
\hline Resistivity & DC or AC resistance & Aqueous ionic species & $\begin{array}{l}\text { Dissolved salts and/or } \\
\text { high mobility chemical } \\
\text { ions }\end{array}$ & $\begin{array}{l}\text { Formation water } \\
\text { saturation }\end{array}$ \\
\hline $\begin{array}{l}\text { Spontaneous } \\
\text { potential }\end{array}$ & DC or AC voltage & $\begin{array}{l}\text { Ion concentration } \\
\text { gradients }\end{array}$ & Dissolved salts & $\begin{array}{l}\text { Formation } \\
\text { composition and } \\
\text { water content }\end{array}$ \\
\hline Induction & $\begin{array}{l}\text { Low frequency } \\
\text { (<20 kHz) AC } \\
\text { impedance }\end{array}$ & $\begin{array}{l}\text { Ions and electrons in } \\
\text { the formation }\end{array}$ & $\begin{array}{l}\text { Chemical species } \\
\text { contributing to } \\
\text { formation AC } \\
\text { conductivity }\end{array}$ & $\begin{array}{l}\text { Formation } \\
\text { composition and } \\
\text { water content }\end{array}$ \\
\hline RF dielectric & $\begin{array}{l}\text { Electromagnetic } \\
\text { propagation parameters: } \\
\text { attenuation }(\alpha) \text { and } \\
\text { propagation delay }(\beta)\end{array}$ & $\begin{array}{l}\text { Electrons in the } \\
\text { formation }\end{array}$ & $\begin{array}{l}\text { Any species } \\
\text { contributing to the AC } \\
\text { impedance of the } \\
\text { formation }\end{array}$ & $\begin{array}{l}\text { Formation } \\
\text { composition and } \\
\text { water content }\end{array}$ \\
\hline $\begin{array}{l}\text { Nuclear } \\
\text { magnetic } \\
\text { resonance }\end{array}$ & & $\begin{array}{l}\text { Molecular species } \\
\text { comprised of atomic } \\
\text { nuclei containing an } \\
\text { odd number of nucleons } \\
\text { (e.g., water) }\end{array}$ & Water & $\begin{array}{l}\text { Fluid content and } \\
\text { porosity }\end{array}$ \\
\hline
\end{tabular}

The following section focuses on: 1) an assessment of high-frequency AC propagation methods (e.g., embodied in the Schlumberger Electromagnetic Propagation Tool or EPT ${ }^{\mathrm{TM}}$ ) and; 2) the use of NMR methods for formation characterization (e.g., embodied in the Halliburton Magnetic Resonance Imaging Logging or MRIL ${ }^{\mathrm{TM}}$ tool).

\subsubsection{Electromagnetic Propagation Methods}

In contrast to low-frequency AC electrical measurements of formation properties, the goal of electromagnetic propagation sensing is to launch an electromagnetic wave from a transmitting antenna into the formation and, after it has traversed the formation volume, sense the wave with a receiving antenna. Propagation through the formation impacts the electromagnetic wave in two ways: 1) the wave is delayed due to a slower propagation velocity in the formation and; 2) the wave amplitude is attenuated due to electrical losses imposed by the formation.

Consider a plane wave, polarized in the $\mathrm{x}$ direction, propagating through a lossy dielectric in the $\mathrm{z}$ direction. The electric field is given by

$$
E_{x}(z)=E_{x}(0) e^{-\alpha z} \cos (\omega t-\beta z)
$$

where the $x$-component of the electric field at $z=0$ is denoted $E_{x}(0)$ and $\omega=2 \pi f$ where $f$ is the wave frequency. The expression can also be written as

$$
E_{x}(z)=E_{x}(0) e^{-\gamma z}
$$


where $\gamma$ is the propagation constant defined as

$$
\gamma=\alpha+j \beta .
$$

$\alpha$ is termed the attenuation coefficient with units $\mathrm{m}^{-1}$ or nepers/meter. Likewise, $\beta$ is termed the phase delay with units radians/meter. Through the use of Maxwell's equations, both $\alpha$ and $\beta$ can be expressed in terms of the electrical $(\sigma$ and $\varepsilon$ ) and magnetic $(\mu)$ properties of the material through which the electromagnetic wave is propagating. These parameters are summarized in Table 2.7 below.

Table 2.7. Electromagnetic Propagation Constant Inside Various Types of Media in Terms of Material Electrical and Magnetic Properties (DuBroff et al. 1996, p. 484). Reprinted by permission of Pearson Education, Inc., Upper Saddle River, New Jersey.

\begin{tabular}{lll}
\hline \multicolumn{1}{c}{ Medium } & \multicolumn{1}{c}{ Velocity in Medium } & \multicolumn{1}{c}{ Propagation Constant } \\
\hline Free space & $\mathrm{c}=\frac{1}{\sqrt{\mu_{0} \varepsilon_{0}}}=\frac{\omega}{\beta} \approx 3 \times 10^{8} \mathrm{~m} / \mathrm{sec}$ & $\gamma=\mathrm{j} \beta$ \\
Lossless dielectric & $\mathrm{U}=\frac{1}{\sqrt{\mu \varepsilon}}=\frac{\mathrm{c}}{\sqrt{\mu_{\mathrm{r}} \varepsilon_{\mathrm{r}}}}=\frac{\omega}{\beta}$ where $\omega=2 \pi \mathrm{f}$ & $\gamma=\mathrm{j} \beta=\mathrm{j} \omega \sqrt{\mu_{0} \varepsilon_{0} \mu_{\mathrm{r}} \varepsilon_{\mathrm{r}}}$ \\
Lossy dielectric & $\mathrm{U}=\frac{\omega}{\beta} \quad$ and $\varepsilon=\varepsilon^{\prime}-\mathrm{j} \frac{\sigma}{\omega}$ where $\varepsilon$ is & $\gamma=\alpha+\mathrm{j} \beta$ \\
& the complex dielectric constant & $=\mathrm{j} \omega \sqrt{\mu \varepsilon}\left(\sqrt{1-\mathrm{j} \frac{\sigma}{\omega \varepsilon}}\right)$ \\
\hline Material Property & & \\
Magnetic permeability & $\mu=\mu_{0} \mu_{\mathrm{r}}$ where $\mu_{0}$ is the permeability of free space $=1.256 \times 10^{-6} \mathrm{~N} / \mathrm{A}^{2}$ \\
Electrical conductivity & $\sigma$ \\
Dielectric constant & $\varepsilon=\varepsilon_{0} \varepsilon_{\mathrm{r}}$, where $\varepsilon_{0}$ is the permittivity of free space $=8.854 \times 10^{-12} \mathrm{~F} / \mathrm{m}$ \\
\hline
\end{tabular}

If one can measure the electric field attenuation $(\alpha)$ and phase shift $(\beta)$ through a known depth, $z$, of material (given an estimate of the formation magnetic permeability, $\mu$ ), it is possible to derive $\sigma$ and $\varepsilon$ 'for the intervening material. The relationships are:

$$
\varepsilon=\frac{\alpha^{2}-\beta^{2}}{\omega^{2} \mu} \text { and } \sigma=\frac{2 \alpha \beta}{\omega \mu} \text {. }
$$

Table 2.8 summarizes permittivity data and electromagnetic propagation velocities for a variety of formation constituents.

The data shown in Table 2.8 provide the motivation for measurement of the dielectric permittivity. Note that nearly an order of magnitude separates the values of water from other formation constituents. Hence, measurement of $\varepsilon$ ' provides an alternative means of evaluating water saturation which is of particular interest in cases where the formation water is relatively fresh. In these cases, resistivity-based methods are insensitive because of the small resistivity difference between hydrocarbons and (fresh) water. The permittivity measurement method is also of interest in evaluating zones where water salinity is unknown, as in the case of secondary recovery projects where water injection has altered the formation water (Ellis and Singer 2007). 
Table 2.8. Electrical Permittivity and Propagation Delays for a Variety of Formation Constituents

\begin{tabular}{llc}
\hline \multicolumn{1}{c}{ Material } & \multicolumn{1}{c}{$\boldsymbol{\varepsilon}^{\prime}$} & $\mathbf{T}_{\text {delay }}(\mathbf{n s} / \mathbf{m})$ \\
\hline Sandstone & 4.65 & 7.2 \\
Dolomite & 6.8 & 8.7 \\
Limestone & $7.5-9.2$ & $9.1-10.2$ \\
Anhydrite & 6.35 & 8.4 \\
Dry colloids & 5.76 & 8.0 \\
Halite & $5.6-6.35$ & $7.9-8.4$ \\
Gypsum & 4.16 & 6.8 \\
Petroleum & $2.0-2.4$ & $4.7-5.2$ \\
Shale & $5-25$ & $7.45-16.6$ \\
Fresh water at $25^{\circ} \mathrm{C}$ & 78.3 & 29.5 \\
and below $10^{10} \mathrm{~Hz}$ & & \\
\hline
\end{tabular}

In practice, logging tools for electromagnetic propagation measurements invariably incorporate multiple transmitters and receivers to permit determination of $\alpha$ and $\beta$ over differential propagation lengths. The principle is illustrated in Figure 2.13 where radio-frequency signals are transmitted at a single location (XMTR) but received at two locations (RCVR). This permits the elimination of tool effects and allows determination of $\alpha$ and $\beta$ over the differential length, $\Delta \mathrm{S}$. More realistic electromagnetic propagation tool designs employing both multiple transmit and multiple receive antennas (forming a "propagation array") appear in Figure 2.14 the use of propagation arrays also permits measurements deeper into the formation.

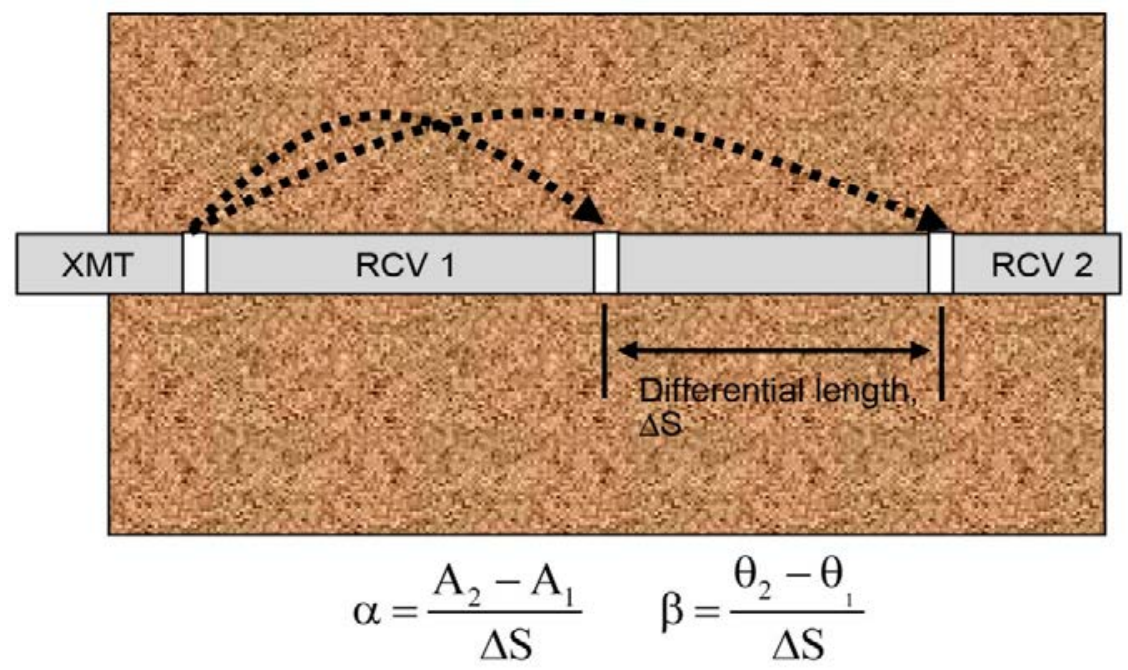

Figure 2.13. Use of Single Transmit Antenna (XMT) and Multiple Receive Antennas (RCV) to Eliminate Tool Effects in the Measurement of $\alpha$ and $\beta$. $A_{1}$ and $A_{2}$ and $\theta_{1}$ and $\theta_{2}$ are the measured amplitudes and phases, respectively, at RCV 1 and RCV 2. 


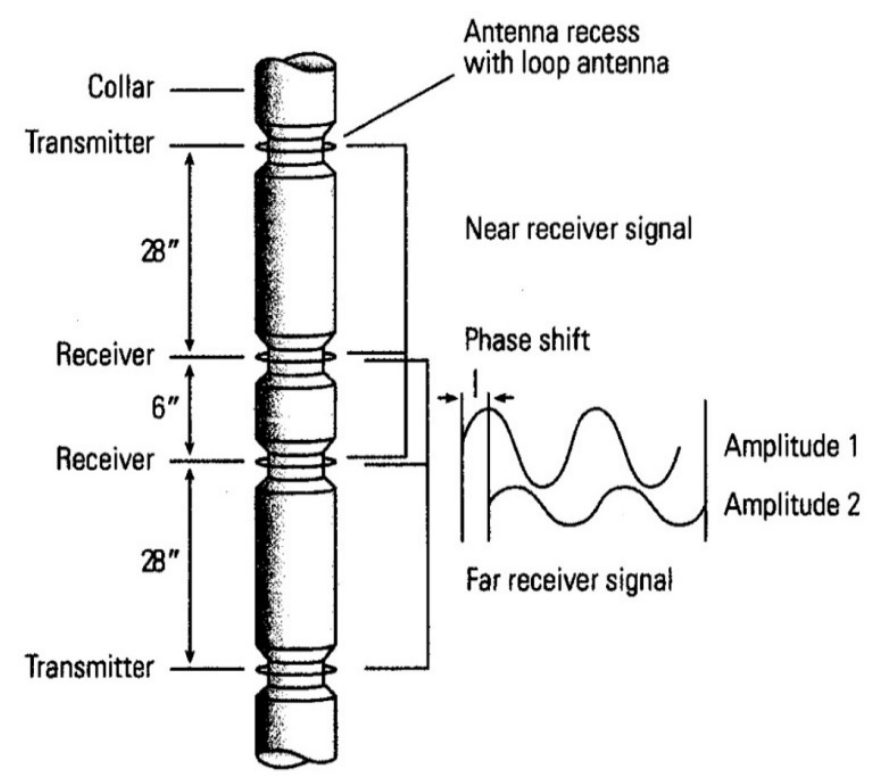

Clark et al. (1988)
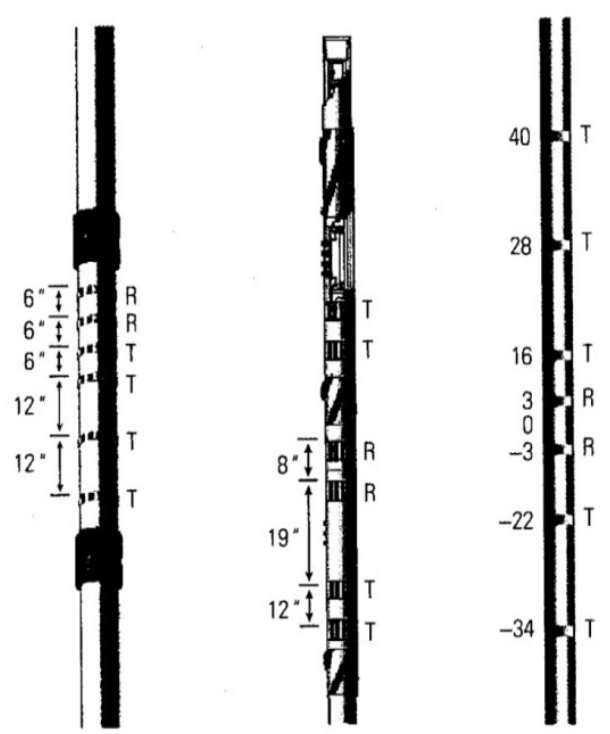

Oberkircher et al. (1993), Meyer et al. (1994), Bonner et al. (1995)

Figure 2.14. Transmit-Receive Antenna Arrays Used in Electromagnetic Propagation Tools ("T" denotes transmit antenna, "R" denotes receive antenna). All reprinted with permission from Society of Petrophysicists and Well Log Analysts.

\subsubsection{Interpretation of Electromagnetic Propagation Logs}

The frequency range of electromagnetic propagation tools is typically from $2 \mathrm{MHz}$ up to $1 \mathrm{GHz}$. Assuming electronics temperature compensation is provided, precision measurement of received signal amplitudes and phase relationships at these relatively low radio frequencies is routine. Hence, determination of $\alpha$ and $\beta$ components of the propagation constant, $\gamma$, is straightforward. As shown above, assumption of a value for magnetic permeability, $\mu$, permits calculation of a bulk conductivity $(\sigma)$ and dielectric constant $\left(\varepsilon^{\prime}\right)$. However, identification of the formation constituents based on measurement of their electrical properties is difficult and is addressed by the use of dielectric mixing laws (Ellis and Singer 2007). The best use of the electrical propagation measurement is to distinguish between water (high-dielectric constant) and oil (low-dielectric constant) and hence it is distinct in terms of what is measured from data given by neutron logging.

\subsubsection{Nuclear Magnetic Resonance}

There is a growing interest in the data that can be determined from the use of NMR in a well logging system (Ellis and Singer 2007). Using NMR tools, a large number of formation petrophysical parameters can be extracted, including total porosity, pore size distribution, the volume of irreducible water (the lowest water saturation that can be achieved in a wellbore core sample by displacing the water with oil or gas), estimates of permeability and wettability, and the characteristics of pore volume fluids. As will be seen in the following discussion, the major technical limitation of the method is its inability to sense formation volumes much beyond the wellbore diameter. 


\subsubsection{History}

The use of proton magnetic resonance sensing (also termed nuclear magnetic resonance [NMR] or magnetic resonance imaging [MRI]) in well logging has a long history. In 1960 Chevron demonstrated the method for detecting protons (hydrogen) in common formation pore fluids to estimate porosity. The variable of interest was the "free fluid index." The sensing volume of these instruments was inside the borehole diameter, making them susceptible to the chemical constituents of the drilling mud. Hence, interest in the method waned until the mid-1990s with rediscovery of a 10-year-old invention by Jasper Jackson of Los Alamos National Laboratory describing an "inside-out NMR method" (Jackson 1984). With new logging tool designs came the possibility of measuring not just the porosity, but distinguishing between oil and water and enabling determination of formation pore structure to enable permeability estimates (Ellis and Singer 2007).

\subsubsection{Physical Principles}

For the purpose of well logging, nuclear magnetic resonance is the process by which the nucleus of the hydrogen atom (i.e., a proton) will absorb and emit radio-frequency energy. The proton is a charged particle with angular momentum and exhibits a magnetic dipole moment. This magnetic dipole will process in the presence of a superimposed magnetic field (B) and can be made to "flip" between two allowed energy states when excited by radio frequency electromagnetic radiation. The principle is illustrated in Figure 2.15.

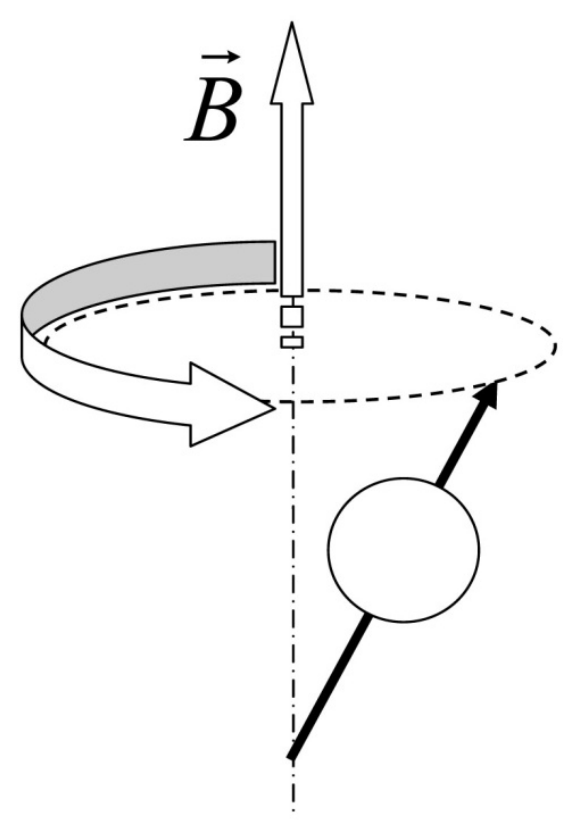

Proton magnetic dipole moment

$\mu_{p}=g_{p} \mu_{N}=8.79 \times 10^{-8} \mathrm{eV} / \mathrm{T}$

where $g_{p}$ is the proton gyromagnetic ratio and $\mu_{N}$ is nuclear magneton

\section{Precession frequency} (Larmor frequency)

$$
v_{L}=\frac{2 \mu_{p} B}{h}=42.5781 \mathrm{MHz} @ \mathrm{~B}=1 \text { Tesla }
$$

Figure 2.15. Precession of a Proton in a Superimposed DC Magnetic Field

Given that the proton has a quantum spin number, $\mathrm{I}=1 / 2$, it can assume two energy states when immersed in an applied magnetic field, B. This concept is summarized in Figure 2.16. 

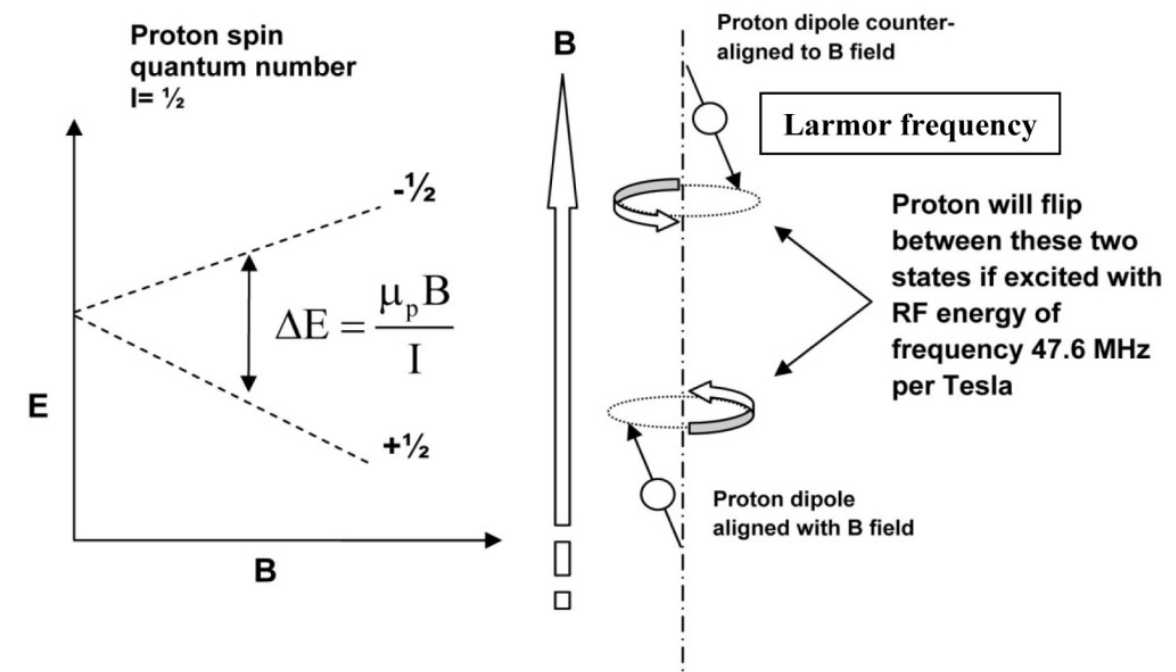

The proton exhibits a magnetic dipole moment, $\mu$. If the proton is immersed in a magnetic field, $B$, it will precess and can orient in two directions, either with the imposed magnetic field or opposed to it. These two states have different energies, the difference denoted by $\Delta \mathrm{E}$. The proton can be made to flip (resonate) between these two energy states by irradiation with a tuned radio-frequency (RF) electromagnetic field. When the photon energy of the RF field $(E=h v)$ equals $\Delta E$, the nucleus can absorb energy from the field (and re-radiate) and is said to be in resonance.

Figure 2.16. Inducing Proton Flips with an Applied Radio Frequency Electromagnetic Field. In a field of 1 Tesla, the transitions can be excited at an RF frequency of $47.6 \mathrm{MHz}$. At lower imposed B fields, the required RF frequency is lower.

The lower-energy state corresponds to the proton's magnetic dipole aligning with the imposed magnetic field. The higher-energy state corresponds to the proton's magnetic dipole opposing the applied magnetic field. The proton can be made to "jump" between states by irradiation with RF energy at the appropriate frequency.

The nuclear resonance frequency, termed the Larmor frequency, is a function of (1) the applied magnetic field, (2) the magnetic dipole moment of the proton, and (3) the chemical environment surrounding the proton (due to electron shielding). This last point makes it possible to identify the environment in which the proton resides (e.g., in $\mathrm{H}_{2} \mathrm{O}$ or $\mathrm{C}_{10} \mathrm{H}_{22}$ ). Ignoring any chemical shifts, for a proton submersed in a 1-Tesla magnetic field, the Larmor frequency is $42.578 \mathrm{MHz}$. The Larmor frequency for a proton immersed in the earth's magnetic field of approximately $45 \mu \mathrm{T}$ is less than $2 \mathrm{kHz}$. This is an important point because many NMR well-logging tools have relied on the earth's magnetic field to induce the precession. Use of the earth's field is particularly appealing given the difficulty of establishing a known B field at extended distances from the tool axis (e.g., significantly beyond the borehole).

\subsubsection{NMR Tool Design}

Commercial NMR well-logging tools excite the formation with a short pulse of RF energy at the Larmor frequency and "listen" for RF energy emitted as the protons relax to their lower-energy state. The time required for this process is termed the "relaxation time" and can provide information on the proton environment. NMR logging tools excite the nuclei of fluids in the geological formation in the vicinity of the wellbore so that parameters such as spin density, longitudinal relaxation time $\left(T_{1}\right)$ and transverse 
relaxation time $\left(\mathrm{T}_{2}\right)$ of the formations can be estimated. From these measurements porosity, permeability, and hydrocarbon saturation can be determined. NMR well-logging tools may utilize one or more permanent magnets and/or electromagnets on the tool to tailor the required magnetic field. A typical tool generates a static magnetic field, $\mathrm{B}_{0}$ (the "polarizing field"), in the vicinity of the wellbore and an oscillating field $\mathrm{B}_{1}$ orthogonal to $\mathrm{B}_{0}$. The purpose of the $\mathrm{B}_{0}$ field is to polarize the magnetic moments of the nuclei in a fixed direction while the $\mathrm{B}_{1}$ field tips the magnetic moments by an angle, $\theta$, controlled by the width $t_{p}$ and the amplitude $B_{1}$ of the oscillating pulse. For NMR logging, the most common pulse sequence is the Carr-Purcell-Meiboom-Gill (CPMG) sequence (Taicher 2003).

The Larmor frequency is linearly dependent on the imposed magnetic field B. This permits physical mapping of borehole regions based on the local resonance frequency. An example is the MRIL-Prime ${ }^{\mathrm{TM}}$ Magnetic Resonance Imaging Logging system of Halliburton (Coates et al. 1999). This system uses the earth's magnetic field $(\sim 50 \mu \mathrm{T})$ so the Larmor frequency is less than $2 \mathrm{kHz}$. Note that different radial regions contribute to the NMR signal at different frequencies permitting some degree of radial mapping.

\subsubsection{State of the Art}

Since the resurgence of petrochemical industry interest in NMR methods in the 1990s, a number of companies have developed tools. Several representative systems from Halliburton, Schlumberger, and Baker-Hughes are summarized below.

\section{Halliburton (2008)}

The MRIL ${ }^{\mathrm{TM}}$ logging service provides the following petrophysical data:

- Measures total fluid-filled porosity

- Provides fluids-only measurement, unaffected by mineralogical effects

- Identifies low-resistivity pay zone within immovable water volumes

- Determines

- Permeability

- Fluid types and net hydrocarbon feet

- Fluid contacts

- Changes in oil viscosity

\section{Schlumberger (2002)}

The Schlumberger NMR tool is trade-named the Combinable Magnetic Resonance Tool or CMRPlus. Features of the CMR-Plus tool include:

- Logging speeds to $2700 \mathrm{ft} / \mathrm{hr}$

- 6-inch measurement aperture for high resolution data

- Short echo spacing for total porosity measurements of the smallest pores

- Combinable with other formation evaluation tools 
- Short, rugged, lightweight tool

The CMR-Plus Tool provides measurements of transverse relaxation time $\left(\mathrm{T}_{2}\right)$ distribution, total porosity, free- and bound-fluid volumes, permeability, capillary bound porosity, and small-bore bound porosity.

\section{Baker Hughes}

The Baker Hughes NMR tool is trade-named the MR ExplorerTM $\left(\right.$ MREX $\left.^{\mathrm{TM}}\right)$ Service. Per the company's advertising information, the tool and service offer the following features:

- A side-looking antenna and a gradient magnetic field for formation evaluation measurements and fluid analysis in almost any borehole environment regardless of borehole size, borehole deviation, or borehole conductivity

- Multiple-frequency operation for faster logging and multiple, simultaneous NMR experiments in a single logging pass

- New NMR acquisition techniques for improved NMR data accuracy and superior hydrocarbon typing and fluids analysis

- Data for $\mathrm{T}_{1}, \mathrm{~T}_{2}$, and diffusion determination are continuously recorded by all hydrocarbon-typing sequences

- Objective Oriented Acquisitions (OOA) to greatly simplify planning and execution of MREX logging jobs

- Combinability with other Baker Atlas formation evaluation services.

\subsubsection{Technical Challenges}

A wide variety of both wireline and LWD magnetic resonance tools are available. While there are a number of operational modes, the raw measurements are common to them all. The tools employ an arrangement of magnets to polarize the protons in a sensitive volume and then the spins are manipulated by the oscillating magnetic field from an antenna so that their relaxation times $\left(T_{1}\right.$ and $\left.T_{2}\right)$ can be observed. These systems and their measurements could provide much higher value if the measurement zone ("sensitive volume") could be extended further beyond the borehole wall. The current range limit appears to be $10-13 \mathrm{~cm}$ (approximately $4-5$ inches).

\subsubsection{UH WLL - Well-Logging Software Tools}

In FY2009 PNNL joined the petrochemical industry consortium that supports the Well Logging Laboratory at the University of Houston (UH WLL). As part of the collaboration, the UH WLL has provided PNNL with a copy of their "Wellog Inversion and Simulation Software" and supporting documentation. The supporting documentation consists of 30 years of technical reports describing R\&D activities at the UH WLL and describes computational methods used in the various codes.

The UH WLL software is a significant collection of simulation and inversion codes controlled by a graphical user interface (University of Houston 2009). The simulation codes rigorously solve Maxwell's 
equations for a variety of well logging tools including: 1) general induction tools, 2) MWD (measurement while drilling) tools, 3) spherically focused logging (SFL) sondes, 4) laterolog sondes, and 5) tri-axial induction tools. The forward modeling simulation codes compute the expected resistivity profile for a number of configurations ranging in complexity from: 1) one-dimensional (1-D) isotropic, 2) 1-D anisotropic, 3) two-dimensional (2-D) isotropic, 4) 2-D anisotropic, 5) three-dimensional (3-D) isotropic, and 6) 3-D anisotropic. The isotropic codes allow the borehole to be modeled as layered concentric media, with each layer having a unique resistivity and dielectric constant. The anisotropic codes allow the conductivity and dielectric constant for each layer to be independently specified in directions parallel and perpendicular to the layer. The 1-D codes allow for a non-zero dip angle, where the dip angle is the angle between the borehole axis and the normal to each layer. The 2-D codes include effects of the borehole and invasions, and the 3-D codes allow for multiple invasions and other geometrical asymmetries. PNNL has installed the Wellog Inversion code, and is currently evaluating it. Wellog Inversion includes 13 FORTRAN programs used for forward modeling of the various sensors and two inversion codes (2-D and 1-D).

The Wellog Inversion code allows for 1-D, 2-D, and 3-D well formations to be read, created, edited, and saved. The formation file includes all the information about the well, including detailed descriptions of the layered media properties and the well geometry. After specification of the formation, a tool can be selected from a large set of available tool models. A representative input display from Wellog Inversion is shown in Figure 2.17. For this example a relatively simple 2-D formation was selected (annulus.fmi) along with a model of the Schlumberger AIT tool (AIT_B_1FT.ind). Running the simulation with these input parameters results in the output display seen in Figure 2.18. The formation is described by the plots on the left and 5 post-processing resistivity curves are shown on the right. The Wellog Inversion software can be used to model a wide variety of formations and logging tools, and can be user-configured to model many well logging scenarios of interest.

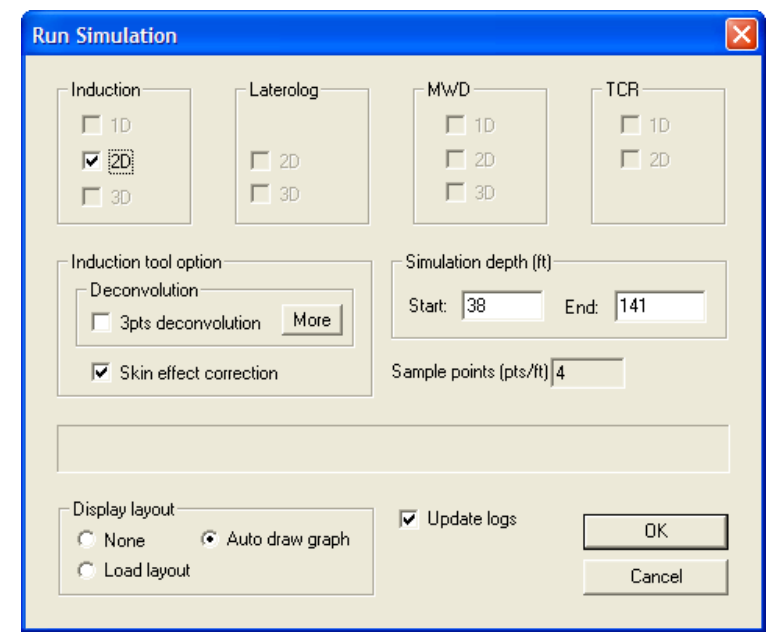

Figure 2.17. Simulation Parameters 


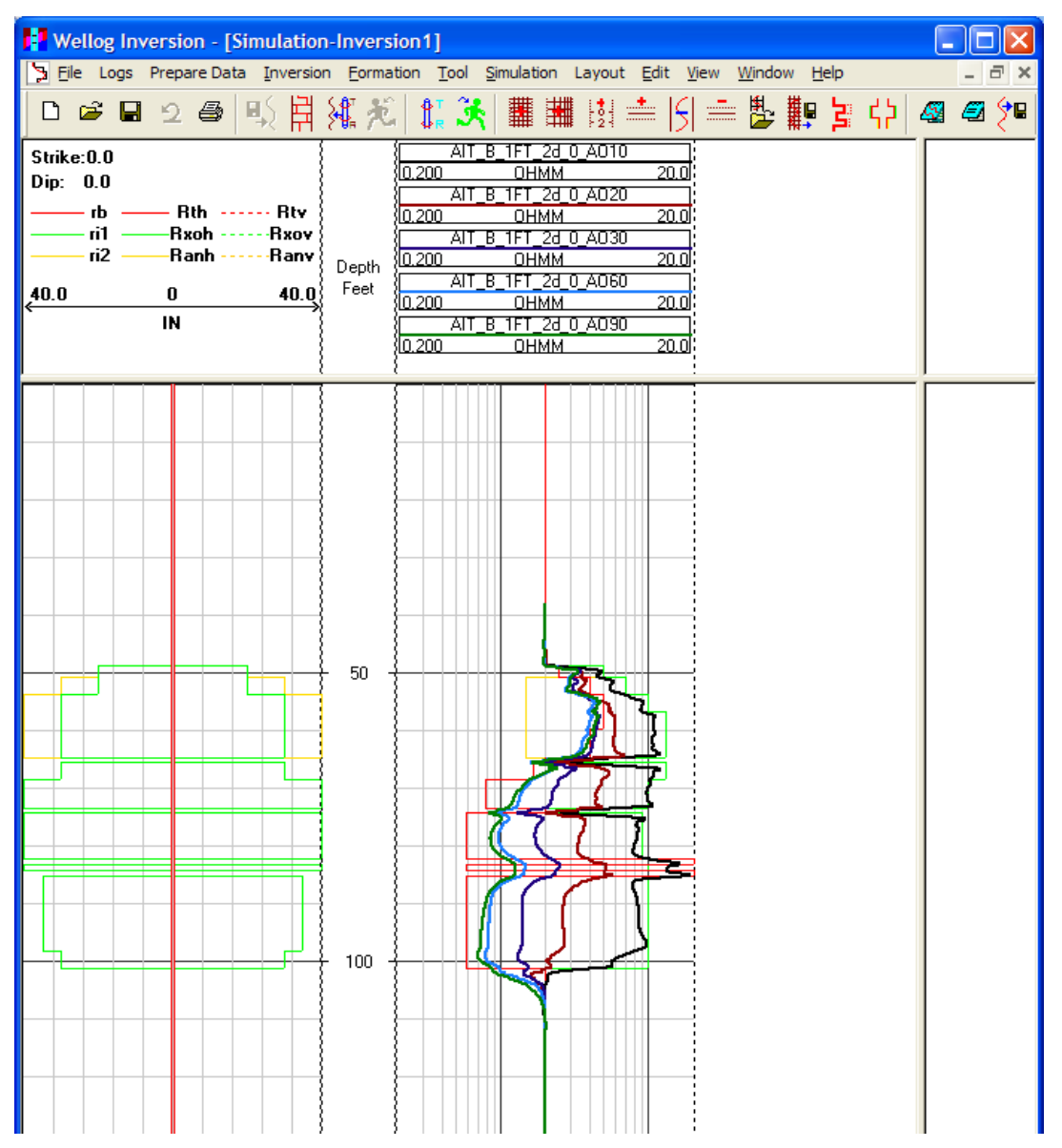

Figure 2.18. AIT Induction Tool Simulation Results

\subsection{Acoustic Well Logging Methods}

Acoustic methods are an important tool that is deployed in well logging. In acoustic well logging measured travel times of acoustic pulses between one or more transmitters and receivers on a wireline sonde are used to measure the velocity of sound in a formation to determine porosity and lithology. Borehole imaging uses rotating, focused acoustic transducers to measure reflectivity times and amplitude to generate images of the borehole wall or casing. Acoustic LWD occurs in harsh environments where drilling is happening simultaneously to provide real-time feedback to the operator to optimize drilling decisions.

There is substantial literature that reports acoustics for well logging, both in terms of laboratory studies and field implementations. This topic has been covered in various review and overview papers including those by Crain (2000), Arroyo Franco et al. (2006), Haldorsen et al. (2006), and (Adolph et al. 2005). It is also considered in general texts on well logging (e.g., Hearst et al. 2000) as well as in a text by Paillet and Cheng (1991).

Acoustic measurements have become an integral part of well logging since the first downhole measurements of velocities were conducted in 1927 to obtain time-depth data for seismic interpretation. 
Traditional wireline acoustic well logging requires carefully lowering a "sonde” tool and supporting electronics on a cable from a winch into an open or cased borehole after the borehole has been drilled. Acoustic waves are generated by a source transducer at one end of the sonde and are recorded by one or more receivers at the other end. The travel times of refracted waves propagating through the formation, mud cake and mud allow the calculation of formation velocity. As the sonde tool is raised, the sensors measure some or all of the following properties as a function of depth:

- sound velocity

- sound scattering, sound dispersion and attenuation

- borehole dimension (Prensky 1994).

The majority of borehole-imaging devices image the borehole wall indirectly through acoustic and electrical signals to generate a partial or full image (map) of the borehole wall or casing. Acousticimaging tools use a rotating, focused, ultrasonic transducer (borehole-televiewer-type devices) to measure transit times and amplitude of the pulse-echo from the borehole wall or from inside the casing. Acoustic amplitude is sensitive to borehole irregularities and this allows acoustic tools to differentiate borehole shape, breakouts, fractures, bed boundaries, etc. Acoustic transit time is proportional to distance thus enabling determination of borehole shape and borehole caliper. While these devices are not affected by conductivity of borehole fluid, their effectiveness is reduced in high-weight muds because of signal attenuation. Improved transducer designs, placing the transducer in direct contact with the mud, and use of lower frequencies have resulted in improved acoustic images (Schlumberger 1993). The high resolution of borehole imaging tools makes them extremely valuable for obtaining positive identification and analysis of natural and induced fractures, borehole breakouts (Plumb and Hickman 1985), thin beds, geologic structure, improved core orientation and core-log correlation (McNaboe 1991; Williams and Sharma 1991; Salimullah and Stow 1992), identification of sedimentary features and interpretation of depositional environment, and evaluation of casing corrosion, wear, or damage (Prensky 1994).

Advances in drilling/logging technology have allowed the acquisition of log data via tools placed in the actual drilling assembly. These tools may transmit data to the surface on a real-time basis or store the data in a downhole memory from which it may be downloaded when the assembly is brought back to the surface. LWD tools present a complication for drill, as well as additional expense. However, their use may be justified when:

- Real-time information is required for operational reasons, such as steering a well in a particular formation or picking of formation tops, coring points, and/or casing setting depths

- Acquiring data prior to the hole washing out or invasion occurring

- Safeguarding information if there is a risk of losing the hole

- The trajectory is such as to make wireline acquisition difficult (e.g., horizontal wells) (Darling 2005).

Although the increased application of horizontal drilling serves as a major impetus to MWD development, advances in MWD technology have consisted largely of incremental improvements to existing technology. Emphasis is on obtaining data in "real-time" for optimizing drilling decisions, for drillbit guidance ("geosteering”), detection of overpressuring (Rasmus and Stephens 1990; Hanson and Tibbitts 1991), and formation evaluation prior to extensive invasion). The general attitude in industry is that MWD has matured and can potentially replace conventional wireline logging in many 
situations, especially in high-risk or in high-angle and horizontal exploration and production wells. The introduction of acoustic devices will secure the role of MWD as a primary logging method. In addition to development of logging tools, much effort has gone into developing modeling, processing, and interpretation techniques for data obtained in high angle and horizontal well (Prensky 1994).

\subsubsection{Acoustic Wave Modes}

In well logging acoustic velocity measurements are used to determine porosity information while attenuation measurements are used primarily for cement bond logs and borehole imaging. The velocities of two types of acoustic bulk or body waves are primarily measured-the P-wave (the compressional wave or "P" - primary wave observed as a first arrival from earthquakes) and the S-wave (the shear or transverse wave). For the $\mathrm{P}$-wave particle motion is parallel to the direction of wave propagation and for the shear wave particle motion is perpendicular to the direction of wave propagation, and the S-wave can also occur in polarized forms - the SH and the SV waves (Graff 1975).

Acoustic logging data fall into two general classes depending on the type of acoustic-wave propagation utilized: transmission or reflection. Measurements of either type have applications in both open and cased holes. Wave motions for longitudinal and shear are shown in schematic form as Figure 2.19. The various modes of acoustic-wave propagation and a summary of their applications in well-logging are shown as Table 2.9.

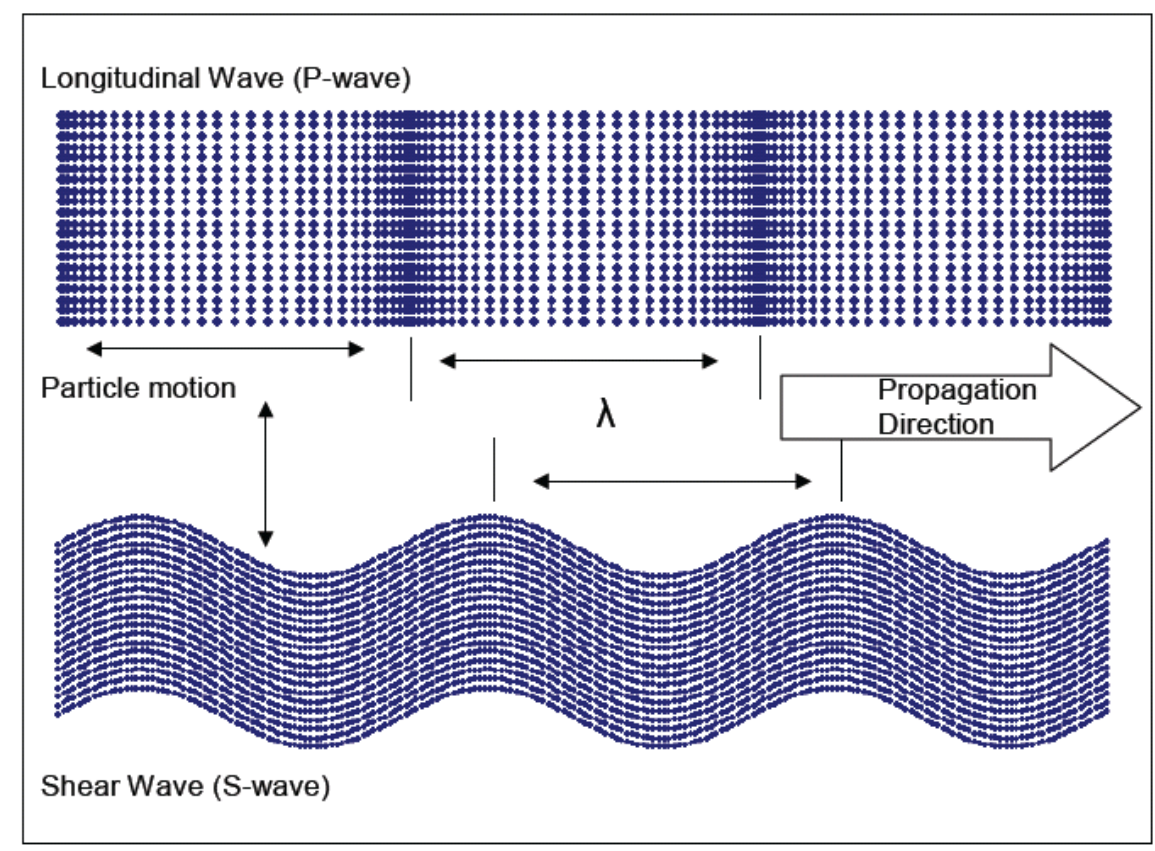

Figure 2.19. Illustration of the Particle Motion Versus the Direction of Wave Propagation for P-waves and S-waves 
Table 2.9. Acoustic-Wave Propagation and Summary of Well-Logging Applications

\begin{tabular}{|c|c|c|}
\hline Wave Mode & $\begin{array}{c}\text { Measurement } \\
\text { (velocity and amplitude) }\end{array}$ & Application \\
\hline \multirow[t]{16}{*}{ Transmission } & & Array tools used in open and cased hole \\
\hline & Full waveform & Seismic calibration and vertical seismic profiling (VSP) \\
\hline & & $\begin{array}{l}\text { Near-borehole and crosswell imaging (offwell structure; } \\
\text { fracture ID; flood monitoring) }\end{array}$ \\
\hline & & Cement-bond evaluation \\
\hline & Compressional wave & Porosity and lithology $(\Delta t)$ \\
\hline & & Hydrocarbon content \\
\hline & & Geopressure detection \\
\hline & & Cement-bond evaluation \\
\hline & & Calibrate surface seismic \\
\hline & & Synthetic seismic \\
\hline & Shear wave & Mechanical properties \\
\hline & & Fracture detection and evaluation \\
\hline & & Permeability determination \\
\hline & & $\begin{array}{l}\text { Shear/compressional ratio for lithology determination and } \\
\text { gas detection }\end{array}$ \\
\hline & $\begin{array}{l}\text { Tube (Stoneley) wave or } \\
\text { surface wave }\end{array}$ & Permeability determination \\
\hline & & $\begin{array}{l}\text { Crosswell imaging and lateral continuity } \\
\text { fracture characterization }\end{array}$ \\
\hline \multirow[t]{10}{*}{$\begin{array}{l}\text { Reflection } \\
\text { (ultrasonic } \\
\text { pulse-echo) }\end{array}$} & & $\begin{array}{l}\text { For use in open- and cased hole } \\
\text { (a) fixed transducers (helical arrays) } \\
\text { (b) rotating transducer (BHTV-type) }\end{array}$ \\
\hline & Velocity & Borehole imaging \\
\hline & & $\begin{array}{l}\text { Caliper for borehole and casing ID (casing wear and scale } \\
\text { buildup) }\end{array}$ \\
\hline & Amplitude & Imaging borehole \\
\hline & & Detection and orientation of vugs and fractures (shear) \\
\hline & & Sedimentology \\
\hline & & Cement-bond evaluation \\
\hline & & Casing evaluation \\
\hline & Resonant frequency & Casing thickness (indirectly, OD, corrosion) \\
\hline & $\begin{array}{l}\text { Time-lapse (amplitude and } \\
\text { phase) }\end{array}$ & $\begin{array}{l}\text { "Active listening" for detecting and measuring flow } \\
\text { velocity behind casing (stationary measurement) }\end{array}$ \\
\hline
\end{tabular}

In addition to the $\mathrm{S}$ and the $\mathrm{P}$ waves other wave types can occur. The Stoneley waves are interface guided waves that are slower than the corresponding $\mathrm{P}$ and $\mathrm{S}$ waves. In the well logging configuration the Stoneley wave is guided and propagates in the annulus between the logging tool and along the borehole wall/fluid interface. In the literature discussing this application these waves are also called tube waves or Stoneley tube waves (Crain 2004).

Transmission full-waveform acoustic logging has emerged as an important borehole technique for formation evaluation and for seismic exploration. Borehole measurements of compressional, shear and Stoneley wave velocities and attenuations define formation properties and are used for the modeling and interpretation of seismic reflection and vertical seismic profiling (VSP) data. In conventional acoustic logging, only the time delay of the compressional wave is recorded and the slowness (inverse of velocity) calculated. With the full-waveform acoustic logging tools, the entire microseismogram at multiple receivers is recorded digitally, allowing records of data to be obtained for varying depth of penetration. 
Shear-wave velocities are critical in fracture analysis, formation-strength determination, stress anisotropy and correlation with surface-seismic surveys. This is of particular concern in soft formations, where the shear-wave component is often absent on full waveforms created by a monopole source, and also in hard formations. Applications include fracture detection and evaluation, permeability measurement, and well completion (Prensky 1994).

Reflection pulse-echo tools measure signal velocity (travel time) and amplitude and have application in both open and cased hole. Developments include improvements in ultrasonic pulse-echo transducer design and placement (in direct contact with the mud) and use of lower frequencies to reduce the signal attenuation and improve image quality and resolution. Other advances in acoustic logging include wellbore resonance, downhole seismic, and behind-pipe flow measurements (Prensky 1994).

\subsubsection{Physics of Acoustic Measurements}

Historically, borehole and laboratory data have shown that acoustic velocities in sandstones are primarily dependent on porosity, clay content, and pressure differential between overburden and reservoir fluid pressures. In clay-free sandstone, compressional acoustic velocity often has a good correlation with porosity, as explained by the popular empirical Wyllie time-average equation (Wyllie et al. 1956):

$$
\Delta t_{\log }=\Phi_{s} \Delta t_{f}+\left(1-\Phi_{s}\right) \Delta t_{m a} \quad \text { or } \quad \Phi_{s}=\frac{\Delta t_{\log }-\Delta t_{m a}}{\Delta t_{f}-\Delta t_{m a}}
$$

where

$$
\begin{aligned}
\Phi_{s} & =\text { sonically-derived porosity } \\
\Delta t_{\log } & =\text { sonic transmit time read on the log } \\
\Delta t_{m a} & =\text { sonic transmit time in the rock matrix (e.g., sand) } \\
\Delta t_{f} & =\text { sonic transmit time in the fluid in the pores (air, water, oil, etc.) }
\end{aligned}
$$

In 1980 a new empirical transform based on field observations of transit time versus porosity was proposed, which provides good transit time-porosity correlations over a wide range of porosities. This is known as the Raymer-Hunt transform.

However, it is well understood and has been reported by many investigators that significant amounts of clay/shale in the rock will lower the acoustic velocity from the Wyllie time-average prediction (Al-Tahini et al. 2007). Recently published work has attempted to derive correlations to both porosity and clay content.

Johnson and Pile (2006) report that in shaly formations the sonic porosity must be corrected for the presence of shale with the equation

$$
\Phi_{S c o r}=\Phi_{S}-\left(V_{s h} * \Phi_{S s h}\right)
$$

where:

$\Phi_{\text {Scor }}=$ corrected sonic porosity 


$$
\begin{aligned}
\Phi_{S} & =\text { sonic porosity determined from the sonic log } \\
V_{s h} & =\text { shale volume } \\
\Phi_{S s h} & =\text { apparent porosity of the shale point }
\end{aligned}
$$

A number of investigators have described the mathematical treatment of wave propagation for boreholes of varying degrees of complexity (Biot 1952; White and Zechman 1968; Peterson 1974; Tsang and Radar 1979; Cheng and Toksoz 1981; Schoenberg et al. 1981; Paillet and White 1982; Baker 1984; Tubman et al. 1984; Timur and Toksoz 1985). Probably the most common choice of theory used in efforts to explain poroelastic data is Biot's theory. Biot (1956a, b) predicts the existence of two kinds of dilatational waves in a homogeneous saturated porous medium loaded by an acoustic wave, the fast wave of propagational type designated as the "wave of the first kind" and the slow wave of diffusive type, which is highly attenuated at low frequency designated as "wave of the second kind". Biot derived expressions for the velocity and attenuation of shear wave and compressional wave in terms of permeability, viscosity, and elastic constant of rocks. The experimental identification of the slow wave by Plona (1980) and the agreement between the experimental data produced by the previous author with theoretical prediction by Berrymann (1980) using Biot theory served as a formal check to the validity of the theory. Several reports of reasonably good agreement between experimental data and theoretical curves of velocity and attenuation dispersion vs. frequency predicted by the Biot model are available in the literature (Keller 1989; Yamamoto et al. 1994). Many investigators agree that this theory can be adequately used to model acoustic wave propagation in water-saturated unconsolidated sand (Stoll 1980; Turgut and Yamamoto 1988; Turgut and Yamamoto 1990) or in highly permeable sediments (Geli et al. 1987). It is, however, important to note that the basic formulation of the theory explicitly assumes long wavelength disturbances in comparison with the dimensions of the macroscopic elementary volume considered in the formulation of the theory and hence very large disturbances in comparison with the elementary pore size where microscopic flow occurs. As a consequence, the theory will be inaccurate in describing the interaction between acoustic waves and porous media when wavelengths are comparable to pore size, or when heterogeneity distribution is so complex that the requirement of statically isotropic medium cannot be guaranteed (Diallo and Appel 2000).

Bała and Cichy (2007) captured the history of theoretical model development for the estimation of $\mathrm{P}$-wave and S-wave velocities in porous media in their comparison between the Biot-Gassmann and Kuster-Toksöz models. It is understood that velocities of P-waves and S-waves are functions of a number of variables, including porosity, pore space configuration, water- and hydrocarbon-saturation, and mineral composition of a rock matrix. In addition, elastic parameters of porous media depend also on pressure and temperature.

Among a number of theoretical models for estimation of P-wave and S-wave velocities in porous media, of great interest is the Kuster-Toksöz model (Kuster and Toksöz 1974; Toksöz et al. 1976), modified by Tao and King (1993), and also the Biot-Gassmann model (Biot 1956a, b). Applying those models provides an alternative to wave estimation over intervals in which the S-wave cannot be identified or when acoustic wavetrain data are not available. It should therefore be advantageous to compare results obtained using these models with those obtained from the interpretation of wavetrains. Velocity models play a major role in seismic data interpretation, employing bright spot analysis, multi-component analysis, and amplitude versus offset (AVO) analysis. 


\subsubsection{Modified Biot-Gassmann Model}

In the Biot-Gassmann model (Gassmann 1951; Biot 1956a, b), the P-wave velocity $\mathrm{v}_{\mathrm{p}}$, S-wave velocity $\mathrm{v}_{\mathrm{S}}$, and bulk density $\rho$, are given by the following formulae:

$$
\begin{gathered}
\mathrm{v}_{\mathrm{P}}^{2}=\frac{1}{\rho}\left[\rho_{\mathrm{ma}} \mathrm{v}_{\mathrm{P}_{\mathrm{ma}}}^{2}(1-\beta)+\mathrm{M} \beta^{2}\right], \\
\mathrm{v}_{\mathrm{S}}^{2}=\frac{\rho_{\mathrm{ma}}}{\rho} \mathrm{v}_{\mathrm{S}_{\mathrm{ma}}}^{2}(1-\beta) \\
\rho=(1-\Phi) \rho_{\mathrm{ma}}+\Phi \rho_{\mathrm{f}}
\end{gathered}
$$

where: $\mathrm{v}_{\mathrm{Pma}}$ and $\mathrm{v}_{\mathrm{Sma}}$ are the velocities of $\mathrm{P}$ and $\mathrm{S}$ waves, respectively, in the solid phase; $\rho$ is the bulk density; $\rho_{\text {ma }}$ is the density of the solid phase (matrix); $\rho_{\mathrm{f}}$ is the density of the liquid in pores; and $\Phi$ is the rock porosity. Quantities $M$ and $\beta$ in the above equations are the elastic parameters, which can be expressed in terms of porosity and bulk moduli of the solid phase and liquid phases occupying pores. Krief et al. (1990) gave the following relation between $\beta$ and the porosity of rock medium:

$$
1-\beta=(1-\Phi)^{\mathrm{m}(\Phi)}
$$

The exponent $\mathrm{m}$ is a function of porosity $\Phi$ (Goldberg and Gurevich 1998; Lee 2002). The parameter $\mathrm{M}$ can be obtained from the relation:

$$
\frac{1}{\mathrm{M}}=\frac{\beta-\Phi}{\mathrm{K}_{\mathrm{ma}}}+\frac{\Phi}{\mathrm{K}_{\mathrm{f}}}
$$

where: $K_{m a}$ is the bulk modulus of the rock matrix and $K_{f}$ is the shear modulus of the liquid. Velocities $\mathrm{v}_{\mathrm{P}}$ and $\mathrm{v}_{\mathrm{S}}$ are estimated in this model on the basis of parameters of a rock formation and media saturating the pore space.

\subsubsection{Kuster-Toksöz Model}

In the Kuster-Toksöz model (Kuster and Toksöz 1974; Toksöz et al. 1976), which was modified by Bała using the differential effective medium (DEM) theory (Cheng and Toksoz 1981; Xu and White 1995; Bala and Cichy 2007), the heterogeneity of a porous medium is described by the statistical distribution of the pore shape coefficients, $\alpha_{\mathrm{m}}$. The porous medium consists of two different homogeneous phases. The solid phase (elastic matrix) comprises randomly distributed inclusions of the other phase, which can be solid, liquid, or gaseous.

Let $\mathrm{K}_{\mathrm{ma}}$ denote the bulk modulus, $\mu_{\mathrm{ma}}$ the shear modulus, and $\rho_{\mathrm{ma}}$ the density of the solid rock matrix (solid phase), while $\mathrm{K}_{\mathrm{f}}, \mu_{\mathrm{f}}$, and $\rho_{\mathrm{f}}$ denote the bulk modulus, shear modulus, and density of the medium occupying the pores, respectively. It is also assumed that the pores are spheroidal. Let us express the pore space in terms of pore shape coefficient $\alpha$ (a ratio of the minor semi-axis, a, to the major semi-axis, c, of ellipsoidal pores: $\alpha=\mathrm{a} / \mathrm{c}$ ). The total porosity of such a medium is the sum of pore concentration (pore density) with given values of coefficient $\alpha_{\mathrm{m}, 1}$. 


$$
\Phi=\sum_{\mathrm{m}=11=1}^{\mathrm{M}} \sum_{\mathrm{l}}^{\mathrm{L}} \mathrm{C}\left(\alpha_{\mathrm{m}, 1}\right)
$$

where: $C\left(\alpha_{m, 1}\right)$ is the volume concentration of pores with given pore shape coefficient $\alpha_{m, 1}, m=1 \ldots M$, $\mathrm{l}=1 \ldots \mathrm{L}, \mathrm{M}$ is the number of pore shape coefficients, and $\mathrm{L}$ is the number of pore-saturating media present together in pores (water, oil, gas), $\mathrm{L}=1$ or 2 or 3 .

Elastic moduli $\mathrm{K}^{*}$ and $\mu^{*}$ for the effective porous medium can be calculated from Eqs. (2.13)-(2.15) in the paper by Toksöz et al. (1976) and formulae (3) and (4) in the paper by Tao and King (1993).

An effective porous medium is an equivalent to homogenous medium with moduli $\mathrm{K}^{*}$ and $\mu^{*}$.

To describe the pore space distribution, we used the pore spectrum proposed by Tao and King (1993), which is given by the following formula:

$$
\Gamma=\mathrm{Nc}^{3},
$$

where: $\Gamma$ is the pore concentration (i.e., pore density), $\mathrm{N}$ is the number of pores per unit volume of rock, and $c$ is the length of the longer semi-axis of a spheroidal pore.

This approach enables adopting an average $c_{a v}$ for all pores. The concentration of spheroidal pores can be given by the following formula:

$$
\mathrm{C}\left(\alpha_{\mathrm{m}}\right)=\frac{4}{3} \pi \mathrm{c}_{\mathrm{av}}^{3} \cdot \mathrm{N}\left(\alpha_{\mathrm{m}}\right) \alpha_{\mathrm{m}}
$$

If we express a rock model in terms of the distribution function $\Gamma$,

$$
\frac{\mathrm{N}\left(\alpha_{\mathrm{m}}\right)}{\mathrm{N}_{1}\left(\mathrm{c}_{\mathrm{av}}\right)}=\alpha_{\mathrm{m}}^{\mathrm{D}}
$$

where $\mathrm{m}=1,2, \ldots, 10$ and

$$
\alpha_{\mathrm{m}}=10^{(1-\mathrm{m}) / 2} .
$$

Constants $\mathrm{D}$ and $\mathrm{c}_{\mathrm{av}}$ are characteristic of a given rock and have different spectra. $\mathrm{N}_{1}\left(\mathrm{c}_{\mathrm{av}}\right)$ is the effective number of spheroidal pores of an average longer semi-axis $c_{a v}$.

Substituting Eq. (2.16) into Eq. (2.15) we have

$$
\mathrm{C}\left(\alpha_{\mathrm{m}}\right)=\frac{4}{3} \pi \mathrm{c}_{\mathrm{av}}^{3} \cdot \mathrm{N}_{1}\left(\mathrm{c}_{\mathrm{av}}\right) \alpha_{\mathrm{m}}^{\mathrm{D}+1} .
$$

The quantity

$$
\Phi=\frac{4}{3} \pi \mathrm{c}_{\mathrm{av}}^{3} \cdot \mathrm{N}_{1}\left(\mathrm{c}_{\mathrm{av}}\right) \Sigma \alpha_{\mathrm{m}}^{\mathrm{D}+1}
$$


is the porosity of the rock medium.

The equation for the P-wave velocity, $\mathrm{v}^{*}$, is given by

$$
v_{P}^{*}=\left[\frac{1}{\rho^{*}}\left(K^{*}+\frac{4}{3} \mu^{*}\right)\right]^{1 / 2}
$$

and for the S-wave velocity, $\mathrm{v}^{*}$, is given by

$$
v_{S}^{*}=\left[\frac{\mu^{*}}{\rho^{*}}\right]^{1 / 2} .
$$

A set of non-linear equations with unknowns $\mathrm{K}^{*}, \mu^{*}$, and $\mathrm{D}$ can be solved using a variety of methods. We applied the method of minimization of the function of several variables fitting the P-wave velocity calculated from Eq. (2.19) to the $\mathrm{v}_{\mathrm{P}}$ (PA) measured by acoustic log. Unlike in the Biot-Gassmann model, only velocity $\mathrm{v}_{\mathrm{S}}$ is estimated in the studied model.

The proposed theoretical Biot-Gassmann model enables transit interval times and velocities of $\mathrm{P}$ and $\mathrm{S}$ waves to be estimated on the basis of lithology and porosity solution from well-logging data, even when acoustic logs are not available. Results provided by the discussed models are good in a comparison to outcomes from the interpretation of recorded acoustic wavetrains both for carbonate and shaly (clayey) sandstone formations.

The Kuster-Toksöz model can be applied to calculate transit times and velocities of $S$ waves. During computations, the P wave interval time [DT(PA)] is fitted to the measured DT(PA). Estimated values of $S$ wave interval time (DTS) and $\mathrm{v}_{\mathrm{S}}$ are correct for intervals with water saturation as well as with hydrocarbon saturation; however, transit interval times are somewhat overestimated for gas-bearing zones (underestimated $\mathrm{v}_{\mathrm{S}}$ ).

Of great importance are the matrix parameters that are adopted for calculations. The choice of the matrix parameters should be based on the lithology (mineral composition) of rock formations. The influence of depth should be taken into account because of compaction and diagenesis that take place in rocks at greater depth.

Adopting real matrix parameters and proper factors of pore-saturating media (gas, oil, water) is of great importance to calculations of elastic parameters of rocks, and finally can decide on correct interpretation of seismic data for hydrocarbon prospecting (Bala and Cichy 2007).

\subsubsection{The Influence of Rock Properties and Reservoir Conditions on Acoustic Measurements}

The adequate evaluation of a sandstone hydrocarbon reservoir requires reasonably precise estimates of porosity and water saturation. Borehole and laboratory data show that acoustic velocities in sandstones are primarily dependent on porosity, pressure differential between overburden and reservoir fluid pressures, and shaliness. 
Historically, the greatest use of acoustic logs has been for the determination of compressional wave velocities $\mathrm{V}_{\mathrm{P}}$ as a function of depth for determining formation porosity. However, because variations in lithology make the porosity estimates from compressional wave transit times alone unreliable, this method generally works well only for clean, non-shaly/non-clayey sandstones and carbonates. In these instances, conventional acoustic logs are used in conjunction with density and/or neutron logs. Wyllie et al. (1956) reported some of the first acoustic velocity laboratory measurements on non-shaly (nonclayey) sandstone. Measurements were performed on air-saturated and water-saturated sandstones over a wide range of porosities at room temperature. Results showed that acoustic velocities through air- and water-saturated sandstones are a function of porosity with velocity decreasing with increasing porosity, and that sound velocity through water-saturated sandstones are higher than those of air-saturated sandstones at room conditions. Furthermore, for water-saturated sandstone, velocity increases with increasing pressure.

Hicks et al. (1956) later showed that velocities through sandstones are also dependent on differential pressures between the outside and inside of liquid-saturated core samples. A comparison of Hicks' data and Wyllie's data at room conditions demonstrated that pressure differential effects on velocity must be considered when using velocity for porosity prediction for well logging where a similar pressure differential could exist between overburden and fluid pressures on in-situ rocks.

Vast amounts of information about the formation and the borehole are contained in full-waveform acoustic logs from acoustic array designs, using either dipole or quadrupole sources. Compressional and shear wave velocities of the formation are among the most desired measurements. These can be obtained from direct measurements of travel-time differences between receivers. A detailed description of such measurement techniques is given by Willis and Toksoz (1983). The importance of shear wave velocities $\mathrm{V}_{\mathrm{s}}$ for identifying lithology is illustrated in Figure 2.20, where $\mathrm{V}_{\mathrm{p}} / \mathrm{V}_{\mathrm{s}}$ is plotted versus $\mathrm{V}_{\mathrm{p}}$ for three rock types (sandstones, limestones, and dolomites). Compressional wave velocities $\left(\mathrm{V}_{\mathrm{p}}\right)$ vary over a wide and overlapping range for these rock types, depending on porosity and lithification. However, the $\mathrm{V}_{\mathrm{p}} / \mathrm{V}_{\mathrm{s}}$ ratio acts as an identifier. If lithology is known, $\mathrm{V}_{\mathrm{p}} / \mathrm{V}_{\mathrm{s}}$ ratios can determine gas or water saturation (Timur and Toksoz 1985). Plotting $\mathrm{V}_{\mathrm{p}} / \mathrm{V}_{\mathrm{s}}$ agains $\mathrm{V}_{\mathrm{p}}$ is also a reliable way to identify gas zones since $\mathrm{V}_{\mathrm{p}}$ is much more affected by gas than is $V_{s}$ (Darling 2005).

Bacri and Salin (1986) reported the sound velocity in a French Vosgian sandstone $(21.5 \pm 0.4 \%$ porosity) saturated with oil and brine at different concentrations using a 350-kHz compressional wave. The velocity variations with the concentration were found to depend drastically on the way of entering the fluids in the sample: injection of non-wetting fluid in a sandstone fully saturated with a totally wetting fluid (drainage) or vice versa (imbibition). The velocity of sound was found to decrease drastically for either an imbibition or drainage; whereas, the velocity difference between the fully oil-saturated and the fully water-saturated sandstone was found to be small. 


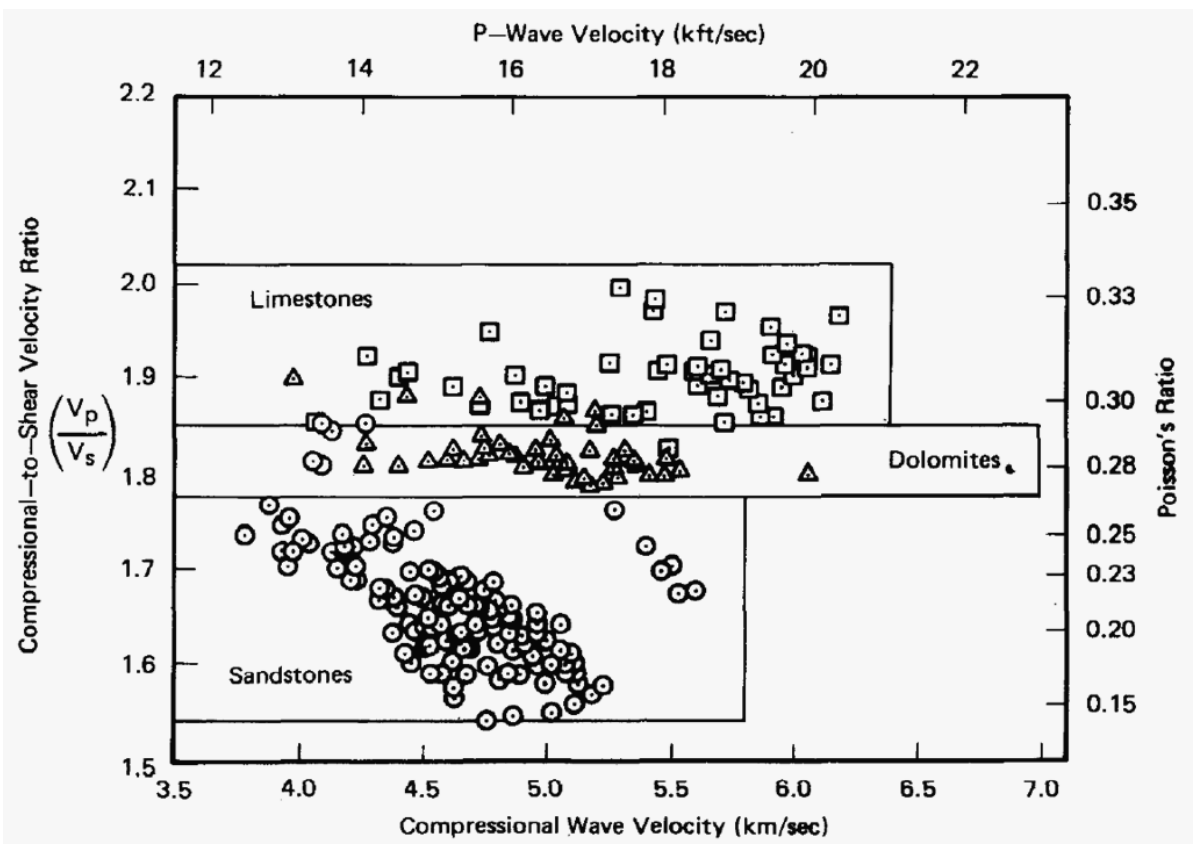

Figure 2.20. Compression-to-Shear Velocity Ratios $\mathrm{V}_{\mathrm{p}} / \mathrm{V}_{\mathrm{s}}$ versus Compressional Wave Velocity Plot for Different Rock Types (Timur and Toksoz 1985). Data are from core measurements. Note that although there is considerable overlap on compressional velocities, the $\mathrm{V}_{\mathrm{p}} / \mathrm{V}_{\mathrm{s}}$ ratio separates the lithologies. Reproduced with permission from the Copyright Clearance Center.

These results can be explained by the sandstone frame moduli, which are controlled by grain contacts (Murphy et al. 1984). The stiffness of these contacts between grains is enhanced by the surface energy of the grain material (Johnson et al. 1971). The larger the interfacial tension between solid grains and the surrounding fluid, the larger the elastic moduli of the sandstone. In high-vacuum conditions, the surface energy of the quartz grains is maximized. When immersed in oil, this surface energy is only slightly smaller and the frame moduli are not affected; but when immersed in water, the surface energy decreases drastically. The surface-energy effect accounts for the large decrease of the velocity of sound as the humidity increases even slightly (Murphy III 1982). Berryman et al. (2000) reported that the degree of saturation also affects acoustic data.

\subsubsection{Laboratory Measurements of Velocity}

There is often a disparity between acoustic frequencies used to measure rock properties in the lab and during actual acoustic logging. In complex media, such as rock matrices, it is well understood by the ultrasonics community that velocity is frequency dependent. This effect is called velocity dispersion. However, many authors have not clarified the conditions of their experiments (e.g., energy source type and frequency range, velocity detection and calculation method, fluid-rock-borehole velocity contrasts). These factors affect which acoustic modes are transmitted. Conclusions drawn from one experiment will not necessarily apply to another with different assumptions. Most waves travel faster at low frequency (normal dispersion) but tube waves are slightly reverse dispersive in fast formations and normally dispersive in slow formations. Compressional waves have very little dispersion. The various wave modes used to measure shear velocity are very dispersive, which may account for errors in shear velocity 
on older logging tools, when high frequency sources were the norm. Modern tools are designed to work below $5 \mathrm{kHz}$ for shear measurements, instead of 20 to $30 \mathrm{kHz}$ on older tools (Crain 2004).

In laboratory measurements to measure the velocities of core samples, the applied frequencies are somewhat higher than frequencies used in logging $(100 \mathrm{kHz}-1 \mathrm{MHz}$ or more in laboratory tests vs. 3-30 kHz in logging), and therefore the volume of investigation is somewhat smaller (Paillet and Cheng 1991; Crain 2004). The lower frequencies and larger volume of investigation in logging averages velocities over larger volumes, while the higher laboratory frequencies result in greater measured velocities than those given by logs according to the velocity dispersion in the following equation:

$$
\frac{V(\omega)}{V\left(\omega_{0}\right)}=1+\frac{1}{\pi Q} \ln \left(\frac{\omega}{\omega_{0}}\right)
$$

where:

$$
\begin{aligned}
Q & =\frac{1}{2 V_{\infty}}, \\
\omega_{0} & =\text { reference frequency, and } \\
V_{\infty} & =\lim _{\omega \rightarrow \infty} V(\omega) .
\end{aligned}
$$

Comparison of laboratory measurements of acoustic velocity of core samples and acoustic log data can be complicated by a number of other factors as well, such as the potential alternation of core samples during and after recovery, zero point reference for depth, cable stretch and measurement error. The sample volume difference can be surmounted by performing a large number of tests on core samples from adjacent intervals, and then spatially smoothing the resultant velocity distribution. A similar process is almost always recommended when comparing geophysical logs to core data.

Even when velocity dispersion, depth errors, sample damage, and spatial averaging over larger sample volumes are taken into account, seismic velocities measured from core samples do not usually correspond to the velocities given by logs. The difference has been found to result from the effects of in situ environment (pressure and temperature) on the seismic velocity of rocks. Substantial differences in velocity can occur at depths less than a few thousand meters. Natural velocity differences make it impossible to calibrate porosity logs where the measured transit times depends upon conditions unrelated to porosity such as the large variation in P-wave velocity with confining pressure (Paillet and Cheng 1991).

\subsubsection{Acoustic Well Logging Tools}

Acoustic log source types fall into three categories: monopole, dipole, or quadrupole. Monopole sources can develop both body and surface waves; dipole and quadrupole sources create only surface waves. Body waves travel in the body of the rock. Surface waves travel on the borehole wall or bounce from the wall to the tool and back to the wall. The surface waves are also called guided waves or boundary waves.

Monopole sources emit sound energy in all directions radially from the tool axis. They are sometimes called axisymmetric or radially symmetric sources. Commercial wireline sonic logging tools, from the 
earliest tool to the present-day, carry a monopole source along with two or more monopole receivers. This tool arrangement creates the conventional compressional sonic log. In fast formations, this tool design can also receive shear waves generated in the formation, where some of the compressional energy is converted to shear energy. A fast formation is a rock in which the shear velocity is faster than the compressional velocity of the fluid in the borehole. A slow formation is a rock in which the shear velocity is equal to or slower than the fluid velocity. The monopole source also generates a shear wave on the borehole surface in fast formations, called a pseudo-Rayleigh wave. The converted shear and the pseudo-Rayleigh arrive at the monopole detector with nearly the same velocity and cannot usually be separated. Monopole sources also generate the Stoneley wave in both fast and slow formations. The low frequency component of the Stoneley is called the tube wave. The monopole source generates several wave modes, some of which have been used more or less successfully, to estimate shear velocity. Other wave modes are mentioned in the literature and described here to help clarify terminology. The following comments deal primarily with the monopole wireline tool, but dipole and LWD are mentioned briefly to contrast important differences.

Dipole sources and receivers are relatively newer and emit energy along a single direction instead of radially. These have been called asymmetric or non-axisymmetric sources. They can generate a compressional wave in the formation, not usually detected except in large boreholes or very slow formations. They generate a strong shear wave in both slow and fast formations. This wave is called a flexural or bender wave and travels on the borehole wall. Unlike the pseudo-Rayleigh from a monopole source, which also travels on the borehole wall at near shear velocity, the flexural wave field is asymmetric.

Quadrupole sources generate asymmetric pressure waves, called screw waves, which behave similarly to those of dipole sources. They can be used on open-hole tools, although no such tool is commercially available. They are more suited to the logging-while-drilling environment where recent developments have shown some success in measuring shear velocity. The quadrupole source generates quadrupole waves, which travel in the collar and the formation, the two being coupled through the annulus. At low frequencies the formation quadrupole travels at the formation shear speed. The quadrupole LWD tool collar is designed to be thick enough that the collar quadrupole mode is "cut off” (very highly attenuated) below some frequency chosen to be well above the frequency used for quadrupole logging, thus minimizing the interference with the formation quadrupole. While there are strong collar arrivals on monopole LWD tools, there have been monopole LWD sonic logs operating successfully for many years, using various mechanical and processing techniques to attenuate the collar arrival. For LWD dipole tools, the collar mode interferes with the formation dipole, forming coupled modes where the formation shear speed is difficult to extract.

A typical logging tool is shown below in Figure 2.21. The sonde normally contains two receivers about $300 \mathrm{~mm}$ apart and an acoustic source some $900-1500 \mathrm{~mm}$ from the nearest receiver. The source generates acoustic pulses at a frequency of typically $20-40 \mathrm{kHz}$. The difference in the times at which the transmitted signal reaches the two receivers is divided by the spacing of the receivers. Each sonic pulse activates a timer so that the differential travel time between the receivers can be measured. If the sonde is tilted in the well, or if the well diameter varies, different path lengths result. This problem is overcome, in a borehole-compensated log, by using a second source on the other side of the receivers so that the tilt effect is self-cancelling when all four travel paths are considered (Kearey et al. 2002). 


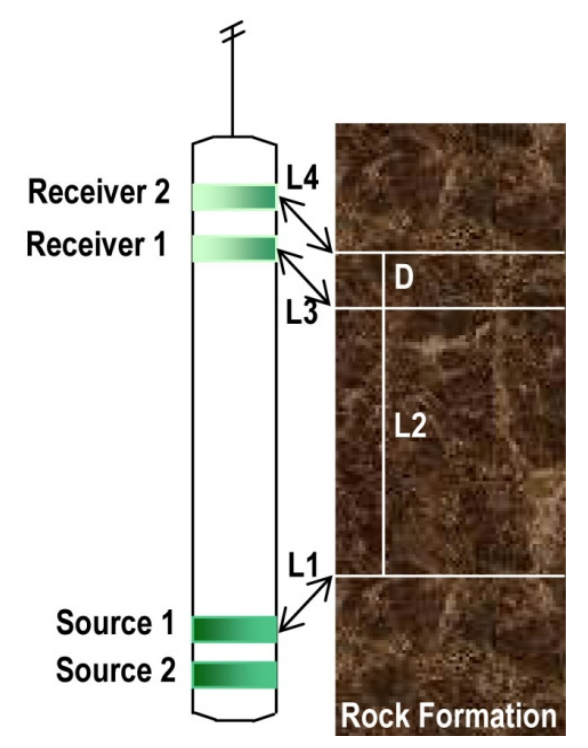

Figure 2.21. Schematic of a Full-Waveform Acoustic Sonde with Two Transmitters and Two Receivers. Compressional refraction paths through the formation are shown (Timur and Toksoz 1985). Reproduced with permission from the Copyright Clearance Center.

\subsubsection{State-of-the-Art Acoustic Devices}

Modern sonic logs, often called dipole shear sonic logs, usually carry monopole and dipole sources, and generate the measured values for compressional, shear, and Stoneley slowness in different ways depending on the formation characteristics. Such a tool can give all three measurements in both slow and fast formations. Modern open-hole sonic logging tools carry both monopole and dipole sources and receivers so that compressional and shear arrivals can be recorded in slow and fast formations. The sources are fired alternately; the sound from one source will not interfere with the other. Some modern sonic logging tools have two sets of dipole sources set orthogonally, with corresponding dipole receivers. Shear data can be recorded in two directions in the formation. These are called crossed-dipole tools. After suitable processing, the two acoustic velocity measurements are translated into a minimum and maximum velocity. The ratio of these velocities is a measure of acoustic anisotropy in the formation. This is an important property in formation stress analysis, hydraulic fracture design, fractured reservoir description, and tectonic studies (Crain 2004).

The increased use of array tool designs (multiple sources and receivers) provides improved vertical resolution, improved and multiple depths of investigation, and enables radial and azimuthal imaging of resistivity and invasion by resistivity tools. Acoustic-array designs, using either dipole or quadrupole sources, can acquire high-quality shear-wave data in most types of reservoir rocks. The resolution and coverage of borehole imaging devices have improved with the addition of more sensors on electrical devices and improved transducer design and placement on acoustic devices.

Schlumberger's Versatile Seismic Imager ${ }^{\mathrm{TM}}$ tool (VSI) is a wireline tool that consists of 20 lightweight, multi-component sensor modules (shuttles) whose sensor packages are acoustically decoupled from the main tool body. 
The Sonic Scanner ${ }^{\mathrm{TM}}$ tool provides axial, azimuthal, and radial information derived from the monopole and dipole measurements for near-wellbore and far-field slowness. The Dipole Shear Sonic Imager $^{\mathrm{TM}}$ (DSI) measures compressional- and shear-wave propagation in the formation. For Stoneley wave acquisition, a specific low-frequency pulse is used.

Tools are discussed on company web sites and the Weatherford's borehole-compensated sonic (HBC) tool measures formation acoustic compressional travel time along the wellbore to understand formation porosity and lithology. The monopole-dipole array (MDA) sensor measures compressional, shear, and Stoneley slowness in fast, medium, and slow formations. This tool combines beam-steering monopole transmitter technology with frequency-selectable, dual-dipole transmitters. The Compact sonic sonde measures formation compressional slowness (inverse velocity) at five spacings with 30-60 cm (1- and 2 -ft) vertical resolution. The vertical seismic profile (VSP) system looks ahead of the bit for overpressure or target zones; provides lateral views to help define structural features, such as faults and dips; provides detailed seismic imaging around the borehole; and calibrates depth and time for P-wave and S-wave modes in open- or cased-hole applications.

Halliburton’s Circumferential Acoustic (CAST-V ${ }^{\mathrm{TM}}$ ) Scanning Tool provides a $360^{\circ}$ profile for borehole imaging for formation evaluation in an open hole and ultrasonic pipe inspection and cement evaluation in a cased hole. The Bi-modal AcousTic (BAT ${ }^{\mathrm{TM}}$ ) Sensor provides compressional and shear slowness $(\Delta t) \operatorname{logs}$ in both fast and slow formations using dual-frequency transmitters and a dual sevenreceiver array configuration.

The AcoustiCaliper ${ }^{\mathrm{TM}}$ MWD Tool provides real-time borehole diameter measurements from three acoustic standoff measurement transducers oriented 120 degrees apart radially. The Fast Circumferential Acoustic Scanning (FASTCAST ${ }^{\mathrm{TM}}$ ) Tool performs pipe inspections and cement evaluations for open or cased holes for casings up to 20 inches $(50.8 \mathrm{~cm})$ in diameter. The Hostile Full WaveSonic Logging (HFWS ${ }^{\mathrm{TM}}$ ) Tool provides compressional wave, refracted shear wave, and Stoneley wave properties of downhole formations. The Sonic Array Waveform Amplitude (BSAT ${ }^{\mathrm{TM}}$ ) Tool integrates two monopole transmitters with an array of five piezoelectric receivers. The full waveform data are digitally recorded permitting data analysis for waveform amplitude, slowness, and arrival time in both open hole and cased hole. The WaveSonic ${ }^{\circledR}$ Crossed-Dipole Sonic Tool measures fast and slow shear wave travel times, P-wave slowness, compressive fluids in pore space, and anisotropy orientation.

Advanced Logic Technology in Germany has developed the full-wave Acoustic Borehole Imager (ABI) tool, a multi-echo (amplitude and travel time) system that operates under a wide range of borehole conditions. In the FAC40 and the ABI40 Televiewer (Figure 2.22), the acoustic beam is created by a rotating mirror. The mirror is used to focus the beam such that maximum resolution is achieved at the borehole wall. The non-moving acoustic transducer first sends out a burst of acoustic energy and later records reflected signals. An acoustic image of the surrounding formation is produced by recording echoes of the acoustic signal generated at the interface between borehole fluid and rock. At each scan point, the maximum amplitude and the corresponding travel time of the reflected signal are measured. 


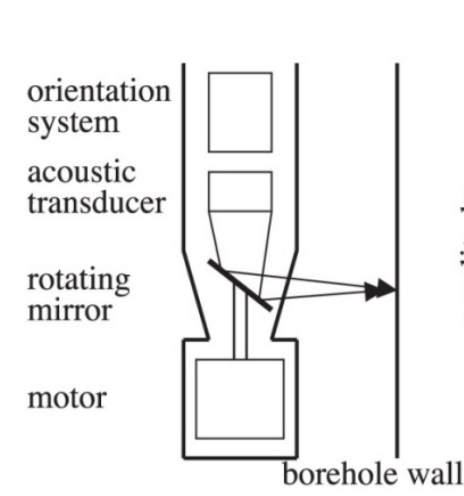

(a)

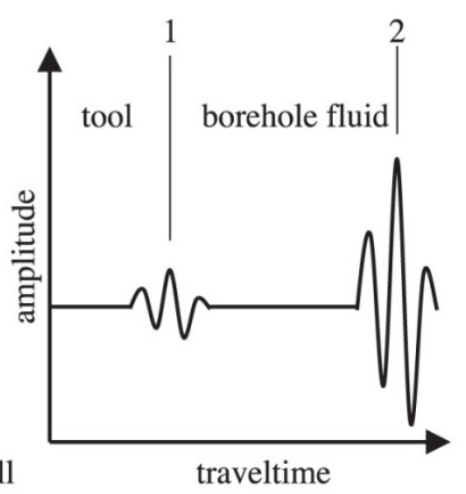

(b)

Figure 2.22. Principle of Televiewer Measurements. (a) Outline of the mechanics of the tool. The conical part of the tool housing represents the acoustic window, which is made of a special synthetic material for optimum transmission of the acoustic energy through the acoustic window. (b) Acoustic waveform received by the acoustic transducer. From left to right, the first signal (1) is the reflection from the acoustic window and the second signal (2) is the reflection from the borehole wall (Deltombe and Schepers 2004). Reprinted with permission.

The first acoustic televiewer (ATV) was developed by the petroleum industry in the late 1960s. ATVs provide continuous and oriented $360^{\circ}$ views of the borehole wall from which the character, relation, and orientation of lithologic and structural planar features can be defined for studies of fractured rock aquifers (Figure 2.23) (Williams and Johnson 2004).
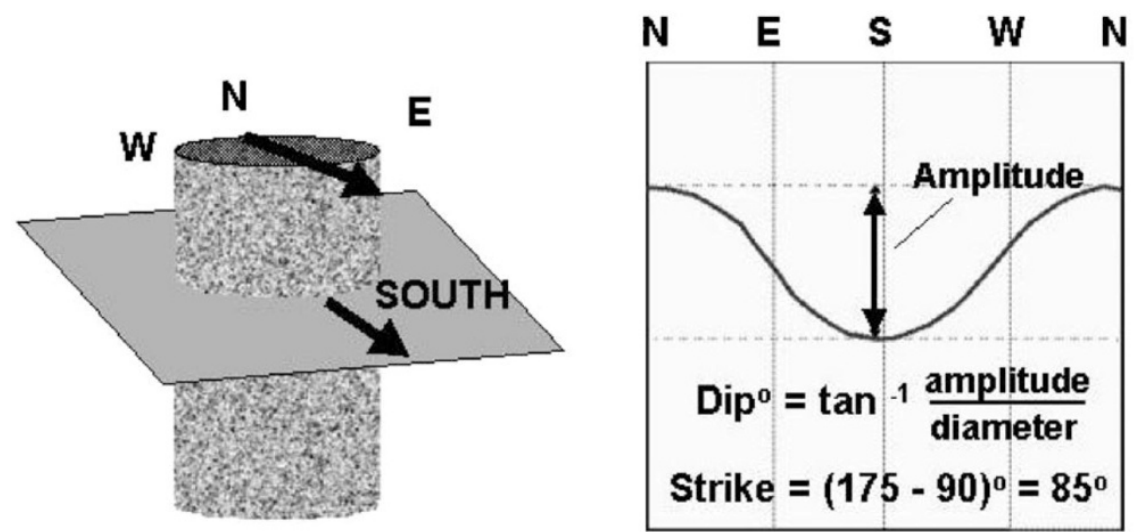

Figure 2.23. Oriented, $360^{\circ}$ Image of the Borehole Wall and Calculation of Strike and Dip of Planar Feature

The general attitude in the well logging industry is that logging while drilling has matured and can potentially replace conventional post-drilling wireline logging in many situations, especially in high-risk or in high-angle and horizontal exploration and production wells (Prensky 1994). 


\subsubsection{Gap Analysis}

In geophysical well logging, acoustic or sonic logging data is perceived as secondary to nuclear or electromagnetic data for the characterization of rock formations. This is perhaps due to the fact that, of the available suite of acoustic measurements, only acoustic velocity and attenuation data are currently measured and utilized to understand rock properties. Although velocity and attenuation measurements are effective for materials characterization, they are some of the most basic acoustic materials characterization measurements and are confined to the low acoustic frequency range in well logging due to the measurement requirement of sound field coherence in materials. Challenges to correlating velocity and attenuation measurements to a certain rock property, such as porosity, include conditions unrelated to porosity such mineralogy, degree of fluid saturation and pore structure. The challenges still faced by state-of-the art acoustic well logging technologies, coupled with the impetus to identify non-nuclear well logging measurement technologies, warrants researching additional acoustic measurements that may supplement basic velocity and attenuation measurements. Propriety work is known to be in progress; however, the exact nature of what is being considered is unknown.

Advanced acoustic measurements such as backscatter, diffuse field, and spectroscopy have the potential to increase the value of acoustic well logging measurements (Weaver 2005; Larose et al. 2006; Weaver and Lobkis 2006; Ghoshal and Turner 2009) and serve as complements to standard velocity and attenuation measurements. Advanced measurements can potentially be used to derive additional or more accurate rock property information using modern acoustic well-logging tools. Such measurements would extend the acoustic frequency range over which well logging measurements are performed by supplementing the low frequency velocity and attenuation measurements (3-30 kHz) with higher frequency advanced acoustic measurements ( $30 \mathrm{kHz}$ up to approximately $200 \mathrm{kHz}$ ). The acoustic spectrum and some application ranges are shown in Figure 2.24.

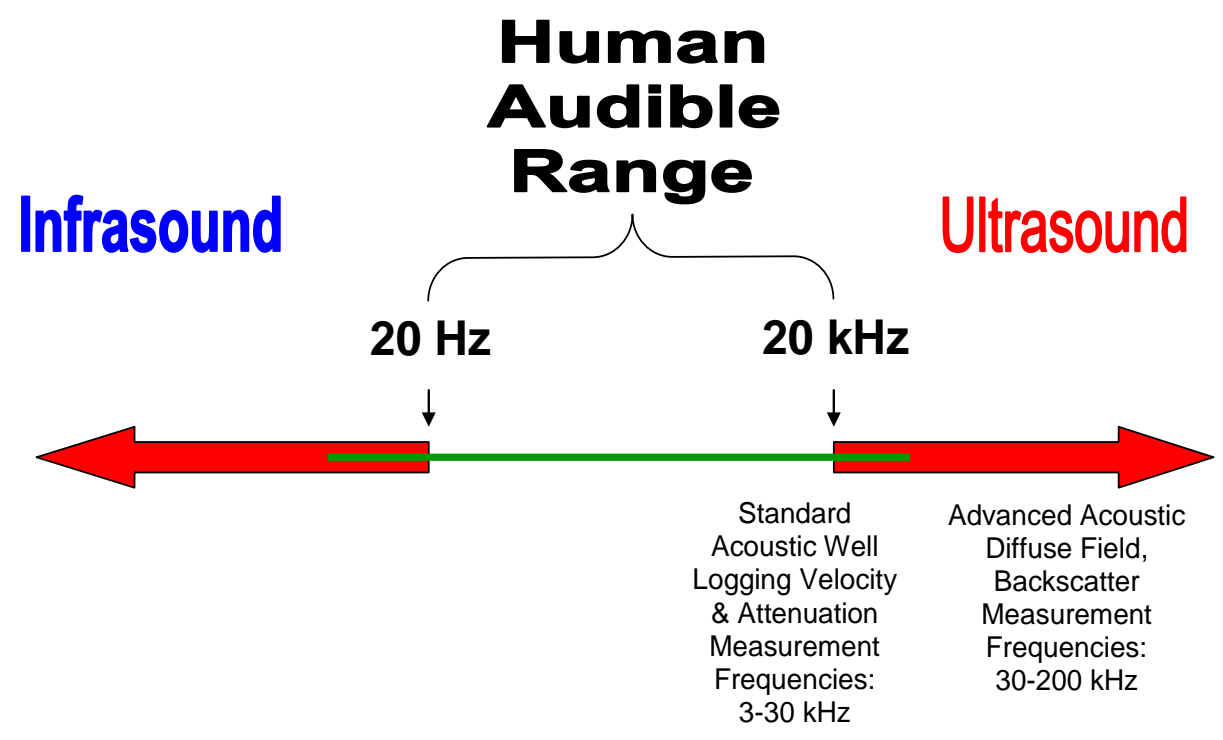

Figure 2.24. Illustration of the Acoustic Frequency Spectrum 
Acoustic velocity and attenuation measurements require coherent sound fields, which require that wavelengths of the measurement frequency in the material be large compared to the microstructure length scales in the material. At such large wavelength-to-microstructure ratios, the medium is an effectively homogeneous continuum and thus microstructure properties cannot be resolved (Weaver and Sachse 1995). In well logging, very low acoustic frequencies are used (e.g., 3-30 kHz), which have wavelengths of several inches in rock material and thus small microstructure features are not resolved. At wavelengths comparable to microstructure length scales a diffuse ultrasonic field develops, providing an opportunity for microstructure characterization. Diffuse field measurements do not require coherent sound propagation. After multiple scatterings or reflections, a wave field has lost most of its original phase coherence and the field variables become random, with zero mean. The mean square of the field, or the mean wave energy, however, remains a meaningful quantity (Weaver and Sachse 1995).

\subsubsection{Prior Work}

There is a growing body of literature that reports diffuse ultrasound measurement and theory for microstructure characterization of polycrystalline, slurry, and Earth material. This topic has been covered in various review and overview papers including those by Weaver and Sachse (1995), Weaver (2005), Weaver and Lobkis (2006), Larose et al. (2006), and Turner and Weaver (1994).

Earlier work has shown that diffuse ultrasonic fields are capable of characterization of high particle density slurries, cement, foams and ultrasonic sources. Weaver and Sachse (1995) showed that measured diffuse ultrasonic energy density in a close-packed disordered assemblage of glass beads immersed in water (a "slurry") evolves in accordance with a diffusion equation. Diffusivity, a parameter of the diffusion equation, was found to exhibit frequency dependence which characterizes the microscale length according to theory.

Using a cement paste matrix with glass bead aggregate, Becker et al. (2003) demonstrated that ultrasonic diffuse field measurements in solid cement specimens could be used to provide a basic understanding of the effect of some microstructure features on the propagation of ultrasonic waves. Measurements were performed on cement specimens having glass bead diameters of $1 \mathrm{~mm}$ and $3 \mathrm{~mm}$ and volume fractions of $22 \%, 32 \%$, and $41 \%$ using ultrasonic frequencies with wavelengths on the orders of the glass beads. By interpreting the acoustic waves using diffusion theory, quantitative measurements of the dissipation and diffusion coefficients were made as a function of frequency and microstructure. It was shown that dissipation coefficients could be used to quantitatively characterize differences between pasteonly and paste-bead cement specimens and could be reconciled with diffusion theory. In cement-based materials diffuse field measurements show promise as an alternative to attenuation and velocity measurements. There has been limited success in experiments seeking to relate microstructure parameters to attenuation and velocity using higher frequencies due to scattering from randomly distributed aggregate and the very high attenuation. In order to obtain coherent signals required to perform attenuation and velocity measurements, either the energy wavelength must be large relative to the glass bead diameters or the volume fraction must be low.

Larose et al. (2006) demonstrated the feasibility of imaging small details of a medium by means of a passive time-correlation technique using data from diffuse wavefields originating from distant sources. It is believed that this technique could be transposed and applied to prospection geophysics, as the application to ambient seismic noise is particularly promising for improving images of the deep Earth or performing passive images of the near surface (Larose et al. 2006). In their 2006 review of diffuse 
ultrasonic waves in solids, Weaver and Lobkis (2006) reported promise for practical passive imaging is good.

\subsubsection{Equations}

Accurate interpretation of experimental data requires robust scattering models. For polycrystalline materials, Ghoshal and Turner (2009) have developed a theoretical model to explain scattering response in a two-dimensional domain that is reconcilable with a numerical model, which can be used to investigate the frequency dependence of the correlation length for complex materials or multi-phase materials, where a theoretical model does not exist.

In general, the mean energy $E$ in diffuse field measurements can be expected to be governed by a diffusion equation:

$$
\frac{\partial E(r, t)}{\partial t}=P(r, t)+D \nabla^{2} E(r, t)-\sigma E(r, t)
$$

where:

$P=$ energy deposition rate at position $r$ and time $t$,

$\sigma=$ energy dissipation rate that is assumed to be linear,

$D=$ diffusivity of ultrasonic energy through the random medium, and

$P$ may be approximated $P=P_{0} \delta(t) \delta^{3}(r)$ (Weaver and Sachse 1995).

Parameters of the diffusion equation $D$ and $\sigma$ are found by using a simple random walk model for diffusing ultrasound and assuming the primary mechanism for dissipation $\sigma$ arises from viscous fluid drag over solid/fluid interfaces. Diffusivity is found to be $D \approx c / 3 n_{s c} \Sigma^{\prime}$, where $c$ is the speed of sound, $n_{s c}$ is the scatterer number density $\left(n_{s c}=3 p / 4 \pi a^{3}\right)$ and $\Sigma^{\prime}$ is an angle weighted average $\int(1-\cos \theta) \frac{d \Sigma}{d \Omega} d \Omega$. Dissipation is found to be $\sigma=[p /(1-p)] a^{-1}(2 \mu \omega / p)^{1 / 2}$, where $p$ is the bead filling fraction and $a$ is the bead radius (Weaver and Sachse 1995).

In an unbounded three-dimensional medium, the solution of the diffusion equation is given by:

$$
E(r, t)=P_{0} \exp \left(-r^{2} / 4 D t-\sigma t\right) / 8(\pi D t)^{3 / 2}
$$

which predicts that the logarithm of the average energy density may be fit to a simple three-term function of time of the form:

$$
\ln \langle E\rangle+(3 / 2) \ln (t)=\left[-r^{2} / 4 D\right] / t+b-\sigma t
$$

where $b=\ln \left[P_{0} / 8(\pi D)^{3 / 2}\right]$ and is related to the logarithm of the total energy deposition $P_{0}$ (Weaver and Sachse 1995). 
During signal analysis, the energy density of a temporal diffuse field signal at a particular frequency is calculated by performing a time-frequency analysis. The temporal signal is divided into a number of overlapping time windows of length $\Delta \mathrm{t}$. To smooth signal edges and reduce artificial side lobes, these windows are multiplied with a Hanning window. A discreet time Fourier transform of each individual window is then calculated. The spectral energy density is then calculated for each time window in a certain frequency band by summing the power spectrum in a bandwidth of width $\Delta \mathrm{f}$ centered around frequency $\mathrm{f}_{\mathrm{c}}$ (Becker et al. 2003).

Diffuse field backscattering measurements are appealing because of the relative simplicity of the measurement and the theoretical description of the scattering processes (Egle 1981; Weaver and Sachse 1995; Ghoshal and Turner 2009). Measurement such as diffuse field measurements should be perceived as potential complements to, not replacements for, standard acoustic velocity and attenuation well-logging measurements, as they are performed in a higher frequency regime that is inaccessible to coherent propagation frequencies. A potential challenge to measurements at diffuse field measurement is the borehole invasion zone. The volume of water expelled from drilling mud, during the creation of the mudcake, will displace the formation fluid, creating the so-called invasion zone. The thickness of this zone, in which the formation fluid has been displaced by mud filtrate, will depend on the formation porosity (Ellis and Singer 2007). For high-frequency measurements requiring signal coherence, the invasion zone may pose a problem due to high attenuation; however diffuse field measurements, which do not require sound field coherence, may prove to be tolerant of the invasion zone. 


\subsection{Technology Comparison}

The goal of replacing some or all of the data obtained from active isotope sources used in well logging with data from other sensing modalities is expected to require technological innovation. It may also require integration of data from several different sensing modalities, as no one modality is likely to provide all the information that isotopic source currently measurements provide. This section starts to address the technology comparison and the approach to be taken in analyzing, correlating, and integrating the data from acoustic and electromagnetic experiments in order to potentially extract information that is currently derived from isotopic nuclear measurements.

In looking at alternatives to the current AmBe sources three approaches are being considered:

1) Reduction in the activity of the AmBe source required (through approaches that included the deployment of enhanced sensors)

2) The use of alternate electronic D-T generators (although these provide neutrons with different spectra and data inter-comparison requires attention)

3) The use of enhanced and novel acoustic and electromagnetic sensing tools, including nuclear magnetic resonance, used either in combination with reduced activity AmBe sources and/or D-T generator derived data.

Important information provided by active isotopic nuclear tools (nuclear tools, for short) includes the following:

- salinity

- oil/water/gas saturation

- hydrogen content

- formation rock density

- formation rock porosity

- shale content

The only one of these parameters that is readily extracted from non-nuclear tools is salinity, which has a good correlation with electromagnetic data. For the rest, some combination of measurement methods is necessary. The analysis approach of PNNL is to consider the potential to use multiple modalities to make laboratory measurements of various formation characteristics, looking for correlations between measured values and formation characteristics. Out of those measurements that show a correlation with a given property, those that have different functional relationships will be combined in order to eliminate unwanted dependence on other properties. Viable sets of such measurements will be candidates for further evaluation in follow-on work.

Some of the measurement variables (applicable to both electromagnetic and acoustic methods) are

- frequency

- amplitude or intensity 
- polarization

Analytical, statistical, and correlative methods to be applied to the measurement sets include

- MATLAB tool set

- Neural networks

- Various forms of data fusion

- Graphical displays

This multi-modal approach to analysis is already widely used in well logging. As just one example of many, gamma and neutron measurements are combined to provide porosity and lithology, and to detect gas-bearing zones (Assaad 2008, pp. 50-51).

In looking at comparisons between technologies both reflection and transmission measurements can be made using acoustic, electromagnetic, and nuclear methods and these are shown in schematic form in Figure 3.1.

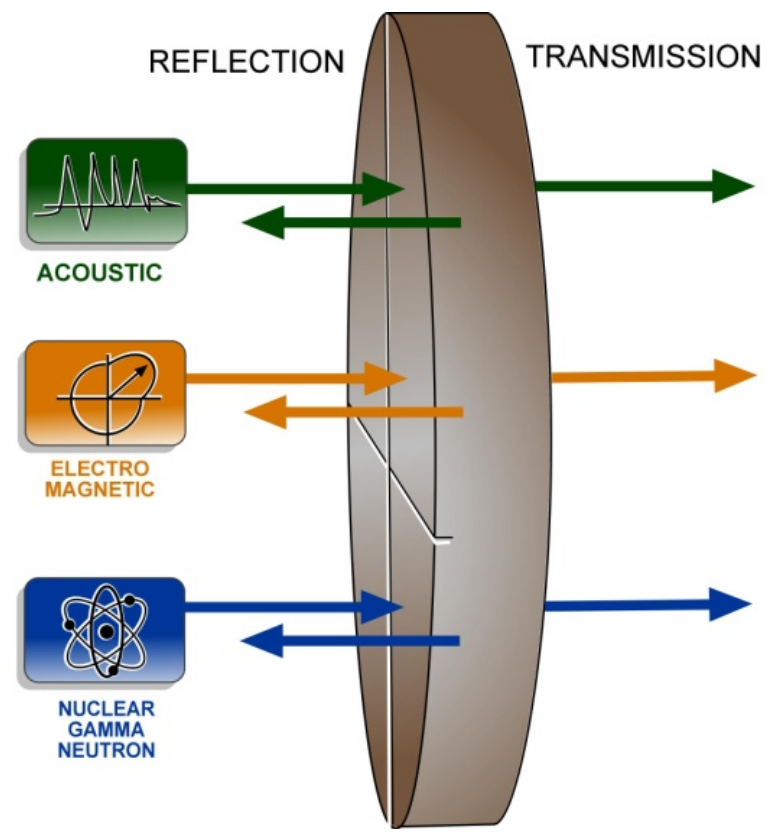

Figure 3.1. Well Logging: Sensor Measurement Techniques

In seeking to understand the feasibility of the potential to replace, or reduce, the use of isotopic sources in well logging, it is necessary to understand the inter-relationships between the sensed data and petro-physical properties in the rock formations. In particular, it is necessary to provide the initial data for an inter-comparison of performance, sensitivity, and correlations to key derived parameters (such as porosity), and relate these back to the relationships between geophysical parameters and the quantities measured by nuclear techniques. The geophysical/petro-physical parameters desired include the 
quantities of fluids, permeability, lithology, clay identification, and mineralogy. A summary of nuclear measurement techniques and the corresponding geophysical parameters are shown as Table 3.1.

Table 3.1. Summary of Nuclear Measurement Techniques for Geophysical Formation

\begin{tabular}{|c|c|c|c|}
\hline $\begin{array}{l}\text { Geophysical } \\
\text { Parameter }\end{array}$ & Physical Parameter & Nuclear Measurement Technique & $\begin{array}{c}\text { Needed } \\
\text { Information }\end{array}$ \\
\hline Hydrocarbon presence & $\mathrm{C} / \mathrm{O}$ ratio & Inelastic gamma-ray spectroscopy & $\begin{array}{l}\text { Lithology and } \\
\text { porosity }\end{array}$ \\
\hline Porosity & $\begin{array}{l}\text { Bulk density } \\
\text { Hydrogen content }\end{array}$ & $\begin{array}{l}\text { Gamma-ray attenuation } \\
\text { Neutron slowing-down length } \\
\text { Capture gamma-ray spectroscopy }\end{array}$ & Lithology \\
\hline Water saturation & $\begin{array}{l}\mathrm{C} / \mathrm{O} \text { ratio } \\
\text { Apparent salinity }\end{array}$ & $\begin{array}{l}\text { Inelastic gamma-ray spectroscopy } \\
\text { Neutron absorption cross section }\end{array}$ & $\begin{array}{l}\text { Lithology and } \\
\text { porosity water } \\
\text { salinity }\end{array}$ \\
\hline Lithology & $\begin{array}{l}\text { Bulk density } \\
\text { Hydrogen content } \\
\text { Average atomic number }\end{array}$ & $\begin{array}{l}\text { Gamma-ray attenuation } \\
\text { Gamma-ray photoelectric absorption }\end{array}$ & Porosity \\
\hline $\begin{array}{l}\text { Mineralogy and clay } \\
\text { types }\end{array}$ & $\begin{array}{l}\text { Th, U, and K } \\
\text { Cs, Si, S, Fe, Gd, and Ti } \\
\text { Al }\end{array}$ & $\begin{array}{l}\text { Natural gamma-ray spectroscopy } \\
\text { Capture gamma-ray spectroscopy } \\
\text { Activation gamma-ray spectroscopy }\end{array}$ & \\
\hline
\end{tabular}

The basis of neutron measurements is neutron scattering - spatial distribution of epithermal or thermal neutrons resulting from the interaction of high-energy neutrons with a formation can be related to its hydrogen content. If the hydrogen (in water or hydrocarbons) is contained within the formation pore space, then the measurement yields porosity.

An U.S. Environmental Protection Agency study reviewed the measurement techniques and their definitions are reported below (Trinity 2002):

- Mechanical or physical measurements: include caliper and temperature logs. The caliper is a tool that measures the diameter of the uncased borehole and can be used, for example, to identify specific "soft” lithologies, zones "washed out” during drilling, etc. Temperature logs measure formation fluid temperature.

- Electrical measurements: include those employing formation resistivity, conductivity, including spontaneous potential. The Spontaneous Potential (SP) log is a recording vs. depth of the difference between the electrical potential of a movable electrode in the borehole and the electrical potential of a fixed surface electrode. SP curves typically assists in lithology determination (i.e., shales or shaley material). The resistivity/conductivity tools also pass electrical currents through formations in various electrode or induction device configurations. These tools yield information that can be used for a variety of measurements, and is commonly used in conjunction with other measurements to assess the formation water saturation.

- Acoustic or sonic tools: these consist of a transmitter that emits a sound pulse and receiver that records the rock response (i.e., sound travel time/characteristics) through adjoining rock formations. Sonic tools are typically used to assess formation porosity, as sound travels more slowly through highly porous, water-filled rock and tight formations. 
- Radioactive tools: these use either radioactive sources or natural rock gamma emissions to assess rock formation characteristics. Logs that use radioactive sources include 1) the Neutron Log, which records formation response to exposure to neutron sources; 2) the Formation Density Log, which determines formation density calculated from rock effects via exposure to gamma sources; and 3) Natural Gamma Log. Basically, the source (a neutron or gamma source) is placed in a long, cylindrical tool designed to travel down the open hole. The source emits neutron or gamma radiation into the surrounding formation while the tool is being drawn up the hole. Sensors in another part of the tool record the response of the formation rock to the irradiation.

Radioactive tools come in several classes:

- Neutron tools: measure the formation porosity (assuming 100\% formation fluid saturation); since hydrogen (the major component of water) scatters neutrons very efficiently, the number of neutrons returning to a detector in the probe is a function of the "amount" of water in the rock pore space and hence a measure of formation porosity. Typical neutron sources are Cf-252, $\mathrm{Pu} / \mathrm{Be}, \mathrm{Po} / \mathrm{Be}, \mathrm{Am} / \mathrm{Be}$ and $\mathrm{Ra} / \mathrm{Be}$.

- Density tools: employ gamma emitters, with density being a function of the amount of Compton scattering associated with the emitted gamma radiation. Gamma ray sources, used with NaI scintillation detectors filtered to Compton Scattering energies, are calibrated in terms of bulk density of the material surrounding the borehole. Typical isotopes used are Co-60 and Cs-137.

- Natural Gamma Ray Logs: measure the natural radioactivity of rock formations (i.e., K40) which are preferentially concentrated in shaley formations; these logs do not require a radioactive source but do measure the natural radioactivity of the formations (Schlumberger 1989).

Neutron and Density logs can be used to calculate formation porosity and formation lithology, and can also be indicators of other formation or formation fluid characteristics (i.e., "bright spots" on neutron logs could indicate the presence of natural gas, wherein the pore space is filled with a lossthan-anticipated amount of hydrogen). In addition, neutron measurements can also be related to neutron activation of carbon and/or various metals present in the sediments and/or rocks surrounding the borehole.

In addition to and as part of these technologies, new/different applications and uses of geophysical logging techniques have been introduced to the mineral, oil and water well industries. Examples of new technologies being marketed today include but are not limited to:

- Magnetic susceptibility tools are used for mineralogy logging of magnetically susceptible formations. The tool is useful for determining magnetite content and iron ores, and records natural gamma emissions and drilling deviations. It measure magnetic susceptibility and uses natural gamma radiation detectors.

- Gyroscopic deviation tools are used for determining borehole deviation and natural gamma mineralogy of magnetically anomalous formations. It employs an axis magnetometer and inclinometer and gyroscope, as well as natural gamma detectors.

- Acoustic televiewers are used for geotechnical observations, whereby a viewer is used to take an oriented acoustic picture of the borehole wall using high resolution sound waves. Information from this tool is used to assess formation fractures, rock strength, etc. 
- Spectral gamma ray logs are used to measure the amounts and types of radioactive material in formations and consists of four curves showing standard gamma Ray in API units, potassium in percentage uranium in ppm and thorium in ppm. The log is used for clay typing or to identify specific natural or artificial isotopes.

- Ion beam analysis (IBA) uses a particle accelerator to inject the nuclei of light atoms such as hydrogen or helium, resulting emitted nuclei, gamma rays or x-rays characteristic of the elemental composition of material being tested.

- Nuclear magnetic resonance (NMR) provides direct measurement of hydrogen-bearing pore fluids (water and oil) and the fluid environment (pore size, rock porosity). This method manipulates the permanent magnetic dipole moment of the hydrogen atom and monitors its alignment/relaxation in response to applied magnetic fields. Measurement of longitudinal relaxation time constant $\left(T_{1}\right)$ and the free induction decay time constant $\left(\mathrm{T}_{2}\right)$ can be used to infer fluid viscosity, molecular diffusion coefficient, and pore surface area to volume ratio.

- Spontaneous potential (SP) measures small electric potentials (millivolts) between depths in the borehole and a grounded electrode at the surface. The SP is caused by a buildup of charge on the well bore walls. Clays and shales generate one charge polarity whereas permeable formations such as sandstone will generate the opposite polarity. The buildup of charge is caused by differences in the salt content of the well bore fluid (drilling mud) and the formation water.

Conventional methods of determining the neutron- scattering properties of a formation employ a source of high-energy neutrons and monitor the resultant thermal or epithermal flux. Although numerous neutron detectors are available, in the hostile environment of well logging, simplicity and reliability are provided by the use of gas counters such as those based on the He3 reaction. To measure the epithermal neutron flux, a shield of thermal neutron-absorbing material such as cadmium is used around the detector.

Some of the physical parameters of the formation and borehole that affect the response of a neutron porosity device are porosity, pore fluid type, salinity, rock type, borehole size, borehole fluid type, mudcake, and pressure. Of these, only porosity is in fact the desired quantity. All the others can be related to a change in the local hydrogen density and thus will have an influence on any measuring device that is sensitive to the concentration of hydrogen.

The relationships between rock and well logging parameters are summarized in a series of tables provided by Schlumberger (1989). It is readily seen from Tables 3.2, 3.3, and 3.4 that the geophysical and petro-physical data set is complex and extensive. The definition of the various parameters used in these tables is given in Table 3.5.

A summary of the basic well logs used for the various correlations with petro-physical parameters is given as Table 3.6. 
Table 3.2. Relationship Between Composition of a Rock and Well Logging Parameters (adapted from Schlumberger 1989, Table 12-1)

\begin{tabular}{|c|c|c|c|c|c|}
\hline \multicolumn{5}{|c|}{ Formation Composition } \\
\hline
\end{tabular}

Table 3.3. Relationships Between Rock Texture and Well Logging Parameters (adapted from Schlumberger, 1989, Table 12-2)

\begin{tabular}{|l|c|c|c|c|c|c|}
\hline & \multicolumn{5}{|c|}{ Texture } \\
\hline
\end{tabular}


Table 3.4. Relationships Between Sedimentary Features and Well Logging Parameters (adapted from Schlumberger 1989, Table 12-3)

\begin{tabular}{|c|c|c|c|c|}
\hline \multirow{3}{*}{ 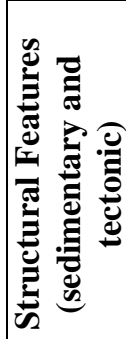 } & \multicolumn{4}{|c|}{ Formation Structure } \\
\hline & $\begin{array}{c}\text { External Form } \\
\text { of Bed }\end{array}$ & $\begin{array}{c}\text { Bedding Plane } \\
\text { Features }\end{array}$ & $\begin{array}{c}\text { Internal } \\
\text { Organization }\end{array}$ & $\begin{array}{c}\text { Postdepositional } \\
\text { Deformation }\end{array}$ \\
\hline & $\begin{array}{c}\text { Size, } \\
\text { Shape, } \\
\text { Boundaries }\end{array}$ & $\begin{array}{l}\text { Lower boundary, } \\
\text { Upper boundary }\end{array}$ & $\begin{array}{c}\text { Massive, } \\
\text { Heterogeneous, } \\
\text { Laminated, Graded, } \\
\text { Oriented, } \\
\text { Growth structure }\end{array}$ & $\begin{array}{l}\text { Vertical movement, } \\
\text { Horizontal movement, } \\
\text { Organic burrows, } \\
\text { Chemical stylolites }\end{array}$ \\
\hline 离 & \multicolumn{4}{|c|}{$\begin{array}{c}\text { Dipmeter, } \\
\text { Microresistivity, } \\
\text { Dips and curves in all logs }\end{array}$} \\
\hline
\end{tabular}

Table 3.5. Acronyms and Symbols for Tables 3.2-3.4

\begin{tabular}{cl}
\hline Symbol/Acronym & \multicolumn{1}{c}{ Definition } \\
\hline DIL & Dual Induction Log \\
DLL & Dual Laterolog \\
EPT & Electromagnetic Propagation Tool \\
GR & Gamma Ray \\
GST & Gamma Spectrometry Log (induced radioactivity) \\
ML & Microlog \\
MLL & Microlaterolog Resistivity \\
MSFL & Micro-spherically-focused Resistivity \\
NGS & Natural Gamma Ray Spectrometry \\
SP & Spontaneous Potential \\
TDT & Thermal Decay Time (neutron) \\
\hline
\end{tabular}


Table 3.6. Basic Well Logs and Their Correlations and Related Attributes (adapted from Schlumberger 1989, Table 12-4)

\begin{tabular}{|c|c|c|c|c|}
\hline $\log$ & Correlations & $\begin{array}{l}\text { Optimum } \\
\text { Conditions }\end{array}$ & $\begin{array}{l}\text { Problem } \\
\text { Conditions }\end{array}$ & Notes \\
\hline$\overline{\text { Caliper }}$ & $\begin{array}{l}\text { Hole diameter, } \\
\text { washouts, fractures }\end{array}$ & Uncased hole & Mudcake, rugosity & $\begin{array}{l}\text { Resolves ambiguities in } \\
\text { results from other logs }\end{array}$ \\
\hline Density & Formation density $\rho$ & Uncased hole & Mudcake, rugosity & Lithological markers \\
\hline Gamma (passive) & $\begin{array}{l}\text { Shaliness, other } \\
\text { radioactivity }\end{array}$ & Moderate diameter & $\begin{array}{l}\text { Large zones of } \\
\text { wash-out }\end{array}$ & $\begin{array}{l}\text { Any drilling fluid; cased } \\
\text { or not }\end{array}$ \\
\hline Induction & $\begin{array}{l}\text { Salinity, water } \\
\text { percentage }\end{array}$ & Uncased & $\begin{array}{l}\text { Salt mud; } \\
\text { Resistivity greater } \\
\text { than } 100 \Omega \cdot \mathrm{m}\end{array}$ & $\begin{array}{l}\text { Shales, other low- } \\
\text { resistivity formations; } \\
\text { porosity affects response }\end{array}$ \\
\hline Laterolog (deep) & $\begin{array}{l}\text { Invaded porous } \\
\text { beds; density }\end{array}$ & Uncased & $\begin{array}{l}\text { Low ratio of } \\
\text { formation } \\
\text { resistivity to water } \\
\text { resistivity }\end{array}$ & $\begin{array}{l}\text { Responds to formation } \\
\text { factor, water resistivity, } \\
\text { shaliness. Good in salt } \\
\text { muds and resistive } \\
\text { formations }\end{array}$ \\
\hline Neutron & $\begin{array}{l}\text { Formation's } \\
\text { hydrogen content, } \\
\text { porosity, lithology }\end{array}$ & Cased or uncased & None & Large shale response \\
\hline $\begin{array}{l}\text { Resistivity (short } \\
\text { spacing) }\end{array}$ & $\begin{array}{l}\text { Invaded porous } \\
\text { beds; density }\end{array}$ & Uncased, invaded & $\begin{array}{l}\text { High formation } \\
\text { resistivity; salt mud }\end{array}$ & $\begin{array}{l}\text { Widely used; responds to } \\
\text { formation factor, water } \\
\text { resistivity, shaliness }\end{array}$ \\
\hline $\begin{array}{l}\text { Resistivity (short } \\
\text { spacing, amplified) }\end{array}$ & & & & $\begin{array}{l}\text { Useful in shales, other } \\
\text { low-resistivity formations }\end{array}$ \\
\hline Sonic & Sonic speed & Liquid fill & Gas & $\begin{array}{l}\text { Depends on lithology and } \\
\text { porosity }\end{array}$ \\
\hline $\begin{array}{l}\text { Spontaneous } \\
\text { Potential }\end{array}$ & $\begin{array}{l}\text { Distinguishes } \\
\text { permeable from } \\
\text { shale layers }\end{array}$ & $\begin{array}{l}\text { Uncased, contrasting } \\
\text { filtrate and water } \\
\text { resistivities, fresh } \\
\text { mud }\end{array}$ & $\begin{array}{l}\text { High formation } \\
\text { resistivity }\end{array}$ & $\begin{array}{l}\text { Shale-sand profiles, } \\
\text { widely used, no problem } \\
\text { with washout or deep } \\
\text { invasions }\end{array}$ \\
\hline
\end{tabular}

\subsection{Technology Performance Comparison}

Well logging, as already discussed, has a long history and successful history. However, when seeking to compare technologies and their ability to extract petro-physical parameters the technology comparisons much more limited. There are few simple correlations between sensed parameters and petro-physical properties. The geophysical rock morphology/geometry is in general 3-D, it is seldom in the form of isotropic, homogeneous horizontal layers. Also, in extracting parameters, various corrections and semiempirical factors are applied (Schlumberger 1989). Comparisons with historic data records are also of considerable importance in terms of guiding interpretations.

The various logging tool types and the formation properties that they sense are summarized in Figure 3.2 (University of Houston Well Logging Laboratory). The large red circle is for a tool that is used to sense a particular parameter (e.g., neutron - porosity); those with blue circles, have some but more limited capability. 


\section{Logging Tools vs. Formation Property}

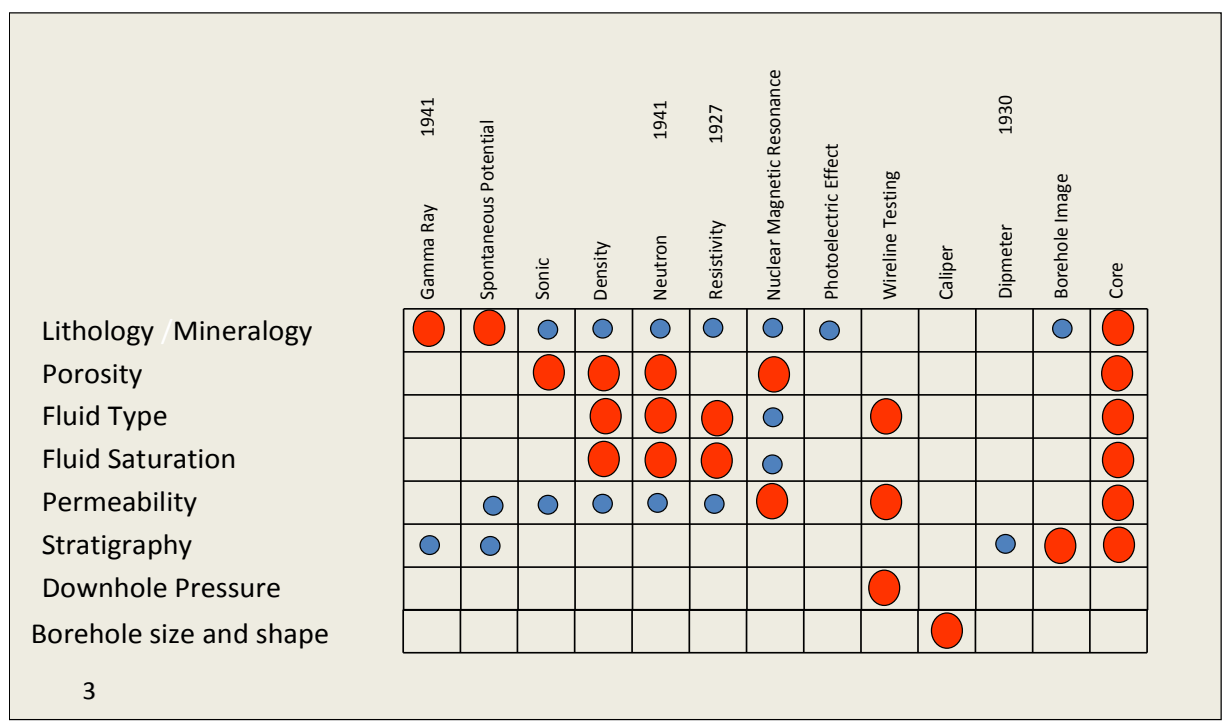

Figure 3.2. Logging Tool Types and Formation Properties Sensed (courtesy University of Houston Well Logging Laboratory)

In determining a particular petro-physical property, in many cases more than one tool can be employed, and it is the mix of art and science involved in log interpretation that for many classes of formations requires the combinations of insights from disparate physically sensed parameters. The process for determining a desired petro-physical parameter is inherently ill posed and it can be an iterative process. It may also require use of additional specialized tools to provide confirmatory or discriminating data.

In seeking to compare the performance and potential equivalence or interchangeability of sensing tools it is necessary to not only consider the primary property- petro-physical parameter relationships (many of which are provided in text books), but the full range of corrections and correlations. For example there are differences between log density and the true bulk density. In porosity, when some acoustic measurements are considered for porosity the pore-shape/orientation significantly changes acoustic parameters that are measured.

There are further complications when depth of investigation, the measurement depth into a formation and achievable resolution. One comparison for several techniques is provided in Figure 3.3. 
Depth Of Investigation Of Logging Tools

\section{Logging Tools}

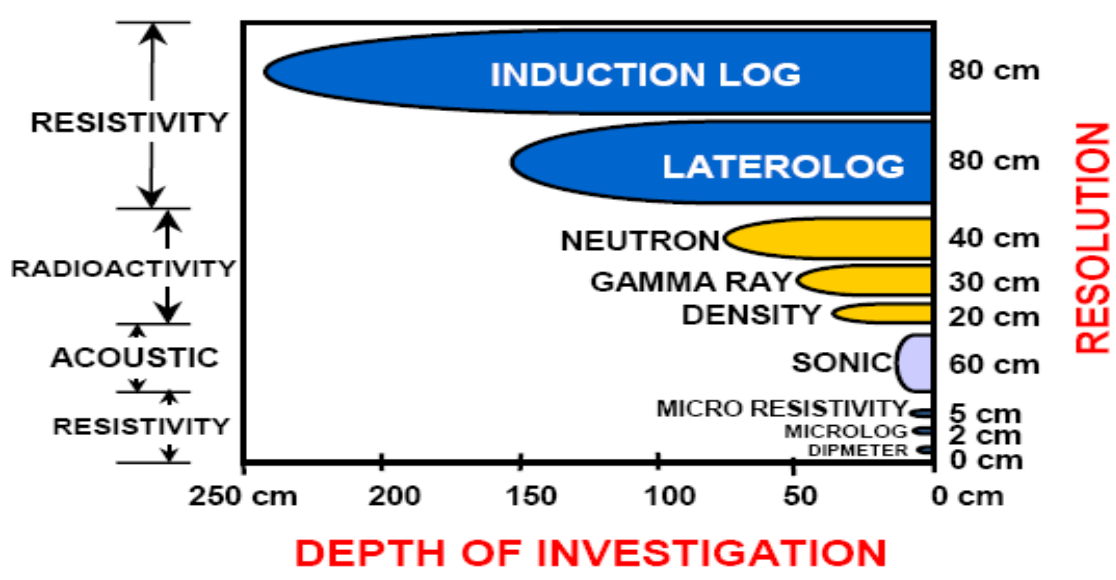

Figure 3.3. Depth of Investigation of Some Logging Tools (courtesy University of Houston Well Logging Laboratory, 2009)

However, other sources (Adolph et al. 2005) now state that sonic methods measure properties around the borehole and tens of feet into the formation (Arroyo Franco et al. 2006). A swept frequency (chirp pulses) is employed by Schlumberger covering the range from $300 \mathrm{~Hz}$ to $8 \mathrm{kHz}$. Also increasingly complex sources are providing directional dipoles to provide spatial discrimination and directional dependencies in 3-D formations. Since the introduction of fully digitized wave forms slowness surfaces are being increasingly investigated.

In understanding the performance, and the requirements for, any non-nuclear technology the depth of penetration into a formation and the volume interrogated by neutrons needs to be known. These data have been reported in several documents:

- Volume investigated is roughly spherical extending 30-60 cm (1-2 feet) into the formation. The minimum tool diameter is $2.5 \mathrm{~cm}\left(1 \mathrm{in}\right.$.), maximum temperature is $260^{\circ} \mathrm{C}\left(500^{\circ} \mathrm{F}\right)$ (Baker et al. 1975 , p. 57).

- Volume and depth of investigation are determined by the moisture content of the rock and contained fluids and this limits the average distance a neutron can travel before being absorbed. Volume of investigation is spherical, with a radius of $40-70 \mathrm{~cm}$ from midpoint between the source and detectors. Depth of investigation is generally $40-70 \mathrm{~cm}$. Measurement resolution is typically 1 count per second. Geological conditions include the presence of clay minerals with significant non-effective porosity, and the presence of minerals such as chlorine with relatively large neutron absorption crosssections. Disadvantages include: logging too fast can significantly degrade the quality of neutron logs, especially when neutron detectors are designed to exclude thermalized neutrons, resulting in relatively low counting rates. Neutron counts measured at a given depth need to be averaged over a time interval so the natural statistical variation in the rate of neutron emission is negligible. Geological conditions include the presence of clay minerals with significant non-effective porosity, and the presence of minerals such as chlorine with relatively large neutron absorption cross-sections (ASTM 2001, reapproved 2007). 
Table 3.7. Depth and Volume of Investigation by Method

\begin{tabular}{|c|c|c|c|}
\hline Method & $\begin{array}{l}\text { Parameter } \\
\text { Measured }\end{array}$ & $\begin{array}{l}\text { Resolution } \\
\text { (Vertical) }\end{array}$ & $\begin{array}{l}\text { Depth (Radius) of } \\
\text { Penetration }\end{array}$ \\
\hline Gamma Density & Porosity & $1 \mathrm{~m}$ (3 feet) & $2.5 \mathrm{~cm}$ (1 inch) \\
\hline Gamma Ray & Lithology & $30-100 \mathrm{~cm}$ (1-3 feet) & $10 \mathrm{~cm}$ (4 inches) \\
\hline Induction & Resistivity & $60 \mathrm{~cm}$ (2 feet) & $0.3-2.43 \mathrm{~m}$ (1-8 feet) \\
\hline Laterolog & Resistivity & $60 \mathrm{~cm}$ (2 feet) & $0.6-2.13 \mathrm{~m}$ (2-7 feet) \\
\hline Microresistivity & Resistivity & $2.5-7.5 \mathrm{~cm}$ (1-3 inches) & $2.5-10 \mathrm{~cm}$ (1-4 inches) \\
\hline Neutron & Porosity & $60-100 \mathrm{~cm}$ (2-3 feet) & $15-20 \mathrm{~cm}$ (6-8 inches) \\
\hline Sonic Transit Time & Porosity & $30 \mathrm{~cm}$ (1 foot) & 15 cm (6 inches) \\
\hline Spontaneous Potential & Lithology & Reciprocal of porosity & Shallow, variable \\
\hline
\end{tabular}

Table 3.7 is condensed from information presented in pages 4-103 of Asquith and Krygowski (2004).

\subsubsection{Comparing the Correctness of Neutron and Other Logging Tools}

In order to provide insight into the feasibility of replacing isotopic neutron logging by other methods, it is of interest to determine the correctness of the information provided by isotopic neutron tools compared to that provided by other methods. Another important consideration is completeness, which is not considered in this section.

A natural approach to ascertaining correctness of the various logging methods is to consider their accuracy: the agreement between the value given by a measurement and the true value of the measured attribute. However, a survey of the well logging literature, starting with over 200 papers and websites, narrowed down to some 25 items of greatest interest, and resulting in over 100 pages of notes, indicates that accuracy, as defined in measurement science, is not an established attribute of well logging tools. The following comment, published in 1997, still holds true, that "current measurement specifications seldom distinguish accuracy from precision. The user is given a single figure (measurement uncertainty) that does not help in selecting the measurement he or she needs.” (Theys 1997).

In order to understand the lack of accuracy specifications for logging tools, it may be useful to consider a hypothetical example. Suppose that there were an instrument capable of measuring, to an accuracy of one part in 1,000 , the quantity of crude oil contained within a specified volume of a geologic formation. This sounds like the perfect well logging tool. However, this instrument, in spite of its accuracy, would not provide, to the prospective well driller, a prediction of the amount of producible oil to an accuracy of 1 part in 1,000, or 1 part in 100, or even 1 part in 2. Many factors, including the permeability of the formation and the zones that would actually contribute to production, need to be taken into account. The actual production of the well could be significantly less or - if permeable zones extended beyond the specified volume of the formation - could even be far greater than the (accurately) measured quantity of crude oil within the specified volume. In other words, the accuracy of the measurement method does not provide a good measure of the accuracy of the useful results.

The measurement systems of oil well logging are designed for a practical purpose: to maximize the profit and minimize the risk from drilling and operating an oil well. While these systems rely on 
sophisticated geophysics, they are not scientific measurement tools. In particular, the accuracy and precision of the measurements themselves are not of particular importance, except to the extent that they provide confidence in the decisions that will be made based on the data. Further, there are no such methods as the hypothetical one above: all the methods are indirect, providing clues to the desired quantities, but not direct measurements of them. And in addition, the data provided by the various methods are combined in various ways and with various weights, by a combination of complex computer algorithms and professional judgment, so that the contribution of any one method to the final answer cannot be reliably evaluated. Nor do the logging companies' customers - the oil companies - have an interest in obtaining or reporting on the accuracy of either the individual methods or the final assessments. Their profitability depends on overall production results, and not on their ability to predict with certainty the outcome of any particular well.

It is interesting to examine Schlumberger's Log Interpretation Principles/Application (Schlumberger 1989), a reference manual of some 240 pages, and its companion volume, Log Interpretation Charts (Schlumberger 2009), some 310 pages of detailed interpretation charts for logging measurements. The only measurements for which accuracy, precision, or repeatability are consistently referenced are depths. For quantities other than depth, there appear to be a total of five explicit references to precision, accuracy, or uncertainty: one reference to the accuracy of porosity calibration standards and four to the precision or uncertainty of resistance measurements.

Since accuracy does not seem to be a fruitful measure, comparison of the various methods may be best approached by considering their precision, resolution, and sensitivity. Well log interpretation is not a numerical formula, but a complex procedure involving a wide variety of data. While modern logging makes extensive use of computer information-theoretic methods, the log analyst and well operators make the interpretations and decisions; and even these cannot be called "definitive” interpretations or "final” decisions: interpretations and decisions will change in the course of drilling and extraction operations. This complexity makes it infeasible to perform a "sensitivity analysis" in the conventional sense, in which the variation of a given parameter is related to variations in the final result. Thus it does not appear possible to provide a quantitative measure of the importance of a given logging method (the isotopic neutron log in particular) to well log interpretation.

The most important aspect of a logging method is its information content: what does it convey? Table 3.8 shows the major well-logging methods and the information content most commonly associated with each.

Table 3.9 expands on Table 3.8. It shows details of the major well-logging methods (as well as a few related non-logging methods) and the information content most commonly associated with each, including (as available) typical figures for precision/, resolution/, and sensitivity, accuracy, and range. Some methods are listed more than once, corresponding to different parameters derived from the method. Very few methods have any published accuracy values, and only the laboratory methods have definitive accuracy values. 
Table 3.8. Well Logging Methods and the Parameters They Measure (Summary). Numbers indicate the upper limits of the relevant parameters, where appropriate and known.

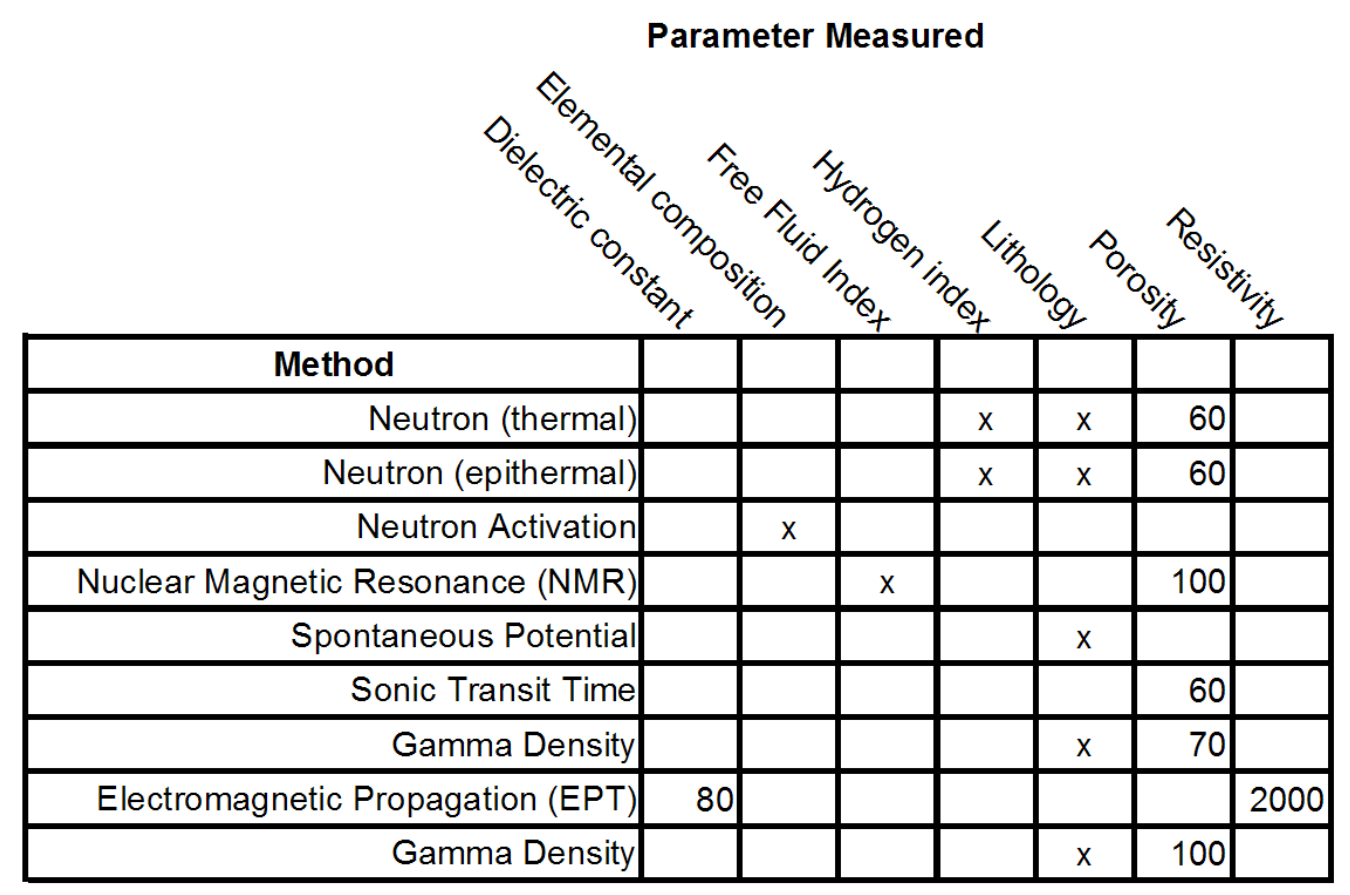

Table 3.9. Methods from Asquith and Krygowski (2004), and Other Sources

\begin{tabular}{|c|c|c|c|c|c|c|}
\hline Method & $\begin{array}{l}\text { Parameter } \\
\text { Measured }\end{array}$ & Comments & $\begin{array}{c}\text { Units (direct } \\
\text { and derived) }\end{array}$ & $\begin{array}{c}\text { Precision, } \\
\text { Resolution, }^{(b)}( \pm) \\
\text { Sensitivity }^{( \pm)}\end{array}$ & $\begin{array}{c}\text { Accuracy } \\
( \pm)\end{array}$ & $\begin{array}{c}\text { Range of } \\
\text { Values }\end{array}$ \\
\hline $\begin{array}{l}\text { Neutron } \\
\text { (thermal) }\end{array}$ & $\begin{array}{l}\text { Hydrogen index, } \\
\text { porosity, } \\
\operatorname{lithology}^{(\mathrm{c})}\end{array}$ & $\begin{array}{l}\text { Combined with } \\
\text { sonic and } \\
\text { gamma density }\end{array}$ & $\begin{array}{l}\text { Ratio to } \mathrm{H}_{2} \mathrm{O} \text {; } \\
\text { porosity units } \\
\text { (p.u.) }\end{array}$ & 0.4 p.u. ${ }^{(\mathrm{d})}$ & $\begin{array}{l}\text { Field: } 1 \text { to } 6 \\
\text { p.u. }^{(\mathrm{e})}\end{array}$ & $\begin{array}{l}\text { API: } 0 \text { to } \\
\text { 1000; } \\
\text { porosity: } 0 \\
\text { to } 60 \text { p.u. } \\
\text { (e) }\end{array}$ \\
\hline $\begin{array}{l}\text { Neutron } \\
\text { (epithermal) }\end{array}$ & $\begin{array}{l}\text { Energy; absorp- } \\
\text { tion; moderation } \\
\text { time (if pulsed); } \\
\text { Hydrogen index; } \\
\text { Porosity, } \\
\text { lithology }\end{array}$ & $\begin{array}{l}\text { Combined with } \\
\text { sonic and } \\
\text { gamma density }\end{array}$ & porosity units & $\begin{array}{l}1 \text { p.u. }{ }^{(\mathrm{d})} \text {, } \\
0.5 \text { to } 6 \text { p.u. }{ }^{(\mathrm{f})} \text {, } \\
2 \text { to } 3 \text { p.u. }\end{array}$ & $\begin{array}{l}\text { Lab: } 0.5 \%{ }^{(\mathrm{h})} \\
0.5 \text { p.u. to } \\
10 \%\end{array}$ & -10 to $60^{(\mathrm{g})}$ \\
\hline $\begin{array}{l}\text { Neutron } \\
\text { Activation }\end{array}$ & $\begin{array}{l}\text { Elemental compo- } \\
\text { sition: } \mathrm{Si}, \mathrm{Al}, \mathrm{C} \text {, } \\
\mathrm{O}, \mathrm{H}, \mathrm{Cl}, \mathrm{Ca}, \mathrm{Fe} \text {, } \\
\text { S, etc. }{ }^{\text {(i) }}\end{array}$ & $\begin{array}{l}\text { Different } \\
\text { techniques yield } \\
\text { different sets of } \\
\text { elements }\end{array}$ & $\begin{array}{l}\text { Ratios between } \\
\text { elements }\end{array}$ & $\begin{array}{l}254 \text { energy } \\
\text { channels }\end{array}$ & $2 \%^{(j)}$ & $\begin{array}{l}\text { Not } \\
\text { applicable }\end{array}$ \\
\hline NMR & $\begin{array}{l}\text { Free Fluid Index; } \\
\text { porosity }\end{array}$ & $\begin{array}{l}\text { Highly dependent } \\
\text { on acquisition } \\
\text { parameters, } \\
\text { including logging } \\
\text { speed } \\
\text { radial resolution: } \\
\text { radiales } \\
1.25,1.5,2.3,2.7 \text {, } \\
4.0 \text { inch }^{(l)}\end{array}$ & $\begin{array}{l}\mathrm{T}_{1} \text { and } \mathrm{T}_{2} \text { times } \\
\text { in ms; porosity } \\
\text { in p.u. }\end{array}$ & 0.5 to 1 p.u. ${ }^{(\mathrm{l})}$ & & $\begin{array}{l}0.4 \text { ms to } \\
9 \text { s; } 0-100 \\
\text { p.u. }{ }^{(l)}\end{array}$ \\
\hline
\end{tabular}




\begin{tabular}{|c|c|c|c|c|c|c|}
\hline Method & $\begin{array}{l}\text { Parameter } \\
\text { Measured }\end{array}$ & Comments & $\begin{array}{c}\text { Units (direct } \\
\text { and derived) }\end{array}$ & $\begin{array}{c}\text { Precision, } \\
\text { Resolution, }^{(\mathbf{b})}( \pm) \\
\text { Sensitivity }^{( \pm)}\end{array}$ & $\begin{array}{c}\text { Accuracy } \\
( \pm)\end{array}$ & $\begin{array}{c}\text { Range of } \\
\text { Values }\end{array}$ \\
\hline $\begin{array}{l}\text { Spontaneous } \\
\text { Potential }\end{array}$ & Lithology & $\begin{array}{l}\text { “... one of the } \\
\text { least understood } \\
\text { measurements } \\
. . . \text { (m) }\end{array}$ & $\begin{array}{l}\text { voltage }(\mathrm{mV}) ; \\
\text { salinity, shale, } \\
\text { invasion }\end{array}$ & $1 \mathrm{mV}^{(\mathrm{n})}$ & & Various $^{(0)}$ \\
\hline $\begin{array}{l}\text { Sonic Transit } \\
\text { Time }\end{array}$ & Porosity & $\begin{array}{l}\text { Combined with } \\
\text { gamma density } \\
\text { and neutron. } \\
\text { Some tools } \\
\text { provide radial } \\
\text { resolution }{ }^{(\mathrm{p})}\end{array}$ & $\begin{array}{l}\text { Time ( } \mu \mathrm{s}, \mathrm{ms}) ; \\
\text { sonic slowness } \\
(\mu \mathrm{s} / \text { foot) }\end{array}$ & $1 \mu \mathrm{s} /$ foot $^{(\mathrm{q})}$ & Lab: $0.5 \%^{(\mathrm{r})}$ & $\begin{array}{l}44 \text { to } 190 \\
\mu \text { s/foot }\end{array}$ \\
\hline $\begin{array}{l}\text { Laboratory } \\
\text { methods }\end{array}$ & Porosity & $\begin{array}{l}\text { Not a log } \\
\text { measurement }\end{array}$ & $\begin{array}{l}\text { porosity units; } \\
\text { percentage }\end{array}$ & & $0.5 \%^{(\mathrm{r})}$ & 0 to $70 \%$ \\
\hline $\begin{array}{l}\text { Gamma } \\
\text { Density }\end{array}$ & $\begin{array}{l}\text { Porosity, } \\
\text { lithology }\end{array}$ & $\begin{array}{l}\text { Active gamma. } \\
\text { Dual-energy } \\
\text { distinguishes bulk } \\
\text { density (porosity) } \\
\text { from lithology. } \\
\text { Combined with } \\
\text { sonic and neutron. }\end{array}$ & $\begin{array}{l}\text { Counts per } \\
\text { time interval; } \\
\text { API units }\end{array}$ & $\begin{array}{l}\text { PE [photo- } \\
\text { electric effect] } \\
\text { (lithology): } \\
5 \%(s)\end{array}$ & Lab: $0.5 \%^{(\mathrm{r})}$ & $\begin{array}{l}\text { Porosity: } \\
0 \text { to } 100\end{array}$ \\
\hline $\begin{array}{l}\text { Artificial } \\
\text { Formation }\end{array}$ & $\begin{array}{l}\text { Reference } \\
\text { porosity }\end{array}$ & $\begin{array}{l}\text { Primary } \\
\text { calibration } \\
\text { standard for } \\
\text { tools }\end{array}$ & p.u. & & 0.5 p.u. ${ }^{(t)}$ & 0 to 100 \\
\hline $\begin{array}{l}\text { Electro- } \\
\text { magnetic } \\
\text { Propagation } \\
\text { EPT }\end{array}$ & $\begin{array}{l}\text { Dielectric } \\
\text { constant, } \\
\text { Propagation time }\end{array}$ & $\begin{array}{l}1.1 \mathrm{GHz} \text {, } \\
\text { shallow }\end{array}$ & $\begin{array}{l}\text { Dielectric con- } \\
\text { stant (unitless), } \\
\text { slowness } \\
\text { (ns/m)x }\end{array}$ & & & $\begin{array}{l}1 \text { to } 80,3.3 \\
\text { to } 30 \mathrm{~ns} / \mathrm{m}^{\text {(u) }}\end{array}$ \\
\hline $\begin{array}{l}\text { Electro- } \\
\text { magnetic } \\
\text { Propagation }\end{array}$ & $\begin{array}{l}\text { Dielectric } \\
\text { constant, } \\
\text { Propagation time }\end{array}$ & $25 \mathrm{MHz}$, deep & $\mathrm{dB} / \mathrm{m}, \mathrm{ns} / \mathrm{m}$ & & & $\begin{array}{l}1 \text { to } 80,3.3 \\
\text { to } 30 \mathrm{~ns} / \mathrm{m}^{(\mathrm{u})}\end{array}$ \\
\hline $\begin{array}{l}\text { Electro- } \\
\text { magnetic } \\
\text { Propagation }\end{array}$ & Resistivity & $\begin{array}{l}2 \mathrm{MHz} \text { CDR } \\
\text { tool. Radial } \\
\text { resolution: Two } \\
\text { depths: } 30 \text { inch, } \\
50 \text { inch }^{\text {(v) }}\end{array}$ & $\mathrm{dB} / \mathrm{m}, \mathrm{S}$ & & & $\begin{array}{l}0.2 \text { to } 2,000 \\
\mathrm{ohm} \cdot \mathrm{m}^{(\mathrm{w})}\end{array}$ \\
\hline $\begin{array}{l}\text { Gamma } \\
\text { Density }\end{array}$ & $\begin{array}{l}\text { Bulk density, } \\
\text { lithology }\end{array}$ & $\begin{array}{l}\text { Active gamma. } \\
\text { Dual-energy } \\
\text { distinguishes bulk } \\
\text { density (porosity) } \\
\text { from lithology. } \\
\text { Combined with } \\
\text { sonic and neutron. }\end{array}$ & $\begin{array}{l}\text { Counts per } \\
\text { time interval; } \\
\text { API units }\end{array}$ & $\begin{array}{l}\text { Bulk density: } \\
0.01 \mathrm{~g} / \mathrm{cm}^{3}(\mathrm{~s}) \\
0.5 \% \\
\text { resolution }^{(\mathrm{x})}\end{array}$ & & $\begin{array}{l}\text { Density: } \\
\text { about } 1 \text { to } 3 \\
\mathrm{~g} / \mathrm{cm}^{3} \text { (y) }\end{array}$ \\
\hline Gamma Ray & Lithology & $\begin{array}{l}\text { Passive gamma: } \\
\text { Natural gamma } \\
\text { ray (gross } \\
\text { count); Spectral } \\
\text { gamma ray }\end{array}$ & $\begin{array}{l}\text { radioactivity } \\
\text { (counts); API } \\
\text { units }^{\left({ }^{2}\right)} \text {; shale, } \\
\text { U, Th, K }\end{array}$ & $\begin{array}{l}\text { Natural: } 4 \text { API } \\
\text { units } \\
\text { Spectral: } 5 \text { API } \\
\text { units }^{(z)}\end{array}$ & $\begin{array}{l}\text { [Several } \\
\text { empirical } \\
\text { formulas] }^{(\mathrm{aa})}\end{array}$ & $\begin{array}{l}\text { API: } 0 \text { to } \\
200^{(\mathrm{bb})}\end{array}$ \\
\hline $\begin{array}{l}\text { Resistivity } \\
\text { (ES) }\end{array}$ & Resistivity & $\begin{array}{l}\text { This method is } \\
\text { no longer used, } \\
\text { but is important } \\
\text { for analysis of } \\
\text { past data }^{\text {(cc) }}\end{array}$ & $\begin{array}{l}\text { DC voltage } \\
\text { (V); resistance } \\
\text { (ohm); } \\
\text { conductivity } \\
(\mathrm{mS} / \mathrm{m})^{\text {(dd) }}\end{array}$ & & $2 \mathrm{mS} / \mathrm{m}^{(\mathrm{ee})}$ & $\begin{array}{l}0.2 \text { to } 2,000 \\
\mathrm{ohm} \cdot \mathrm{m}^{(\mathrm{w})}\end{array}$ \\
\hline Induction & Resistivity & & $\begin{array}{l}\text { AC voltage }(\mathrm{V}) \text {; } \\
\text { resistance }(\mathrm{ohm}) \text {; } \\
\text { conductivity } \\
(\mathrm{mS} / \mathrm{m})^{(\mathrm{dd})}\end{array}$ & $\begin{array}{l}0.1 \mathrm{ohm} \cdot \mathrm{m} \\
\text { (shallow); } 0.25 \\
\mathrm{~S} \cdot \mathrm{m} \text { (medium, } \\
\text { deep) }\end{array}$ & $\begin{array}{l}0.40,0.75 \\
\mathrm{mS} / \mathrm{m}^{(\mathrm{ee})}\end{array}$ & $\begin{array}{l}\text { Best if } \\
\text { resistivity } \\
\text { less than } 125 \\
\text { ohm·m }{ }^{(g g)}\end{array}$ \\
\hline
\end{tabular}




\begin{tabular}{|c|c|c|c|c|c|c|}
\hline Method & $\begin{array}{l}\text { Parameter } \\
\text { Measured }\end{array}$ & Comments & $\begin{array}{c}\text { Units (direct } \\
\text { and derived) }\end{array}$ & $\begin{array}{c}\text { Precision, } \\
\text { Resolution, }^{((b)}( \pm) \\
\text { Sensitivity }^{( \pm)}\end{array}$ & $\begin{array}{c}\text { Accuracy } \\
( \pm)\end{array}$ & $\begin{array}{c}\text { Range of } \\
\text { Values }\end{array}$ \\
\hline Laterolog & Resistivity & $\begin{array}{l}\text { Low-frequency, } \\
60-84 \text { inch vs. } \\
24-36 \text { inch }^{\text {(hh) }}\end{array}$ & $\begin{array}{l}\text { AC voltage } \\
\text { (V); resistance } \\
(\text { ohm); } \\
\text { conductivity } \\
(\mathrm{mS} / \mathrm{m})^{(\mathrm{dd})}\end{array}$ & $0.2 \mathrm{ohm} \cdot \mathrm{m}^{(\mathrm{hh})}$ & & $\begin{array}{l}0.2 \text { to } 2,000 \\
\mathrm{ohm} \cdot \mathrm{m}^{\text {(w) }}\end{array}$ \\
\hline $\begin{array}{l}\text { Micro- } \\
\text { resistivity }\end{array}$ & Resistivity & $\begin{array}{l}\text { Good vertical } \\
\text { resolution }\end{array}$ & $\mathrm{V}$, ohms; mS/m & $0.1 \mathrm{ohm} \cdot \mathrm{m}^{(\mathrm{ii})}$ & & $\begin{array}{l}0.2 \text { to } 2,000 \\
\mathrm{ohm} \cdot \mathrm{m}^{(\mathrm{w})}\end{array}$ \\
\hline
\end{tabular}

These footnotes provide specific references where applicable; otherwise they are inferred by the authors from multiple sources.

a. $\mathrm{S}=$ siemens $(1 / \mathrm{ohm})$

b. Specifications of precision, resolution, and sensitivity are not clearly distinguished in the sources; hence they are summarized together. Where a source identifies one term or another, this is mentioned in the appropriate Note.

c. "BTW, contrary to [a] popular ... misconception by some researchers, both in the industry and academia, neutron tools are NOT used by oil companies for porosity measurements; it is a lithology indicator.” - private communication from Dr. Ahmed Badruzzaman, Ph.D. ANS Fellow (Sr. Staff Research Scientist and Nuclear R\&D Leader, Chevron Energy Technology Company, San Ramon, California 94583; Coordinator, SPWLA Nuclear SIG) to the authors, by email, May 23, 2010.

"Compensated neutron tools measure the hydrogen index of downhole formations. The measurements are converted to porosity values, which in combination with density tool measurements provide an indication of lithology and gas in zones of interest.... Because the CNT responds primarily to the hydrogen content of the formation, the measurements are scaled in porosity units....

"Applications

"ш Porosity determination

“ $\mathbf{m}$ Lithology identification

" $\backsim$ Gas detection

"- Correlation in cased wells" (Schlumberger 2004b)

d. Asquith and Krygowski (2004), p. NEU 2 (pdf 52), precision

e. Accuracy for four Schlumberger tools (CNT, SCNT, HGNS, QCNT) is listed as \pm 1 p.u. from 0-20 p.u., \pm 2 at 30 p.u., and \pm 6 at 45 p.u. (Schlumberger 2004b)

f. Web page, published by the The Integrated Ocean Drilling Program, United States Implementing Organization (IODPUSIO).

$$
\begin{aligned}
& \text { Epithermal porosity: } \\
& \text { 0-7 pu: } \pm 0.5 \mathrm{pu} \\
& \text { 7-30 pu: } \quad \pm 7 \% \\
& \text { 30-60 pu: } \quad \pm 10 \%
\end{aligned}
$$

g. Precision: Approximate figure, based on analysis (later in this section) of a Schlumberger plot in the October 1994 issue of Oilfield Review (Schlumberger 1994).

Range: Halliburton: Dual-Spaced Epithermal Neutron (DSENSM) Porosity Log Service

http://www.halliburton.com/ps/default.aspx?pageid=319\&navid=712

Range and accuracy: Schlumberger: APS sonde, Brochure SMP-5167, 2002

APS measurement, Near-to-array epithermal porosity

$$
\begin{aligned}
& 0-7 \text { p.u. } \pm 0.5 \text { p.u. } \\
& 7-30 \text { p.u. } \pm 7 \% \\
& 30-60 \text { p.u. } \pm 10 \%
\end{aligned}
$$

h. Schlumberger (1989), page 5-20, indicates that porosity tools are calibrated on a standard known to \pm 0.5 porosity units.

i. Relative amounts (ratios) are measured. Schlumberger Oilfield Glossary, on Schlumberger's website, http://www.glossary.oilfield.slb.com/Display.cfm?Term=neutron-activation\%20log and http://www.glossary.oilfield.slb.com/Display.cfm?Term=elemental\%20capture\%20spectroscopy

j. Accuracy details: “Elemental statistical uncertainty at nominal conditions (1,800-ft/hr logging speed, resolution degradation factor of 5, 16,000-cps count rate, and closure normalization factor of 3): Si 2.16\%, Ca 2.19\%, Fe 0.36\%, S 1.04\%, Ti 0.10\%, and Gd 3.48 ppm.” Both precision and accuracy are from Schlumberger brochure "ECS Elemental Capture Spectroscopy Sonde” (Schlumberger 2004a). 


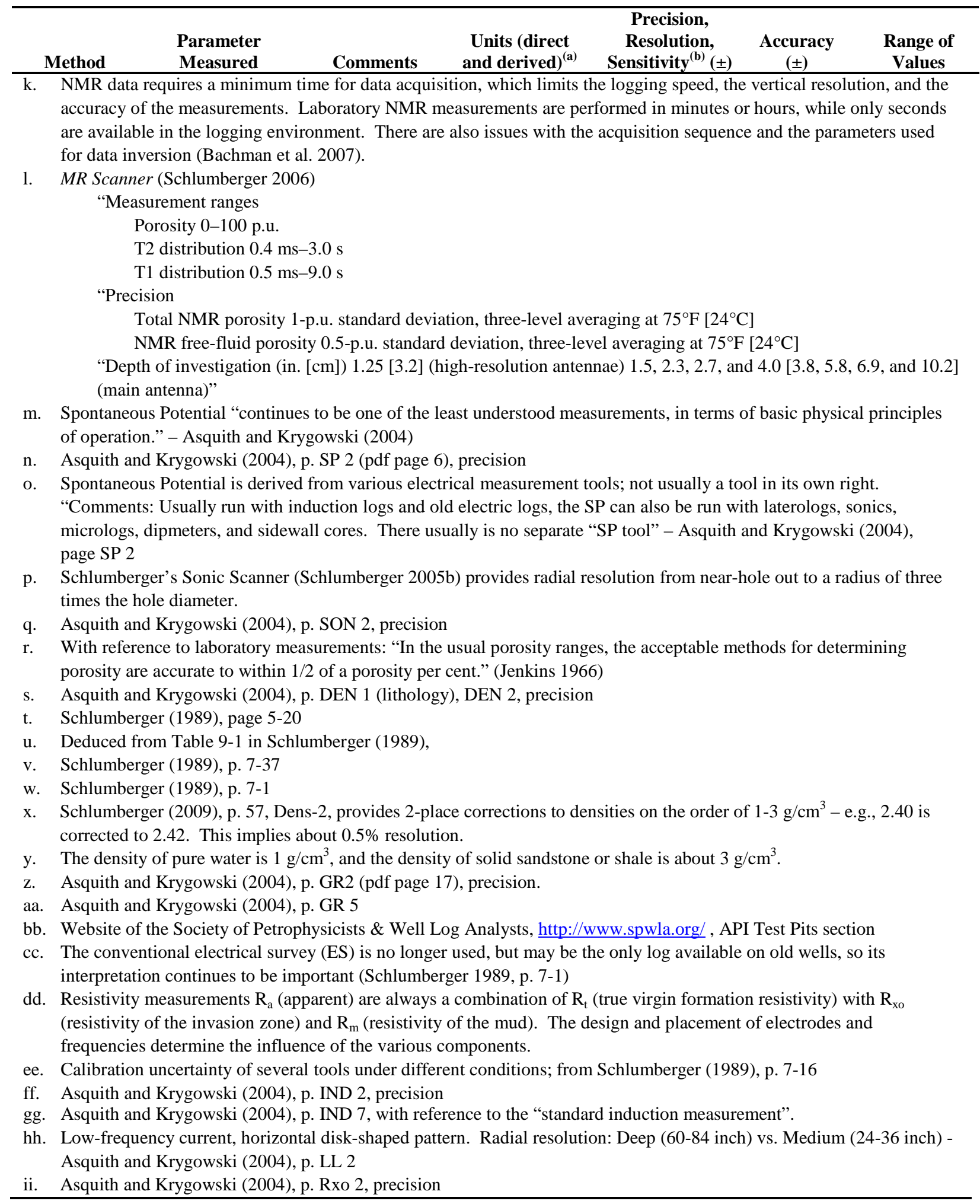


Along with accuracy, another conventional measurement metric is the ratio of signal to noise. While this does have some application in well logging, generally logging methods are designed (or redesigned, when necessary) to treat all data as signal. When noise is found, the source of it is frequently of interest in its own right. Thus, while the concept is acknowledged in well-logging literature, it is not usually evaluated, nor is it cited as a figure of merit.

A useful measure for the value of well-logging data is probability of correctness, also known through its complement, uncertainty. This is easier than accuracy to quantify in the well-logging domain, because it can be referred to experience. After the use of a method in (say) 100 holes, there will be a certain number in which the method has been found to correspond to an expected outcome. This number can then be cited as a percentage value for confidence in the method - as long as the well in question has enough similarity to the 100 others.

In the days of paper charts, there was an obvious criterion for resolution: the interpolation of data on the chart, based on grid spacing and line widths. With digitized measurements, the resolution could be asserted as one bit, though this depends on details of the conversion from analog to digital form.

The issues with well logging methods can be seen as a special instance of the disparity between data and knowledge, a topic of intense research in many fields today. It is challenging to make well-logging measurements (data), but the difficulty of interpretation of the measurements (turning the data into knowledge) is becoming appreciated as perhaps even more difficult than acquiring the data in the first place.

It may be appropriate to consider some kind of "figure of merit" for different logging methods. This would express the value of the method for the purpose of accurately predicting well performance. The authors do not have a specific proposal for such a figure of merit at this time.

Logging specialists have been supplemented (but certainly not supplanted) by sophisticated statistically oriented computer methods, including artificial intelligence, neural networks, etc. The necessity of using these types of process is an indicator of the inadequacy of the numerical data obtained from logs. An example in the literature is the recent paper by Kadkhodaie-Ilkhchi et al. (2009).

It would be very interesting to examine statistics relating the predictions of well logging to the actual pay of the well. Such statistics are not readily available, at least in the public domain. However, statistics that are freely and publicly available concern the drilling and production of wells and the estimated "proven" reserves. Even the fact that the term "proven" simply means "estimated from actual well logging” (as distinct from estimates derived from surface-based interrogation) is an indication of the general uncertainty inherent to petroleum exploration and production. The great number of dry wells (over 50\% in some areas, according to a review of various U.S. oil maps) indicates the difficulty of predicting pay before drilling. And the changes from year to year in the "proven" reserves indicate the uncertainty that remains even during the production phase.

In the absence of general statistics, in order to get a sense of the statistical variation of logs in individual wells, two examples of plotted logs were analyzed. One was a plot from Schlumberger, showing several tools, including Near-to-far Porosity and CNL Neutron porosity. The other was a repeat section by Tucker Wireline Services, showing the Compensated Sonic Travel Time. Each plot was converted through image analysis to a table of values, then re-plotted to confirm that the data had been 
digitized correctly. The tables were then analyzed for sections of unusually large variation. Histograms and statistical measures such as the standard deviation were computed, both with and without the regions of high variability.

The Schlumberger plot comes from an article in the Oilfield Review, October 1994, discussing the APS Accelerator Porosity sonde (Schlumberger 1994) [more complete reference for Schlumberger 1994 as follows: It is from an article, "Neutron Porosity Logging Revisited.” It refers to a figure captioned, "Comparison of APT and CNL logs run in an Oklahoma well." It is on page 7 of Oilfield Review, issue of October 1994.]. The comparison was made between a run of the Accelerator Porosity Tool's Near-toFar Porosity Sandstone Corrected trace (FPSC) and a trace from a separate run of the CNL Neutron porosity (TNPH). Both of these neutron traces were plotted together in the article, in different colors, with a porosity axis range of 0 to 60 porosity units (p.u.). The article comments that the two logs would be close to the same, once the CNL porosity was corrected by about 6 p.u. An analysis was performed by the present authors to see how close the traces would be after application of the recommended correction factor. That is, how much difference would there be in the details of the two traces, and what would be the standard deviation of the distance between them? The traces were converted, using a screen capture image, providing a data point about every 6 inches, which fully captured the detail in the traces. When adjusted for a best fit, the traces were almost always within 3 p.u. of each other, with a standard deviation of about 1.5 p.u. Figure 3.4 shows the two traces extracted and overlaid, with a small depth alignment correction.

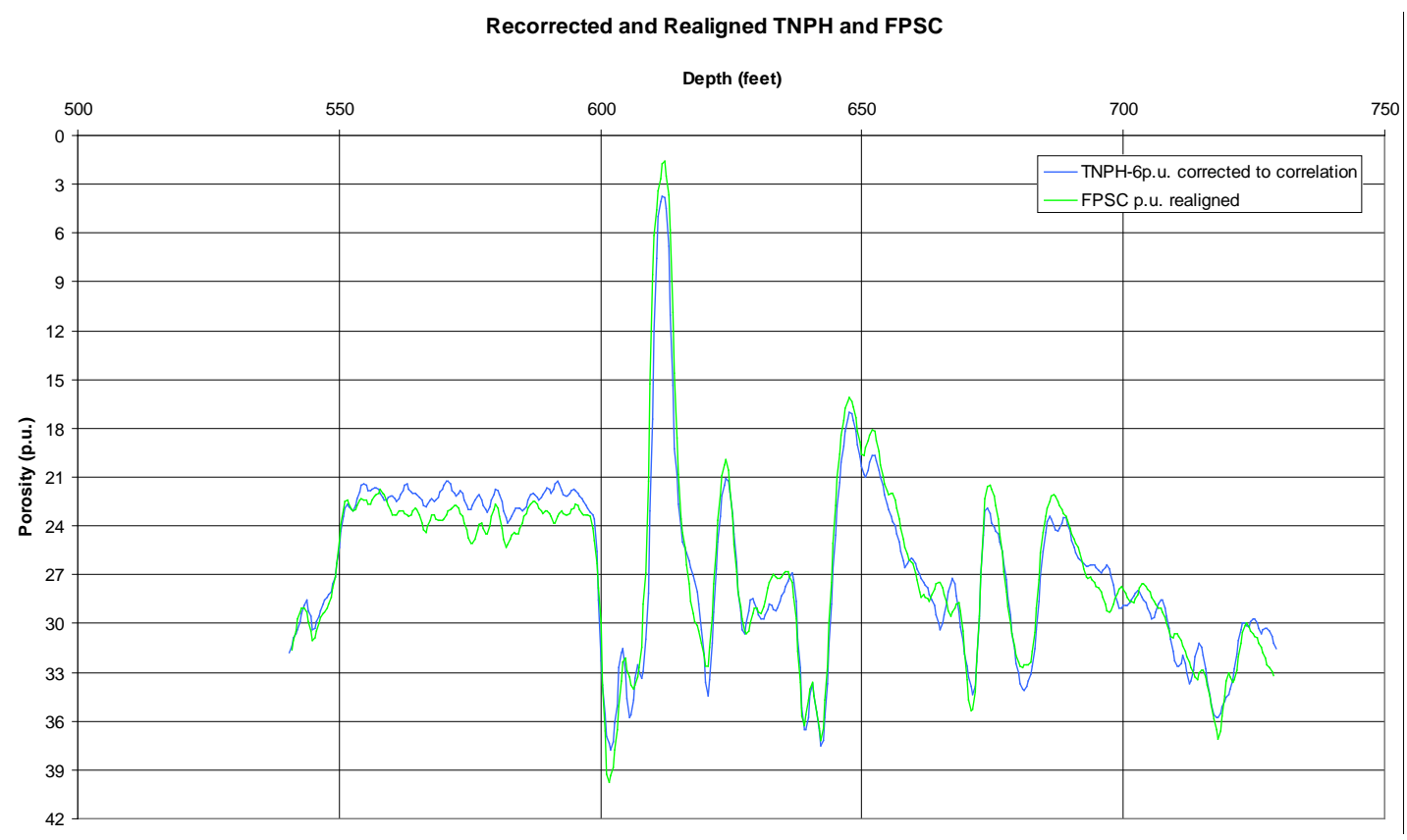

Figure 3.4. Schlumberger Data, Comparison of Accelerator Porosity Tool's Near-to-Far Porosity Sandstone Corrected Trace (FPSC) and a Trace from a Separate Run of the CNL Neutron Porosity (TNPH)

Some of the variation between the tools is a result of thin formation layers, where the two tools change rapidly at different rates. If these large excursions are excluded, the standard deviation drops to about 0.5 p.u. A histogram of the differences shows some asymmetry and a broad, fairly flat peak 
(Figure 3.5) with the mean and median close together. In summary, "close to the same” seems to mean "within \pm 2 to 3 p.u. in most regions." This corresponds well to the values given in Table 3.9 for thermal and epithermal neutron tools.

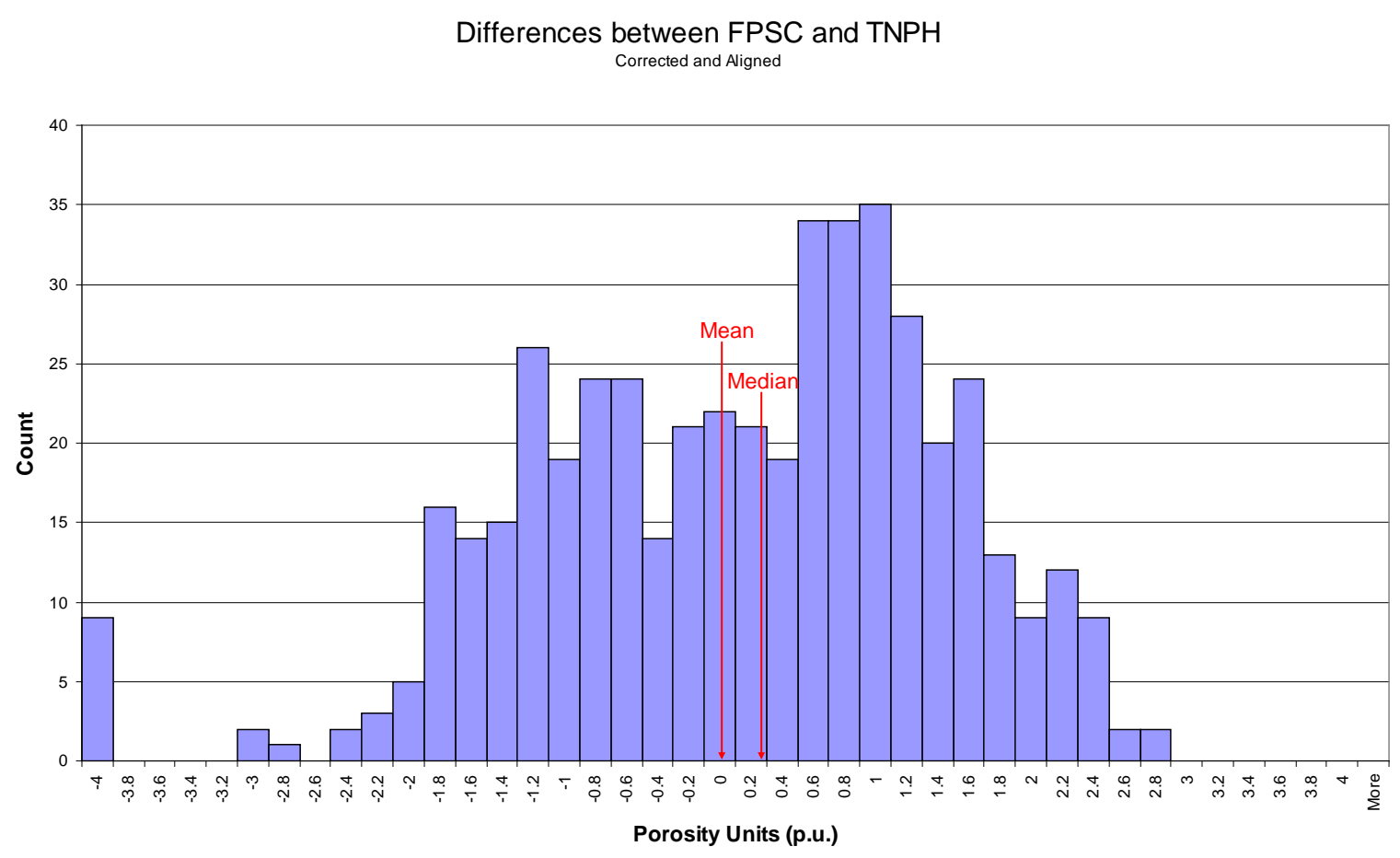

Figure 3.5. Histogram of Difference Between Two Porosity Traces in Schlumberger Example

The Tucker Wireline plot of Compensated Sonic Travel Time comes from the Canadian Well Logging Society's Test Files repository (page http://www.cwls.org/logtests.php , file http://www.cwls.org/tifflogs/tucker_sonic_demo.tif ). The file is a large gray-scale image file containing a full log over a depth range of $800 \mathrm{~m}$ plus a $100-\mathrm{m}$ repeat section of part of the full log from 920 to $1015 \mathrm{~m}$, with a range of 100 to $500 \mu \mathrm{s} / \mathrm{m}$ and an over-range display from 500 to $900 \mu \mathrm{s} / \mathrm{m}$. For the analysis, the repeat section was overlaid on the full log for visual comparison, and the two curves were extracted and compared for analytical comparison. In this case the two traces are from the same tool but different runs. Figure 3.6 shows the two plots extracted and overlaid. The standard deviation of their difference, including the region with large variation, is $18.8 \mu \mathrm{s} / \mathrm{m}$; with those sections removed, it drops to $3.8 \mu \mathrm{s} / \mathrm{m}$, which is somewhat greater than the corresponding value for precision for Sonic Transit Time given in Table 3.9.

There was one section of about 3 meters over which the two logs were markedly different (by over $100 \mu \mathrm{s} / \mathrm{m}$ ) but for the most part the differences were less than $\pm 5 \mu \mathrm{s} / \mathrm{m}$, with a standard deviation of $3.8 \mu \mathrm{s} / \mathrm{m}$. Figure 3.7 shows a histogram of the difference between the main and repeat logs, with the abnormal sections removed. 
Tucker Log and Repeat

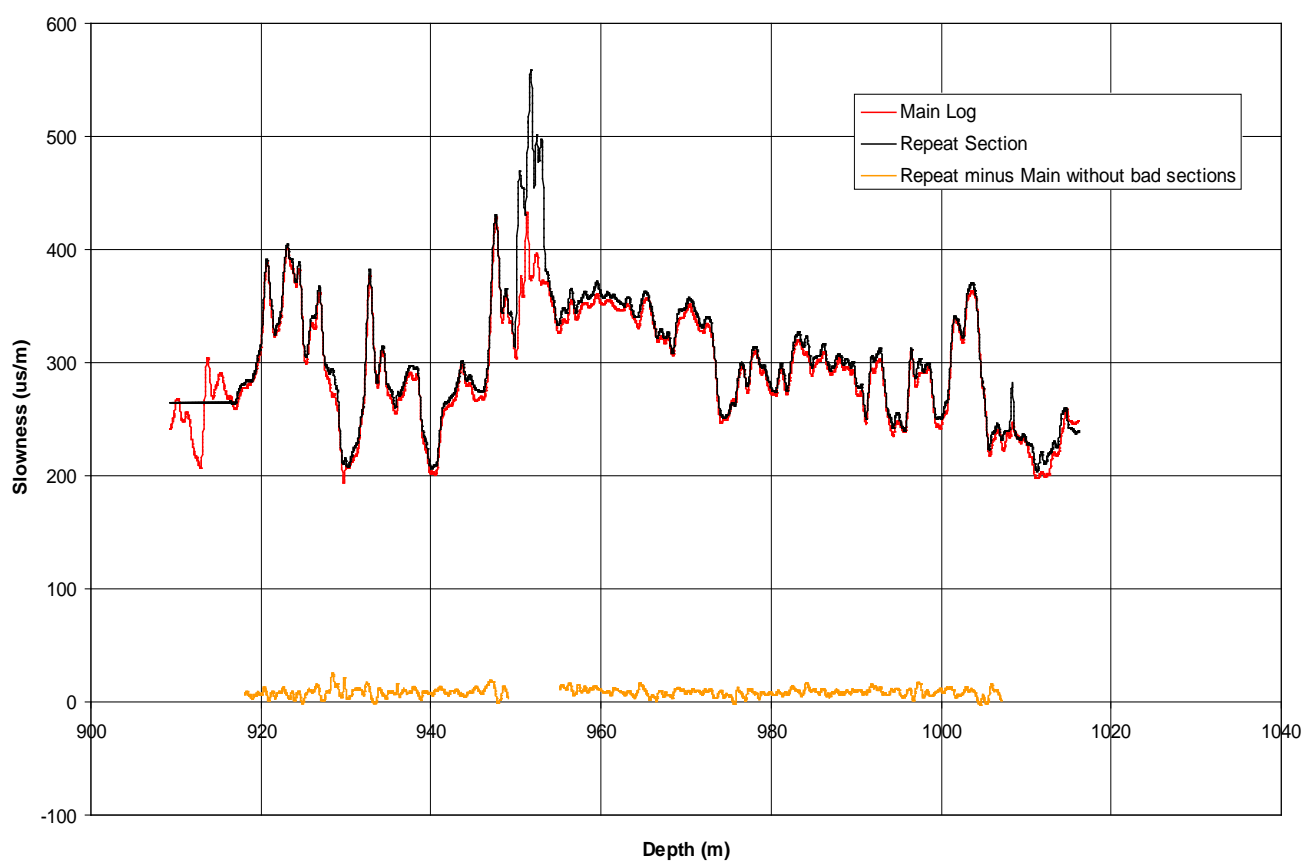

Figure 3.6. Tucker Log: Main Run and Repeat Run

Tucker Repeat Minus Main without abnormal sections

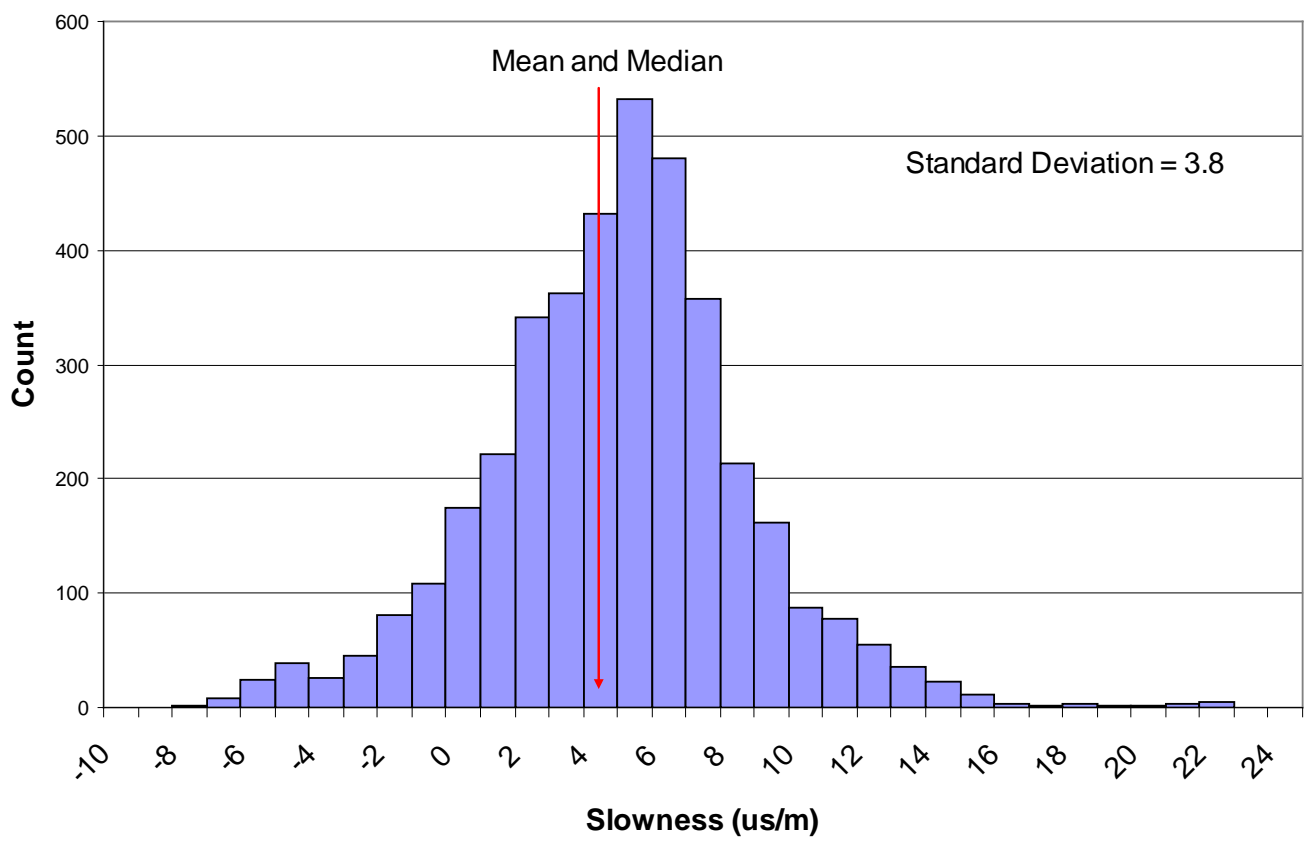

Figure 3.7. Histogram of Difference Between Tucker Main Log and Repeat Section (regions with large excursions removed) 
An interesting sidelight on the accuracy of log interpretation can be gained by reading the caveats included by all the major well logging companies with their log data. They point out that the interpretations are based on inferences from electrical measurements or other measurements. Some explicitly state that the company provides no interpretation whatsoever, and that any interpretation provided by their employees is a casual conversation and not part of the paid services provided. Others indicate that accuracy of interpretation cannot be guaranteed and that the logging company will not be liable for any results stemming from the interpretations.

\subsubsection{Volumetric Variations and Their Relation to Measurement}

The earth is not homogeneous; if it were, there would be no oil deposits. A significant difficulty in well logging is that the scale of the instruments does not always correspond to the scale of inhomogeneity of the formations. This applies in all three dimensions: parallel to the drilling direction, radially perpendicular to the drilling direction, and angularly (azimuthally) around the drilling direction.

Orientation terminology can be somewhat awkward in a discussion of logging measurements, because the direction of drilling is not always vertical, and because both the drilling direction and the radius may be referred to as "depth.” In the drilling direction, in a vertical section, the tool's sensing field often extends across multiple formation layers, providing some sort of an "averaged" response to the strata, which may be difficult or impossible to deconvolve. In the radial dimension, the radius (depth) of sensitivity is limited and the sensitivity decreases with distance; the sensitivity of the tool is usually highest close to the borehole, giving undue emphasis to drilling effects such as the drilling mud itself, invasion of the mud into the formation, and washout of the borehole wall. In the angular (azimuthal) dimension, each tool has some angular window, either narrow or wide (up to 360 degrees). If the window is narrow, then the tool is sensitive to its direction, and gives a result that may not be characteristic of the formation, as there is seldom the opportunity to rotate the tool at each vertical position (generally no rotation in wireline logs, and a spiral rotation in logging-while-drilling logs). If the window is wide, then there is no way to know with certainty whether the result is a true reading of the formation, or an "average" of different formation characteristics. In an angled or horizontal section, the radial and angular variations may include multiple layers, further complicating the interpretation.

Figure 3.8 is a graphical presentation of the vertical resolution, maximum penetration, and finest (smallest) resolution of typical tools for several logging methods. It diagrams a 20-cm borehole as a vertical cylinder and the effective interrogation region of each logging method as a colored wedge. The radial size of the wedge is the penetration depth. The vertical thickness of the wedge is the vertical resolution. The angular extent of the wedge (ranging from 1 degree to 360 degrees for the various tools) is the minimum azimuthal resolution of the method. Some of the tools, such as the microresistivity pad, consist of an array; this diagram shows the sensing pattern of a single element of the array. The purpose is to display graphically the capabilities, in terms of penetration depth and resolution, of each method. The details and numerical values for each method are shown in Table 3.10. 


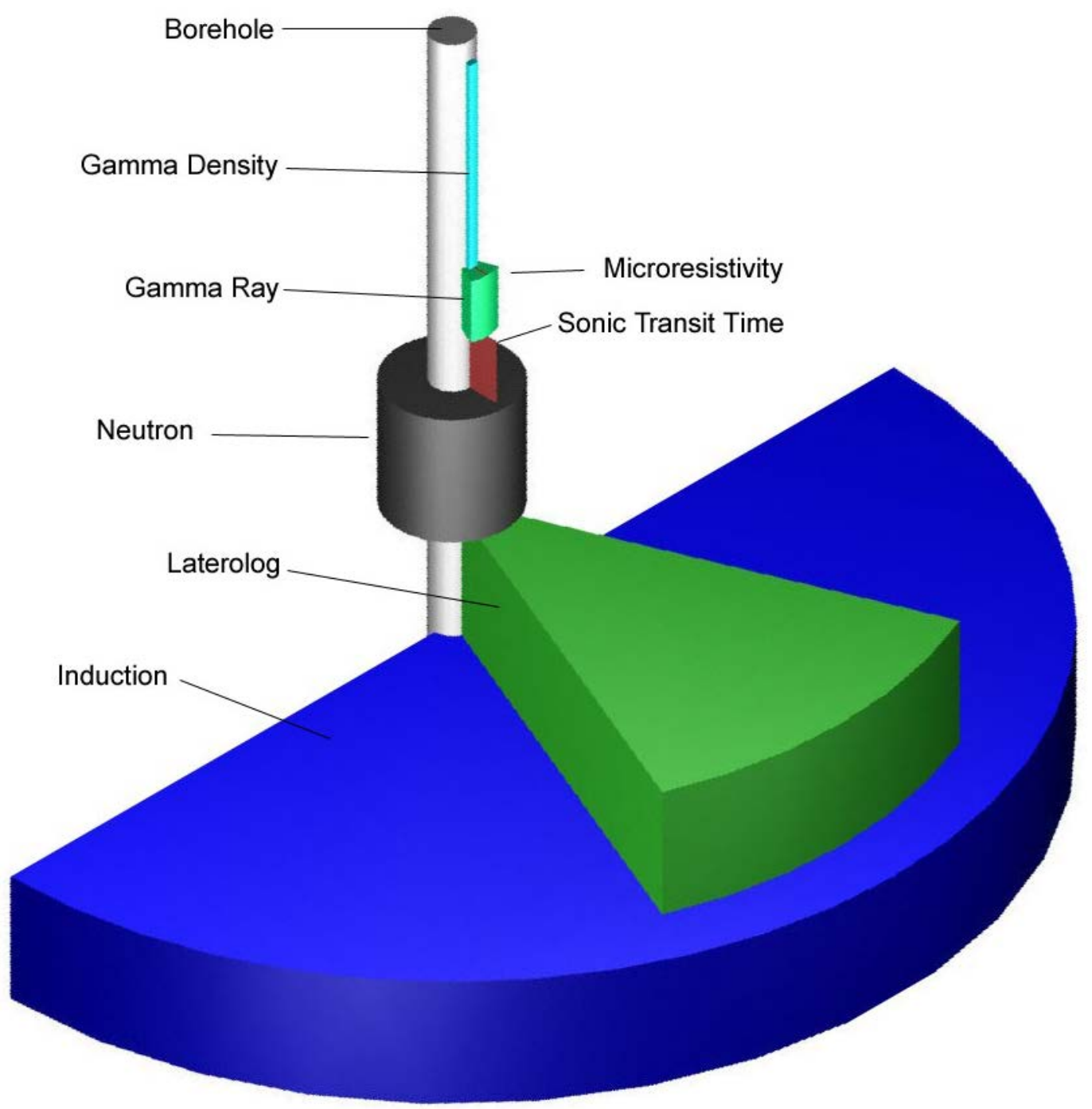

Figure 3.8. Vertical Resolution, Maximum Penetration, and Finest Azimuthal Resolution of the Tools Characterized in Table 3.10, Scaled to a 20-cm Borehole. The microresistivity tool is the thin red line between the two gamma tools.

Table 3.10 (an expansion and slight revision of Table 3.7) displays details of the parameters of the tools shown in Figure 3.8. The angular (or azimuthal) resolution is given as a range. Most wireline tools do not provide any azimuthal resolution, as they are cylindrical detectors, with an azimuthal resolution indicated as "none.” However, logging-while-drilling tools often have an angular dependence, leading to the resolution shown in the table. In connection with all of the tabulated values (vertical, radial, and azimuthal) it is interesting to note that Phillippe Theys, who served as the director of data quality at Anadrill/Schlumberger, felt that single figures for depth of penetration and vertical resolution (and by extension, azimuthal resolution) are inadequate to accurately express tool behavior; thus these figures should not be considered as definitive, but merely indicative (Theys and Flaum 1991). 
Table 3.10. Depth and Resolution of Investigation by Method

\begin{tabular}{|c|c|c|c|c|}
\hline Method & $\begin{array}{l}\text { Parameter } \\
\text { Measured }\end{array}$ & Resolution (Vertical) & $\begin{array}{l}\text { Depth (Radius) of } \\
\text { Penetration }\end{array}$ & $\begin{array}{c}\text { Angular } \\
\text { (Azimuthal) } \\
\text { Resolution Limit }\end{array}$ \\
\hline Gamma Density & Porosity & $1 \mathrm{~m}(3 \mathrm{ft})$ & $2.5 \mathrm{~cm}$ (1 in.) & $22.5^{\circ}[$ Note 1$]$ \\
\hline Gamma Ray & Lithology & $30-100 \mathrm{~cm}(1-3 \mathrm{ft})$ & $10 \mathrm{~cm}$ (4 in.) & $45^{\circ}$ [Note 2] \\
\hline Induction & Resistivity & $60 \mathrm{~cm}(2 \mathrm{ft})$ & $0.3-2.4 \mathrm{~m}(1-8 \mathrm{ft})$ & $180^{\circ}$ \\
\hline Laterolog & Resistivity & $60 \mathrm{~cm}(2 \mathrm{ft})$ & $0.6-2.1 \mathrm{~m}(2-7 \mathrm{ft})$ & $45^{\circ}$ [Note 3] \\
\hline Microresistivity & Resistivity & $\begin{array}{l}0.25-7.5 \mathrm{~cm} \text { ( } 1-3 \text { in.) } \\
\text { [Note } 3 \text { ] }\end{array}$ & $2.5-10 \mathrm{~cm}(1-4$ in. $)$ & $\begin{array}{l}0.25-7.5 \mathrm{~cm} \\
{[\text { Note } 4]}\end{array}$ \\
\hline Neutron & Porosity & $60-00 \mathrm{~cm}(2-3 \mathrm{ft})$ & $15-20 \mathrm{~cm}$ (6-8 in.) & Little to none \\
\hline Sonic Transit Time & Porosity & $30 \mathrm{~cm}(1 \mathrm{ft})$ & $15 \mathrm{~cm}$ (6 in.) & $90^{\circ}$ to $1^{\circ}$ [Note 5 ] \\
\hline Spontaneous Potential & Lithology & Reciprocal of porosity & Shallow, variable & None \\
\hline
\end{tabular}

Notes:

1. Shipboard Scientific Party (2002, Ch. 2, Explanatory Notes, pg. 8) mentions “four quadrants of azimuthal data” in connection with a gamma density tool. (Hinz and Wilson 2006) mentions 16 azimuthal bins of gamma-ray data for the Halliburton Sperry azimuthal lithodensity imaging sensor.

2. CBG Corp.'s brochure “Gamma-Ray Tools for Geosteering, MWD and Wireline Logging” (Undated) shows a diagram labeled “CBG Azimuthal Gamma-Ray Response," with 45-degree increments between data points. The specifications (p. 4) do not include an azimuthal resolution.

3. Schlumberger's HALS (High-Resolution Azimuthal Laterolog Sonde) provides azimuthal information. While the azimuthal resolution is not specified, plots from HALS (Schlumberger 2001, pg. 9) seem to display a resolution of about $45^{\circ}$.

4. While $2.5 \mathrm{~cm}$ is given in some sources as the best resolution, Payenberg et al. (2000) indicates that the Schlumberger Formation MicroScanner and Fullbore Formation MicroImager provide resolution as fine as $0.25 \mathrm{~cm}$ in both vertical and azimuthal directions.

5. Readings are taken at $90^{\circ}$ separation. For anisotropy measurements, they can then be processed using Alford rotation or other processing to provide directional velocity accurate to $1^{\circ}$. Bose (2002) provides theoretical limits from $0.1^{\circ}$ to $10^{\circ}$ or more, as a function of noise and degree of anisotropy. Tao et al. (2006) shows examples of unlike waveforms, in which raw processing leads to errors of $90^{\circ}$, while wavelet processing provides results that appear reasonable within a few degrees, though there is no true state against which to measure the results.

\subsubsection{Variability of Some Important Parameters}

Permeability is one of the most important petrophysical parameters. Thus it may be surprising that the notion of "similar" for permeability generally means "within an order of magnitude," and that predictions that are accurate within a factor of five are cited as "accurate" or "reasonable." The paper by Pape et al. (1999) gives some insight into this. It has a graph (Figure 6 in that paper) that displays vividly the degree of inhomogeneity in a formation, as well as the concept of "similar." It shows a well log overlaid with measured core values. The vertical resolution of the graph is about one meter. The porosity varies by as much as $15 \%$ over a single increment (i.e., a meter). The permeability varies by 3 to 4 orders of magnitude (i.e., a factor of 1,000 to 10,000 ) at the same scale. Both these variations are confirmed by core samples as well as the log results. The individual values for core versus log permeability are typically within the local limits of variation, but sometimes appear as outliers by one to two orders of magnitude. Figure 3.9 is a histogram of the difference between core measurements of porosity and the log values, using values extracted from the "a" portion of the graph. The permeability measurements are 
similar, with the modification that 5 units of porosity correspond to about one order of magnitude of permeability. Figure 3.9 shows that about half of the logged porosity values correspond within one unit to the core measurement, with the other half spread across \pm 5 p.u. Correspondingly, the calculated permeability values will be mostly within a factor of two of their measured core values, with the remaining half spread across \pm 2 orders of magnitude (i.e., within a factor range of 0.1 to 10 ).

Log versus core porosity

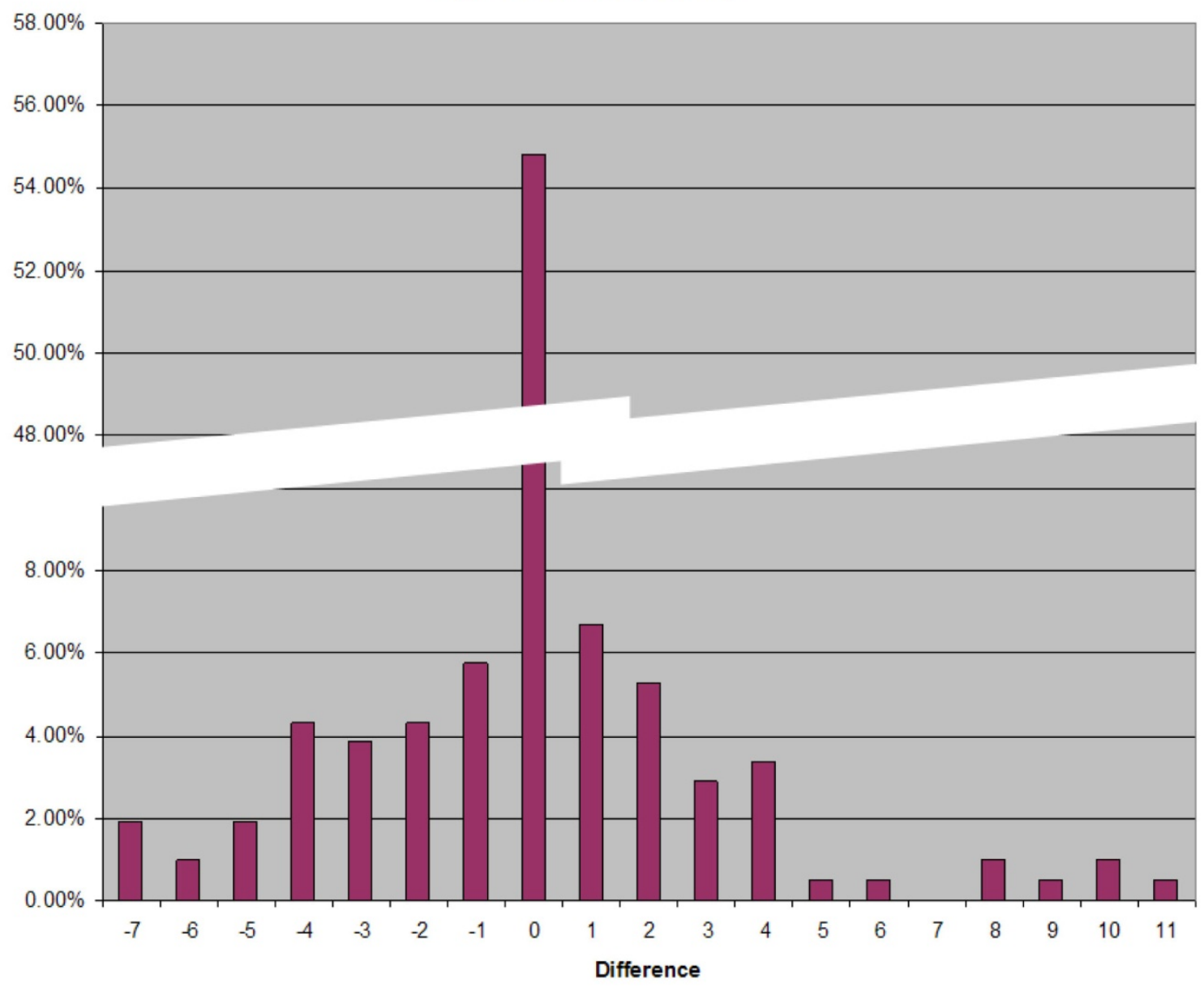

Figure 3.9. Histogram of the Difference Between Measured Core Porosity and Calculated Log Value of Porosity, Extracted from Figure 6a of Pape et al. (1999).

Another paper (Ayan et al. 1994) points out that an accurate local value of permeability may not be relevant, since there may be a high-permeability path around a low-permeability zone; or conversely, a high-permeability zone may be surrounded by low-permeability formation. In either case, an average of local values would not provide meaningful information.

Ayan et al. (1994) also points out that there are two kinds of volumetric variability of importance: heterogeneity (inhomogeneity) and anisotropy. Heterogeneity refers to variations in geophysical parameters from one location to another. Anisotropy refers to variations in (some) geophysical parameters at a single point when measured in different directions. All parameters are subject to 
heterogeneity, while only certain parameters (such as permeability) can exhibit anisotropy. Permeability anisotropy is of particular interest, as it determines whether oil can flow, for example, horizontally or vertically, and thus influences the (expensive) decision to drill horizontally.

The paper (Anderson et al. 1994) tabulates anisotropy as applying to dielectric constant, magnetic properties, permeability, resistivity, rock strength, thermal conductivity, and wave velocity. Heterogeneity is applicable to all the preceding plus density, natural gamma ray activity, neutron-capture cross section, porosity, saturation, wettability, mineralology, grain size, grain shape, sorting, packing, bedding, foliation, folding, jointing, and faulting. In relation to this, it is noteworthy that neutron measurements in particular are sensitive to heterogeneity but not (directly) to anisotropy.

\subsubsection{The Significance of Heterogeneity}

Heterogeneity is the foundation of well logging. If the earth were homogeneous, either there would be no oil wells, or any hole dug anywhere would slowly fill with oil, just as a hole at the beach fills with water. In fact, the degree of heterogeneity of oil formations varies greatly from one formation to another. Detection and characterization of local formation properties is the purpose of well logging. Before drilling has commenced, surface-based sensors and sensors in nearby wells (if they exist) have been used in order to determine that drilling is likely to be useful. During the course of drilling, a suite of sensors is used to map the properties of the formation, with particular attention to porosity, permeability, and presence of fluids. The simplest formations to develop are the most homogeneous, and they were the earliest ones to be exploited. Current exploration is primarily in very heterogeneous environments, and requires far more sophisticated methods than were used in the early days of oil drilling.

Neutron tools are particularly valued for their ability to detect heterogeneity of lithology, through spectroscopy of induced gamma radiation, and through analysis of neutron porosity. This information is used in conjunction with other data to answer the important questions: "Where is there oil?", "Can the oil be extracted?", and "What is the best way to extract it?” Otherwise, heterogeneity of lithology in and of itself is of no special interest to oil exploration, as it might be to earth science or geology.

The horizontal scale of heterogeneity may be far greater than the range of penetration of neutron tools. In that case, sonic and electromagnetic methods, possibly between wells or from surface to well, are the tools of choice to measure the heterogeneity. Neutron tools can, however, help provide much of the same information as core samples, at a far lower cost.

\subsubsection{The Significance of Anisotropy}

Anisotropy is of vital importance in well drilling. The anisotropy of greatest interest is that of permeability. This determines the direction of oil flow, whether a horizontal well section is needed, and the direction in which to drill horizontally.

Anisotropy can occur at any scale, from nanometers to kilometers. At small scales, it is thought of as a material property, such as vertical or horizontal permeability. At large scales it is thought of as a geometric property, such as a vertical fault or the dip and azimuth (slope and downhill direction) of a formation. Large-scale anisotropy is necessarily accompanied by heterogeneity, while small-scale anisotropy can be either homogeneous or heterogeneous. 
As indicated above, neutron logs are not used to measure anisotropy, for the following reasons. Azimuthal sensitivity is a prerequisite to making measurements of anisotropy. Neutrons cannot be effectively shielded or directed, and the nature of the neutron diffusion measurement is inherently isotropic. Thus neutron measurements have little or no azimuthal variation, and are not able to measure anisotropy.

\subsubsection{Fractals in Petrophysics}

Fractal dimension has significance for formation evaluation, and is applicable to neutron and other logging measurements. The fractal dimension of a random structure refers to an exponential dependence of certain statistical parameters on the scale at which the parameters are measured. The fractal dimension is expressed as a decimal number. It is closely related to the ratio of surface area to volume, and hence to the relationship between porosity and permeability in the formation (Riepe 1998). Not only the threedimensional physical structure, but also the one-dimensional traces of log measurements have fractal dimensions, and the fractal dimensions of the log and the structure are related, though not in a trivial way (Arizabalo et al. 2006).

Fractal dimension of a structure is a rather subtle concept. In the popular literature, fractals are described as self-similar structures, and one sees curious and beautiful examples of analytic fractals. In geophysics, however, the fractal nature is statistical rather than analytic, and, unlike the analytic examples, there are upper and lower bounds to the fractal behavior. This has led to complaints by "purists" that these are not fractals at all. This complaint, however, is founded on confusion between analytic and statistical fractal behavior. Moreover, geologic fractals may be self-affine rather than selfsimilar, which further complicates the description and the mathematics involved. What is important to the use of fractal analysis in petrophysics is that it does give useful results, and there are sound physical and mathematical reasons for those good results (Radlinski et al. 2000).

Pape et al. (1999) discusses methods of calculating fractal dimensions of core samples. The paper describes a relationship between the formation factor, tortuosity, and porosity, and shows examples of correlations between these (nominally independent) parameters. It shows that the fractal dimension can be used to relate effective pore radius, tortuosity, and porosity, and concludes that the fractal dimension can be regarded as "the fundamental geometric parameter for the description of the pore-space structure" (Pape et al. 1999, pg. 1458). It further describes a relationship, based on fractal theory, between permeability and porosity, thus allowing prediction of permeability from porosity (preferably in conjunction with other log measurements), provided the fractal dimension of the formation is known. This provides a means by which neutron logs can be used in determining permeability.

\subsection{Differences between Chemical (Isotopic) and Electronic (Accelerator) Neutron Sources}

Neutron logs acquired with low-energy (average n-energy $5 \mathrm{MeV}$ ) chemical neutron sources are fundamentally different from those acquired with high energy (14 MeV) electronic D-T neutron sources. The differences arise from: 
1) The geometry of the interrogated region

a) High energy neutrons penetrate deeper into the formation (well beyond the invaded zone) before reaching thermal energies

b) The directionality of electronic neutron sources results in a non-isotropic sampling volume

2) The larger sampling volume (accruing to an electronic source) means a significant fraction of the emitted neutrons (and induced gammas) are lost to the formation (i.e., the neutrons and the associated gammas do not return to $\mathrm{NaI}$ or ${ }^{3} \mathrm{He}$ detectors in the tool)

3) The gamma spectrum generated by D-T inelastic neutron scattering is shifted to higher energies Differences in "neutron log signatures" will slow adoption of electronic neutron sources for relogging applications. These archived well logs were probably acquired using AmBe sources. This disparity in log characteristics can only be addressed with a significant computational and experimental research program. Suggestions for these program components are:

1) Use of Monte-Carlo neutron transport models (e.g., MCNP) to understand differences in low- and high-energy neutron logs arising from a given formation. Ideally, after validation, the modeling results could be used to derive a "transformation algorithm" suitable for simulating a low-energy neutron response from data acquired using a high-energy electronic neutron source.

2) An in-field experimental effort where neutron log data are acquired using both chemical and electronic neutron sources in the same wells. Acquiring low/high energy neutron data on identical formations with different tools can be used to validate computational neutron transport models and aid the development of a "translation algorithm."

3) The relative similarity of the neutron spectrum from the T-T reaction (Wong et al. 1965) and AmBe sources (Guarrini and Malaroda 1971) offers an opportunity for potentially greater log data convergence. However, the T-T neutron production cross section is $100 \mathrm{X}$ lower compared to that of the D-T reaction. Yet, advances in electronic neutron generator development, together with the development of improved sensors could offset this. 



\subsection{Conclusions}

The study is developing and providing the DOE NA-22 with a better understanding of the requirements for and extent-of-use of chemical radiation sources in petrochemical well logging.

Three approaches are being investigated to reduce the requirements for AmBe sources in well logging:

a. Reduction in the activity of the AmBe source required (through approaches that included the deployment of enhanced sensors)

b. The use of alternate electronic neutron generators (based on D-T, D-D and T-T reactions, although these provide neutrons with different spectra and data inter-comparison requires attention)

c. The use of enhanced and novel acoustic and electromagnetic sensing tools, including nuclear magnetic resonance, used either in combination with reduced activity AMBe sources and/or D-T generator derived data.

In looking at issues that inhibit the replacement of chemical isotope sources in well logging:

a. Formation density measurements implement the Compton scattering method, requiring the use of ${ }^{60} \mathrm{Co}$ or ${ }^{137} \mathrm{Cs}$ isotopic gamma sources. There is no non-chemical replacement for these radiation sources.

b. Formation fluid identification (brine or oil) uses elastic/inelastic neutron backscattering and/or neutron activation methods with chemical neutron sources (AmBe or ${ }^{252} \mathrm{Cf}$ ). Electronic neutron sources are potentially a replacement for these chemical neutron sources. An emerging neutronfree method, nuclear magnetic resonance, may allow elimination of neutron sources all together.

c. Formation porosity measurements can require the use of both gamma and neutron sources (as well as non-nuclear sensing methods).

1) The study has identified reasons for the reluctance of the well logging industry to embrace the use of non-chemical radiation sources. These include:

(a) The difficulty of inter-comparing neutron logs acquired with low energy AmBe or ${ }^{252} \mathrm{Cf}$ sources to those acquired using a high energy, directional electronic neutron source. This "data interpretation gap” could be addressed by a focused NA-22 program (discussed below).

(b) The unavailability of low-cost, robust electronic neutron sources to the re-logging industry. Electronic neutron sources are generally limited to expensive LWD tools used by the larger well-logging services companies (Schlumberger, Halliburton, BakerHughes, etc.). Lower hardware costs and improvements in electronic source reliability could speed utilization in the re-logging industry. 
(c) Electronic sources must be re-furbished after several hundred hours of use. Chemical sources require no maintenance.

(d) Electronic neutron sources have not yet achieved high reliability. Consequently, two neutron logging tools are often required at the well site in the event one fails.

2) Electronic neutron sources offer important potential advantages over chemical sources.

(a) Well logging personnel are not required to handle radioactive materials, thus eliminating potential exposure or contamination.

(b) Electronic neutron sources can be interlocked to only operate below a chosen well depth, eliminating the possibility of personnel exposure.

(c) Down-well loss of an electronic neutron source does not result in well-contamination. Tool neutron activation is minimal and the radioactive tritium gas (a beta-emitter) in the $\mathrm{D}-\mathrm{T}$ source is rapidly dissipated.

(d) Electronic sources are pulsed, permitting acquisition of time-dependent gamma and neutron scattering/activation data. These time-dependent signals are indicative of "neutron slowing down time," a measure of hydrogen and carbon content in the formation. This information cannot be obtained using a continuous, chemical neutron source.

\section{Other issues: “Culture Gap”}

There is another major impediment to industry-adoption of alternatives to chemical radiation sources. This impediment can be termed the "Culture Gap.” The nuclear well-logging industry has been accustomed to operating under modest regulatory constraints from government nuclear regulatory and security agencies. Certainly they have, in the USA, complied with Nuclear Regulatory Commission policies regarding radiation source acquisition, handling, and personnel safety. However, the industry's support for amelioration of national security issues associated with control of chemical radiation sources is tentative. They have only recently ( $<10$ years) become more closely scrutinized over the loss of sealed neutron and gamma sources downhole (or otherwise). There is distrust on both sides. Government regulators appear to doubt industry's commitment to source control. Likewise, industry views the threatened increased in government control, and risk of loss of access to AmBe and other sources, and regulation invasive and costly. There is a need for better communication between the two communities. To this end, it seems advisable for NA-22 to initiate a series of workshops fostering reconciliation between the two viewpoints. Such workshops could be organized and hosted by an academic organization (e.g., the Well Logging Laboratory at the University of Houston). The venue would permit government regulators to educate the well logging industry regarding the security threat (viewed by industry as inflated). Conversely, industry would have a forum to educate the regulators regarding the technical and economic issues and impacts associated with source replacement. Surely such a dialogue would be fruitful to both parties and may result in a compromise solution short of complete chemical source replacement. 


\section{Correctness of logging methods:}

- Accuracy is not a major consideration in logging.

- Variability of formation parameters (resulting from variability of the lithology and geophysics of the formations) is large and unpredictable.

- Repeatability is good for most measurement modalities.

- Precision of measurements is very good.

- Conflicting results from multiple measurement modalities is common.

- Different modalities vary widely in their resolution and penetration.

- Assessment of formation parameters is achieved through empirical combination of multiple measurements in different modalities.

- Neutron measurements, while cited in density units, are most commonly used for lithology determination.

- No single measurement modality is sufficient.

- No single measurement modality is indispensable.

- Heterogeneity, anisotropy, and fractal geometry are important aspects of petrophysics. 



\subsection{References}

Adolph B, C Stoller and et al. 2005. "No More Waiting: Formation Evaluation While Drilling." Oilfield Review Autumn 7(3):4-21.

Al-Tahini AM, CH Sondergeld and CS Rai. 2007. "Effect of Cementation on Ultrasonic Velocities in Sandstones." Geophysics 72(2):E53-E58.

Anderson B, I Bryant, M Lüling, B Spies and K Helbig. 1994. "Oilfield Anisotropy: Its Origins and Electrical Characteristics." Oilfield Review 6(4):48-56.

Arizabalo RD, K Oleschko, G Korvin, M Lozada, R Castrejón and G Ronquillo. 2006. "Lacunarity of Geophysical Well Logs in the Cantarell Oil Field, Gulf of Mexico." Geofísica Internacional 45(2):99113.

Arnold DM and J Butler. 1988. "Logging Calibration Technology and Facilities." IEEE Transactions on Nuclear Science 35(1):844-846.

Arroyo Franco JL, MA Mercado Ortiz, GS De, L Renlie and S Williams. 2006. "Sonic Investigations In and Around the Borehole." Oilfield Review Spring 18(1):14-33.

Asquith G and D Krygowski. 2004. "Guide to Petrophysical Interpretation." In Basic Well Log Analysis (Second Edition). The American Association of Petroleum Geologists, Tulsa, Oklahoma. AAPG Methods in Exploration Series 16.

Assaad FA. 2008. Field Methods for Petroleum Geologists. Springer, Berlin.

ASTM. 2001. Standard Guide for Conducting Borehole Geophysical Logging-Neutron. ASTM D 6727, ASTM International, West Conshohocken, Pennsylvania. Reapproved 2007.

Ayan C, N Colley, G Cowan, E Ezekwe, M Wannell, P Goode, F Halford, J Joseph, A Mongini, G Obondoko and J Pop. 1994. "Measuring Permeability Anisotropy: The Latest Approach." Oilfield Review 6(4):24-35.

Bachman HN, S Crary, R Heidler, J LaVigne and R Akkurt. 2007. "Porosity Determination from NMR Log Data: The Effects of Acquisition Parameters, Noise, and Inversion." In SPE Annual Technical Conference and Exhibition. November 11-14, 2007, Anaheim, California. DOI 10.2118/110803-MS. Society of Petroleum Engineers.

Bacri JC and D Salin. 1986. "Sound Velocity of a Sandstone Saturated with Oil and Brine at Different Concentrations." Geophysical Research Letters 13(4):326-328.

Baker LE, AB Campbell and RL Hugen. 1975. Well-Logging Technology and Geothermal Applications: A Survey and Assessment with Recommendations. SAND75-0275, Sandia National Laboratories, Albuquerque, New Mexico.

Baker LJ. 1984. "The Effect of the Invaded Zone on Full Wave Train Acoustic Logging." Geophysics 49(6):796-809. 
Bala M and A Cichy. 2007. "Comparison of P- and S-waves Velocities Estimated from Biot-Gassmann and Kuster-Toksöz Models with Results Obtained from Acoustic Wavetrains Interpretation." Acta Geophysica 55(2):222-230.

Bayuk IO, M Ammerman and EM Chesnokov. 2008. "Upscaling of Elastic Properties of Anisotropic Sedimentary Rocks." Geophysical Journal International 172(2):842-860.

Becker J, LJ Jacobs and J Qu. 2003. "Characterization of Cement-Based Materials Using Diffuse Ultrasound." Journal of Engineering Mechanics 129(12):1478-1484.

http://link.aip.org/link/?QEM/129/1478/1.

Berryman JG. 1980. "Confirmation of Biot's Theory." Applied Physics Letters 37(4):382-384. http://link.aip.org/link/?APL/37/382/1.

Berryman JG, PA Berge and BP Bonner. 2000. "Transformation of Seismic Velocity Data to Extract Porosity and Saturation Values for Rocks." The Journal of the Acoustical Society of America 107(6):3018-3027. http://link.aip.org/link/?JAS/107/3018/1.

Biot MA. 1952. "Propagation of Elastic Waves in a Cylindrical Bore Containing a Fluid." Journal of Applied Physics 23:997-1005.

Biot MA. 1956a. "Theory of Propagation of Elastic Waves in a Fluid-Saturated Porous Solid: I. Low Frequency Range." Journal of Acoustical Society of America 28:168-178.

Biot MA. 1956b. "Theory of Propagation of Elastic Waves in a Fluid-Saturated Porous Solid: II. High Frequency Range." Journal of Acoustical Society of America 28:179-191.

Bonner SD, JR Tabanou, PT Wu, JP Seydoux, KA Moriarty, BK Seal, EY Kwok and MW Kuchenbecker. 1995. "New 2 MHz Multiarray Borehole-Compensated Resistivity Tool Developed for MWD in Slim Holes." In 70th SPE Annual Technical Conference and Exhibition. October 22-25, 1995, Dallas, Texas.

Bose S. 2002. "Performance Bounds on Shear Anisotropy Azimuth Estimation Using Borehole Sonic Logging Tools." In Sensor Array and Multichannel Signal Processing Workshop Proceedings, 2002, pp. 174-178. August 4-6, 2002, Rosslyn, Virginia. Institute of Electrical \& Electronics Engineers (IEEE), Piscataway, New Jersey.

Butler J, AK McCracken, PB Kemshell and AK Ziver. 1990. "A New Approach to the Characterisation of Rock Formations for Use in logging Tool Calibration Facilities." IEEE Transactions on Nuclear Science 37(2):912-922.

CBG. Undated. "Gamma-Ray Tools for Geosteering, MWD and Wireline Logging." CBG Corp., Austin, Texas. p. 3.

Cheng CH and MN Toksoz. 1981. "Elastic Wave Propagation in a Fluid-Filled Borehole and Synthetic Acoustic Logs." Geophysics 46(7):1042-1053.

Clark B, DF Allen, D Best, SD Bonner, J Jundt, MG Luling and MO Ross. 1988. "A Dual Depth Resistivity Measurement for Formation Evaluation While Drilling." In Transactions of the SPWLA 29th Annual Logging Symposium. June 5-8, 1988, San Antonio, Texas. Society of Petrophysicists \& Well Log Analysts. 
Coates GR, L Xiao and MG Prammer. 1999. NMR Logging Principles \& Applications. Publication No. H02308, Halliburton Energy Services, Houston, Texas.

Crain ER. 2000. Crain's Petrophysical Handbook on CD-ROM. Self Published, Canada.

Crain ER. 2004. "How Many Acoustic Waves Can Dance On The Head Of A Sonic Log?" Canadian Logging Society:10-16.

Csikai J. 1987. Handbook of Fast Neutron Generators. CRC Press, Boca Raton.

Darling T. 2005. Well Logging and Formation Evaluation. Elseiver, Oxford, United Kingdom.

Deltombe J-L and R Schepers. 2004. "New Developments in Real-Time Processing of Full Waveform Acoustic Televiewer Data." Journal of Applied Geophysics 55(1-2):161-172.

http://www.sciencedirect.com/science/article/B6VFC-4B7D6WP-

3/2/6f31adae66571c523eeb20e979b75eaf.

Desbrandes R and G Brace. 1985. Excyclopedia of Well Logging. Editions Technip, Paris. ISBN 27108046469782710804642.

Diallo MS and E Appel. 2000. "Acoustic Wave Propagation in Saturated Porous Media: Reformulation of the Biot/Squirt Flow Theory." Journal of Applied Geophysics 44(4):313-325.

http://www.sciencedirect.com/science/article/B6VFC-40GJD8V-

2/2/51f8c1feb843b54f243e3c99938f4cd1.

DuBroff RE, SV Marshall and GG Skitek. 1996. Electromagnetic Concepts and Applications, 4th Edition. Prentice Hall.

Egle DM. 1981. "Diffuse Waves in Solid Media." The Journal of the Acoustical Society of America 70:476-480.

Ellis DV. 1990. "Some Insights on Neutron Measurements." IEEE Transactions on Nuclear Science 37(2):959-965.

Ellis DV, CR Case and JM Chiaramonte. 2003. "Porosity from Neutron Logs I: Measurement." Petrophysics 44(6):383-394.

Ellis DV and JM Singer. 2007. Well Logging for Earth Scientists, 2nd Edition. Springer-Verlag, Dordecht, The Netherlands.

Gassmann F. 1951. "Elastic Waves Through a Packing of Spheres." Geophysics 16(4):673-685.

Geli L, P-Y Bard and DP Schmitt. 1987. "Seismic Wave Propagation in a Very Permeable WaterSaturated Surface Layer." Journal of Geophysical Research 92:7931-7944.

Ghoshal G and JA Turner. 2009. "Diffuse Ultrasonic Backscatter in a Two-Dimensional Domain." Acta Mechanica 205(1-4):35-49.

Gilchrist Jr. WA. 2009. "Tutorial - Compensated Neutron Log Response Issues." Petrophysics 50(5):416-426. 
Goldberg I and B Gurevich. 1998. "A Semi-Empirical Velocity-Porosity-Clay Model for Petrophysical Interpretation of P- and S-Velocities." Geophysical Prospecting 46(3):271-285.

Graff KF. 1975. Wave Motion in Elastic Solids. Clarendon Press, Oxford.

Griffin JW, DL McMakin, LJ Bond, TL Moran, RV Harris, JM Fricke, M Larch and JA Pettibon. 2009. Evaluation of Non-Nuclear Techniques for Well Logging: Initial Electromagnetic Measurements.

PNNL-18826, Pacific Northwest National Laboratory, Richland, Washington.

Guarrini F and R Malaroda. 1971. "Two Different Technique Measurements of the Neutron Spectrum of an Am-Be Source." Nuclear Instruments and Methods 92(2):277-284.

Haldorsen JBU, DL Johnson, T Plona, B Sinha, H-P Valero and KW Winkler. 2006. "Borehole Acoustic Waves." Oilfield Review Spring 18(1):34-43.

Halliburton. 2008. MRIL®-Prime Brochure. Brochure H01912-A4, Halliburton, Houston, Texas.

Hanson JM and GA Tibbitts. 1991. "Pore Pressure Ahead of the Bit." In SPE/IADC Drilling Conference, pp. 179-188. March 11, 1991, Amsterdam, Netherlands. Society of Petroleum Engineers. http://www.onepetro.org/mslib/app/Preview.do?paperNumber=00021916\&societyCode=SPE.

Hearst JR, PH Nelson and FL Paillet. 2000. Well Logging for Physical Properties: A Handbook for Geophysicists, Geologists and Engineers, Second Edition. John Wiley \& Sons Ltd., West Sussex, England.

Hicks WG and JE Berry. 1956. "Application of Continuous Velocity Logs for Determination of Fluid Saturation of Reservoir Rocks." Geophysics 21:739-754.

Hinz D and J Wilson. 2006. "Steering Into the Sweet Spot." Hart's E\&P. http://www.epmag.com/archives/features/5917.htm.

IODP-USIO. Downhole Logging Tools, Triple Combo Tools, Accelerator Porosity Sonde (APS*). Integrated Ocean Drilling Program-United States Implementing Organization. Accessed August 3, 2010. Available at http://iodp.ldeo.columbia.edu/TOOLS LABS/TRIPLE/aps.html.

Jackson JA. 1984. "Nuclear Magnetic Well Logging." The Log Analyst 25(5):16-30.

Jenkins RJ. 1966. "Accuracy of Porosity Determinations (Abstract)." The Log Analyst VII(2).

Johnson DE and KE Pile. 2006. Well Logging in Nontechnical Language, 2nd Ed., PennWell Corp., Tulsa, Oklahoma.

Johnson KL, K Kendall and AD Roberts. 1971. "Surface Energy and the Contact of Elastic Solids." Proceedings of the Royal Society of London. A. Mathematical and Physical Sciences 324(1558):301-313. http://rspa.royalsocietypublishing.org/content/324/1558/301.abstract.

Kadkhodaie-Ilkhchi A, MR Rezaee and H Rahimpour-Bonab. 2009. "A Committee Neural Network for Prediction of Normalized Oil Content from Well Log Data: An Example from South Pars Gas Field, Persian Gulf." Journal of Petroleum Science and Engineering 65:23-32.

Kaplan I. 1962. Nuclear Physics, 2nd Edition. Addison-Wesley Publishing Company. 
Kearey P, M Brooks and I Hill. 2002. An Introduction to Geophysical Exploration, 3rd Edition. Blackwell Science Ltd., Oxford, United Kingdom.

Keller JD. 1989. "Acoustic Wave Propagation in Composite Fluid-Saturated Media." Geophysics 54(12):1554-1563.

Knoll GF. 2000. Radiation Detection and Measurement, 3rd Edition. John Wiley and Sons, Inc.

Krief M, J Garat, J Stellingwerff and J Ventre. 1990. "A Petrophysical Interpretation Using the Velocities of P and S Waves (Full-Waveform Sonic)." The Log Analyst 31(8):355-369.

Kuster GT and MN Toksöz. 1974. "Velocity and Attenuation of Seismic Waves in Two-Phase Media. Part I, Theoretical Formulations." Geophysics 39(5):587-606.

Larose E, OI Lobkis and RL Weaver. 2006. "Passive Correlation Imaging of a Buried Scatterer." The Journal of the Acoustical Society of America 119(6):3549-3552. http://link.aip.org/link/?JAS/119/3549/1.

Last GV and DG Horton. 2000. Review of Geophysical Characterization Methods Used at the Hanford Site. PNNL-13149, Pacific Northwest National Laboratory, Richland, Washington.

Lee MW. 2002. "Biot-Gassmannn Theory for Velocities of Gas Hydrate-Bearing Sediments." Geophysics 67(6):1711-1719.

McNaboe GJ. 1991. "Comparison of Formation Microscanner Images to Cores in Sandstone Reservoirs, Saudi Arabia." In SPE 7th Middle East Oil Show, pp. 831-839. November 16, 1991, Bahrain. Society of Petroleum Engineers, Inc.

http://www.onepetro.org/mslib/app/Preview.do?paperNumber=00021436\&societyCode=SPE.

Meyer WH, LW Thompson, MM Wisler and JQ Wu. 1994. "A New Slimhole Multiple Propagation Resistivity Tool." In Transactions of the SPWLA 35th Annual Logging Symposium. June 19-22, 1994, Tulsa, Oklahoma. Society of Petrophysicists \& Well Log Analysts.

Mikhailov OV, J Queen and MN Toksoz. 2000. "Using Borehole Electroseismic Measurements to Detect and Characterize Fractured (Permeable) Zones." Geophysics 65(4):1098-1112.

Mills WR, DC Stromswold and LS Allen. 1991. "Advances in Nuclear Oil Well Logging." Nuclear Geophysics 5(3):209-227.

Mirto E, G Weller, T el-Halawani, J Grau, M Berheide, F Allioli, M Evans, R Berto, M Borghi, M Firinu and M Giorgioni. 2006. "New Developments in Sourceless Logging-While-Drilling Formation Evaluation: A Case Study from Southern Italy." In Society of Petroleum Engineers Europec/EAGE Annual Conference and Exhibition. June 12-15, 2006, Vienna, Austria. Society of Petroleum Engineers (SPE).

Murphy III WF. 1982. "Effect of Partial Water Saturation on Attenuation in Massilon Sandstone and Vycor Porous Glass." The Journal of the Acoustical Society of America 71(6):1458-1468. http://link.aip.org/link/?JAS/71/1458/1.

Murphy WF, KW Winkler and R Kleinberg. 1984. "Frame Modulus Reduction in Sedimentary Rocks: The Effect of Adsorption on Grain Contacts." Geophysical Research Letters 11(9):805-808. 
NRC. 2008. Radiation Source Use and Replacement: Abbreviated Version. National Research Council (NRC). The National Academies Press, Washington, D.C. ISBN 0-309-11015-7. Theodore L. Phillips, Chair, Committee on Radiation Source Use and Replacement.

Oberkircher J, G Steinberger and B Robbins. 1993. "Applications for A Multiple Depth of Investigation MWD Resistivity Measurement Device." In Transactions of the SPWLA 34th Annual Logging Symposium. June 13-16, 1993, Calgary, Alberta, Canada. Society of Petrophysicists \& Well Log Analysts.

Paillet FL and CH Cheng. 1991. Acoustic Waves in Boreholes. CRC Press, Boca Raton, Florida.

Paillet FL and JE White. 1982. "Acoustic Models of Propagation in the Borehole and Their Relationship to Rock Properties." Geophysics 47(8):1215-1228.

Pape H, C Clauser and J Iffland. 1999. "Permeability Prediction Based on Fractal Pore-Space Geometry." Geophysics 64(5):1447-1460.

Patlovich S, RJ Emery and L Whitehead. 2005. "Characterization and Geolocation of Sources of Radioactivity Lost Downhole in the Course of Oil and Gas Exploration and Production Activities in Texas, 1956 to 2001." Health Physics 89 (Supplement 5):S69-S77.

Payenberg THD, SC Lang and R Koch. 2000. "A Simple Method for Orienting Conventional Core Using Microresistivity (FMS) Images and a Mechanical Goniometer to Measure Directional Structures on Cores." Journal of Sedimentary Research, Section B: Stratigraphy and Global Studies 70(2):419-422. http://jsedres.sepmonline.org/cgi/content/abstract/70/2/419.

Peterson EW. 1974. "Acoustic Wave Propagation Along a Fluid-Filled Cylinder." Journal of Applied Physics 45(8):3340-3350. http://link.aip.org/link/?JAP/45/3340/1.

Pfutzner HG, JL Groves and M Mahdavi. 1994. "A New Compact D-T Pulsed Neutron Generator System Suitable for Non-destructive Analysis Applications." In Nuclear Science Symposium and Medical Imaging Conference, 1994 IEEE Conference Record, 2, pp. 812-815. October 30-November 5, 1994, Norfolk, Virginia.

Plona TJ. 1980. "Observation of a Second Bulk Compressional Wave in a Porous Medium at Ultrasonic Frequencies." Applied Physics Letters 36(4):259-261. http://link.aip.org/link/?APL/36/259/1.

Plumb RA and SH Hickman. 1985. "Stress-Induced Borehole Elongation--A Comparison Between the Four-Arm Dipmeter and The Borehole Televiewer in the Auburn Geothermal Well." Journal of Geophysical Research 90(B7):5513-5521.

Prensky SE. 1994. "A Survey of Recent Developments and Emerging Technology in Well Logging and Rock Characterization." The Log Analyst. 35(2):15-45 and 35(5):78-84.

Prensky SE. 1999. "Advances in Borehole Imaging Technology and Applications." Geological Society, London, Special Publications 159:1-43.

Prensky SE. 2002. "Recent Developments In Logging Technology." Petrophysics 43(3):197-216.

Radlinski AP, EZ Radlinska, M Agamalian, GD Wignall, P Lindner and OG Randl. 2000. "The Fractal Microstructure of Ancient Sedimentary Rocks." Journal of Applied Crystallography 33(3):860-862. 
Rasmus JC and DMRG Stephens. 1990. "Real-Time Pore Pressure Evaluation Utilizing MWD/LWD Measurements and Drilling-Derived Formation Strength." In SPE Annual Technical Conference and Exhibition, pp. 403-411. September 23-26, 1990, New Orleans, Lousianna. Society of Petroleum Engineers Inc.

Riepe L. 1998. "Specific Internal Surface: The “Forgotten?” Petrophysical Measurement! or Application of Fractal Pore Models for Improved Permeability Estimations from Logs!”." In 1998 Symposia of The Society of Core Analysts. The Society of Core Analysts, Dublin, California. Paper SCA 1998-40. scaweb.org.

Rosemann EL. 2009. "Challenges for Isotopes." Well Servicing Magazine. Available at http://wellservicingmagazine.com/challenges-isotopes.

Salimullah ARM and DAV Stow. 1992. "Application of FMS images in poorly recovered coring intervals: examples from ODP Leg 129." Geological Society, London, Special Publications 65(1):71-86. http://sp.lyellcollection.org/cgi/content/abstract/65/1/71.

Samworth JR and MA Lovell. 2001. "CALLISTO - A New World-Standard Facility for Calibration of Nuclear Well Logs." In Rock the Foundation Convention, pp. 115-1 - 115-5. June 18-22, 2001, Calgary, Canada. Canadian Society of Petroleum Geologists. Paper \#115. http://www.cspg.org/conventions/abstracts/2001abstracts/4BA-C-115.pdf (use of Figure 1).

Schlumberger. 1989. Log Interpretation: Principles/Applications. Schlumberger Educational Services, Houston.

Schlumberger. 1993. Ultrasonic Imaging--USI, Ultrasonic Imager; UBI, Ultrasonic Borehole Imager. Document No. SMP-9230, Schlumberger Wireline and Testing, Houston, Texas.

Schlumberger. 1994. "Neutron Porosity Logging Revisited." Oilfield Review:4-8. http://www.slb.com/ /media/Files/resources/oilfield_review/ors94/1094/p04_08.ashx.

Schlumberger. 2001. Platform Express. SMP-5177. Available at http://www.slb.com/ /media/Files/evaluation/brochures/wireline open hole/petrophysics/platform/platfo rm_express_br.ashx.

Schlumberger. 2002. CMR-Plus. Brochure SMP-5771, Schlumberger Marketing Communications, Houston.

Schlumberger. 2004a. "ECS Elemental Capture Spectroscopy Sonde." Schlumberger Marketing Communications, Houston. \#FE_04_016_0.

http://www.slb.com/ /media/Files/evaluation/product_sheets/wireline_open_hole/petrophysics/porosity/e CS.ashx

Schlumberger. 2004b. "Neutron Porosity Tools." Schlumberger Marketing Communications, Houston. \#FE_04_032_0. http://www.slb.com/ /media/Files/evaluation/product sheets/wireline open hole/petrophysics/porosity/n eutron porosity tools.ashx.

Schlumberger. 2005a. "Sonic Scanner." Schlumberger Marketing Communications, Houston. \#05-FE130 
Schlumberger. 2005b. Sonic Scanner: Acoustic Scanning Platform. Schlumberger Marketing Communications. Houston. Available at http://www.slb.com/resources/other_resources/brochures/evaluation/sonic_scanner_brochure.aspx.

Schlumberger. 2006. MR Scanner. Brochure 06-FE-180, Schlumberger Marketing Communications, Houston. Available at http://www.slb.com/resources/other_resources/brochures/evaluation/mrscanner_brochure.aspx

Schlumberger. 2007. "Multifunction LWD Service EcoScope." Schlumberger Marketing Communications, Houston. Brochure 07-DR-310. www.slb.com/media/services/drilling/lwd/ecoscope.pdf.

Schlumberger. 2009. "Log Interpretation Charts (2009 Edition)." Schlumberger Limited, Houston. Brochure 07-DR-310. http://www.slb.com/resources/publications/books/log_charts.aspx.

Schoenberg M, T Marzetta, J Aron and RP Porter. 1981. "Space-Time Dependence of Acoustic Waves in a Borehole." The Journal of the Acoustical Society of America 70(5):1496-1507. http://link.aip.org/link/?JAS/70/1496/1.

Schweitzer JS and DV Ellis. 1988. "Review of Nuclear Techniques in Subsurface Geology." IEEE Transactions on Nuclear Science 35(1):800-805.

Shipboard Scientific Party. 2002. "Chapter 2: Explanatory Notes." In Proceedings of the Ocean Drilling Program, Volume 196, Initial Reports, Deformation and Fluid Flow Processes in the Nankai Trough Accretionary Prism: Logging While Drilling and Advanced CORKs [CD-ROM], 2002. eds: H Mikada, K Becker, JC Moore, A Klaus and et al. Available from: Ocean Drilling Program, Texas A\&M University, College Station TX 77845-9547, USA. Page 8.

Snieder R, S Hubbard, M Haney, G Bawden, P Hatchell, A Revil and DOE Geophysical Monitoring Working Group. 2007. "Advanced Noninvasive Geophysical Monitoring Techniques." Annual Review of Earth and Planetary Sciences 35:653-683.

Snyder DD and DB Fleming. 1985. "Well Logging--A 25-Year Perspective." Geophysics 50(12):25042529. http://link.aip.org/link/?GPY/50/2504/1, http://dx.doi.org/10.1190/1.1441881.

Spies BR. 1996. "Electrical and Electromagnetic Borehole Measurements: A Review." Surveys in Geophysics 17(4):517-556.

Stoll RD. 1980. "Theoretical Aspects of Sound Transmission in Sediments." The Journal of the Acoustical Society of America 68(5):1341-1350. http://ink.aip.org/link/?JAS/68/1341/1.

Stoller C. 2009. "Downhole Tools Having Combined D-D and D-T Neutron Generators." U.S. Patent US 2009/0045329 A1.

Stromswold DC. 1995. "Calibration Facilities for Borehole and Surface Environmental Radiation Measurements." Journal of Radioanalytical and Nuclear Chemistry, Articles 194(2):393-401.

Stromswold DC. 2005. "Calibration Facilities for Boreholes and Surface Environmental Radiation Measurements." Journal of Radioanalytical and Nuclear Chemistry 194(2):393-401.

Taicher GZ. 2003. "NMR Logging in the Earth's Magnetic Field." U.S. Patent 6,586,931. 
Tang XM and A Cheng. 2004. Handbook of Geophysical Exploration: Seismic Exploration, Volume 24, Quantitative Borehole Acoustic Methods. S Treitel and K Helbig, Elsevier, Amsterdam. eds. S Treitel and K Helbig.

Tao G, F He, B Wang and W Sun. 2006. "Multi-Scale Analysis for Azimuthal Anisotropy of Reservoir Rocks from Cross-Dipole Logs." Journal of Geophysics and Engineering 3(2):135-142.

Tao G and MS King. 1993. "Porosity and Pore Structure from Acoustic Well Logging Data." Geophysical Prospecting 41(4):435-451.

Theys PP. 1997. "Accuracy - Essential Information for a Log Measurement." In SPWLA 38th Annual Logging Symposium, pp. 1-14. June 15-18, 1997, Houston, Texas. Society of Petrophysicists \& Well Log Analysts.

Theys PP and C Flaum. 1991. "Geometrical Specifications of Logging Tools: The Need for New Standards." In SPWLA 32nd Annual Logging Symposium, 1991. June 16-19, 1991, Midland, Texas. Society of Petrophysicists \& Well Log Analysts, Houston, Texas. Paper 1991-YY.

Thompson AH, S Hornbostel, J Burns, T Murray, R Raschke, J Wride, P McCammon, J Sumner, G Haake, M Bixby, W Ross, BS White, M Zhou and P Peczak. 2006. "Field Tests of Electroseismic Hydrocarbon Detection." Geophysics 72(1):N1-N9.

Timur A and MN Toksoz. 1985. "Downhole Geophysical Logging." Annual Review of Earth and Planetary Sciences 13:315-344.

Toksöz MN, CH Cheng and A Timur. 1976. "Velocities of Seismic Waves in Porous Rocks." Geophysics 41(4):621-645.

Trinity. 2002. Final Report - Industrial Applications of Sealed Radiation Sources and Alternative Non Nuclear Technologies. Trinity Engineering Associates (Trinity), Cincinnati, Ohio. Contract 68-D-00210; Work Assignment E210 1-16. Prepared for the U.S. Environmental Protection Agency, Office of Radiation and Indoor Air, Washington, D.C.

Tsang L and D Radar. 1979. "Numerical Evaluation of Transient Acoustic Waveform Due to a Point Source in a Fluid-Filled Borehole." Geophysics 44(10):1706-1720.

Tubman KM, CH Cheng and MN Toksoz. 1984. "Synthetic Full Waveform Acoustic Logs in Cased Boreholes." Geophysics 49(7):1051-1059.

Turgut A and T Yamamoto. 1988. "Synthetic Seismograms for Marine Sediments and Determination of Porosity and Permeability." Geophysics 53(8):1056-1067.

Turgut A and T Yamamoto. 1990. "Measurement of Acoustic Wave Velocities and Attenuation in Marine Sediments." The Journal of the Acoustical Society of America 87(6):2376-2383.

http://link.aip.org/link/?JAS/87/2376/1.

Turner JA and RL Weaver. 1994. "Radiative Transfer and Multiple Scattering of Diffuse Ultrasound in Polycyrstalline Media." The Journal of the Acoustical Society of America 96(6):3675-3683.

University of Houston. 2009. Well Logging Lab Software Code Catalog (1992 - 2009). University of Houston, Houston, Texas. 
Weaver RL. 2005. "Information from Seismic Noise." Science 307:1568-1569.

Weaver RL and OL Lobkis. 2006. "Diffuse Fields in Ultrasonics and Seismology." Geophysics 71(4):S15-S19.

Weaver RL and W Sachse. 1995. "Diffusion of Ultrasound in a Glass Bead Slurry." The Journal of the Acoustical Society of America 97(4):2094-2102. http://link.aip.org/link/?JAS/97/2094/1.

White JE and RE Zechman. 1968. "Computed Response of an Acoustic Logging Tool." Geophysics 33(2):302-310. http://link.aip.org/link/?GPY/33/302/1.

Williams GR and MM Sharma. 1991. The Formation Microscanner As A Measure of Heterogeneity In Core-Log Studies. Report No. GRI-91/0239, Gas Research Institute, Chicago, Illinois.

Williams JH and CD Johnson. 2004. "Acoustic and Optical Borehole-Wall Imaging for Fractured-Rock Aquifer Studies." Journal of Applied Geophysics 55(1-2):151-159.

http://www.sciencedirect.com/science/article/B6VFC-49NXH90-

3/2/591da2bb0de8fa04142df46f336098a1.

Willis ME and MN Toksoz. 1983. "Automatic P and S Velocity Determination from Full Waveform Digital Acoustic Logs." Geophysics 48:1631-1644.

Wong C, JD Anderson and JW McClure. 1965. "Neutron Spectrum from the T+T Reaction." Nuclear Physics 71(1):106-112.

Woznicka U, J Jarzyna and E Krynicka. 2005. "Evaluation of Uncertainty of the Comprehensive Interpretation of Borehole Logs by the Multiple Re-Run Statistical Method." Applied Radiation and Isotopes 62(5):817-827.

Wyllie MRJ, AR Gregory and LW Gardner. 1956. "Elastic Wave Velocities in Heterogeneous and Porous Media." Geophysics 21(1):41-70.

Xu S and RE White. 1995. "A New Velocity Model for Clay-Sand Mixtures." Geophysical Prospecting 43(1):91-118.

Yamamoto T, L Nye and M Kuru. 1994. "Porosity, Permeability, Shear Strength: Crosswell Tomography Below an Iron Foundry." Geophysics 59(10):1530-1541.

Zhang YM, PC Xai and YJ Yu. 2000. "Review of Nuclear Magnetic Resonance Magnet for Oil Well Logging." IEEE Transactions on Applied Superconductivity 10(1):763-766.

Zhu Z, MW Haartsen and MN Toksoz. 1999. "Experimental Studies of Electrokinetic Conversions in Fluid-Saturated Borehole Models." Geophysics 65(4):1349-1356. 



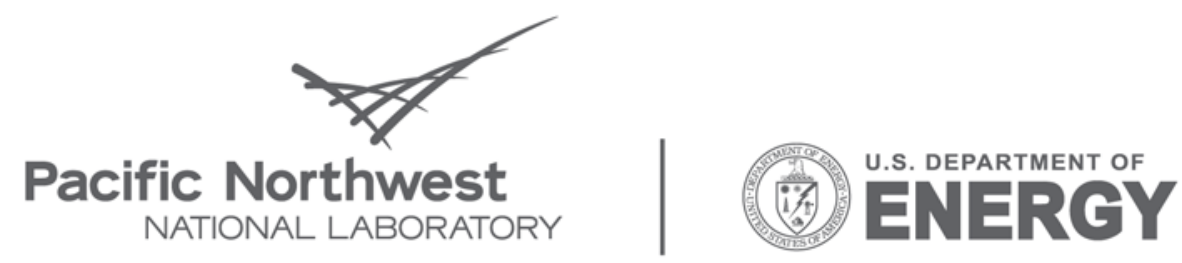

Proudly Operated by Battelle Since 1965

902 Battelle Boulevard

P.O. Box 999

Richland, WA 99352

1-888-375-PNNL (7665)

www.pnl.gov 